\title{
NETWORK-BASED OPTIMIZATION TECHNIQUES FOR WIND FARM LOCATION DECISIONS
}

\author{
A Thesis
}

by

\section{JORGE IGNACIO DOMINGO CISNEROS SALDANA}

\author{
Submitted to the Office of Graduate and Professional Studies of \\ Texas A\&M University \\ in partial fulfillment of the requirements for the degree of \\ MASTER OF SCIENCE
}

$\begin{array}{ll}\text { Chair of Committee, } & \text { Sergiy Butenko } \\ \text { Committee Members, } & \text { Efstratios N. Pistikopoulos } \\ & \text { Ivan Damjanovic } \\ \text { Intercollegiate Faculty Chair, Efstratios N. Pistikopoulos }\end{array}$

August 2017

Major Subject: Energy

Copyright 2017 Jorge Ignacio Domingo Cisneros Saldana 


\begin{abstract}
This thesis develops network-based approaches to analysis and optimization of wind energy systems. The wind energy system is a complex system that produces a massive amount of wind speed data over time, characterized by high level of variability. We study this system using the powerful tools of graph theory and network analysis, which provide a valuable tool for extracting important information from systems generating large amounts of data.
\end{abstract}

The main contribution of this thesis is a network-based method for finding appropriate locations for wind farms that maximize the overall energy, while controlling the effects of wind speed variability. For this purpose, we constructed networks that model potential wind farm locations as vertices and represent the pairwise correlations of the corresponding wind speed measurements using edges. More specifically, two vertices are connected by an edge if the correlation of their wind speeds considered over the given time period is below zero. If the weights of vertices are given by the average wind speed at the corresponding locations, then the problem of finding appropriate locations for wind farms is formulated as the problem of finding a tightly knit cluster of vertices with high weights. More specifically, we model clusters using the graph-theoretic concept of a clique and its relaxations, 2-plex and 3-plex.

To test the proposed approaches, we used real data from Bolivian studies of wind velocities conducted over a 10-year period at 201 locations spanning the entire Bolivian territory. The solutions obtained using the proposed approaches provide sets of diverse 
locations with high possible wind energy outputs. In particular, using clique relaxations results in larger number of diversified locations compared to that given by the maximum clique solutions.

Another studied problem deals with determining a small number of locations that would be representative of the overall behavior of wind speeds in the whole system. This problem was addressed searching for small dominating sets in graphs where edges correspond to pairs of locations with positively correlated wind speeds.

Finally, we proposed a methodology for evaluating costs of setting up wind farms in certain locations in Bolivia. The cost of setting up wind farms involves many variables, wind speeds being an important factor in determining the profitability of the system. We observe that for sites with higher wind speeds the net present value (NPV) of setting up and operating wind farms is positive and the internal rate of return (IRR) is higher than the discount rate, which ensures some profit to the investor. More specifically, the study has shown that with wind speeds around $6.9 \mathrm{~m} / \mathrm{s}$, the $2 \mathrm{MW}$ and $3 \mathrm{MW}$ wind turbine installments yield IRR of $13 \%$ and $15 \%$, respectively. On the other hand, we concluded that lower wind speeds would result in projects that would not be able to recover the investment in the first 25 years. However, these projects could be profitable if the government develops policies for some green credits, or carbon bonus as income for generating and selling clean energy produced from wind power plants. The results obtained in this study could help the governments and investors interested in developing wind energy farms in Bolivia and other countries with similar geographical characteristics. 


\section{DEDICATION}

First, I dedicate this project to God Almighty, my creator, my source of inspiration, wisdom, knowledge and understanding.

I dedicate my dissertation work to my family. A special feeling of gratitude to my loving parents, Jorge Luis Cisneros and Irina Marucia Saldana whose training, words of encouragement and push for tenacity are part of my inner being. My sister Shantall Cisneros, has never left my side and is very special. I also dedicate this dissertation to my friends and relatives who have supported me throughout the process. I will always appreciate all they have done, especially my maternal grandmother Exaltation Villegas for helping me develop my first research skills and my paternal grandfather Jorge Cisneros for helping me when I needed.

I am dedicating this thesis to two beloved people who have meant and continue to mean so much to me. Although they are no longer in this world, their memories continue to influence my life. First and foremost, to my paternal grandmother Maria Figueroa whose love for me knew no bounds and, who taught me the value of hard work. Thank you so much, I will never forget you. Next, my nana Marcela who raised me, loved me, and taught me important things for life.

Last but not least, to my beloved Pamela Luna, for her love, patience, and support believing in me and accompanying me while fulfilling my dreams. You have been my best cheerleader all this time. 


\section{ACKNOWLEDGEMENTS}

I would like to thank my committee chair, Dr. Sergiy Butenko, for the many hours of teaching, proofreading, support, guidance and encouragement through my graduate studies, my committee members, Dr. Efstratios Stratos Pistikopulous, and Dr. Ivan Damnjanovic, for their assistance throughout the course of this research.

Thanks to my friends at ISEN lab, Eugene Lykhovyd and Mohammad Hosseinian, who assisted and helped me to mature my research skills.

Also, thanks to my friends and colleagues in the MSc in Energy program, as well as faculty and staff of the Energy Institute, especially to Dr. Valentini Pappa and Jeff Sammons, for making my time at Texas A\&M University a great experience.

Next, I want to thank my roommate and friend Juan Pablo Sarmiento, for being there for me throughout the duration of the program.

Finally, I must express my very profound gratitude to my family, my parents and to my sister for providing me commitment with unfailing support and continuous encouragement throughout my studies and through the process of researching and writing this thesis. This accomplishment would not have been possible without them.

Thank you all for always having confidence in me, this is not the end... 


\section{CONTRIBUTORS AND FUNDING SOURCES}

\section{Contributors}

This work was supervised by a thesis committee consisting of Professor Sergiy Butenko

of the Department of Industrial and Systems Engineering, Professor Efstratios Pistikopulos of the Department of Chemical Engineering, and Professor Ivan Damnjanovic of the Department of Civil Engineering, all of whom are affiliated faculty of the Energy Institute.

All work for the thesis was completed by the student Jorge Ignacio Domingo CisnerosSaldana, under the advisement of Professor Sergiy Butenko of the Department of Industrial and Systems Engineering.

\section{Funding Sources}

Graduate study and this thesis research were supported by a fellowship from the Bolivian Government through the Ministry of Education. 
$\mathrm{AC}$ Alternate Current

AI Artificial Intelligence

DC Direct Current

DFIG Doubly Fed Induction Generator GSC Grid Side Converter GWh Giga watt - hour IRR Internal Return Rate $\mathrm{kW}$ Kilo Watt MDS Minimum Dominating Set MW Mega Watt NPV Net Present Value PBP Pay Back Period PMSG Permanent Magnet Synchronous Generator RDS Russian Doll Search RSC Rotor Side Convertor SCIG Squirrel cage Induction Generator UK United Kingdom USA United States of America USSR Union of Soviet Socialist Republics VFC Variable Frequency 


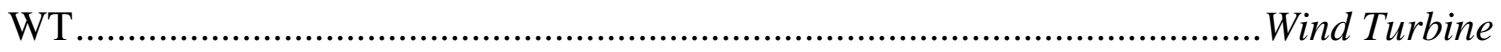




\section{TABLE OF CONTENTS}

Page

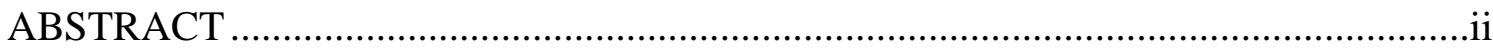

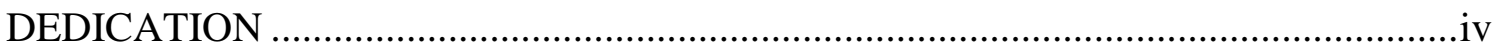

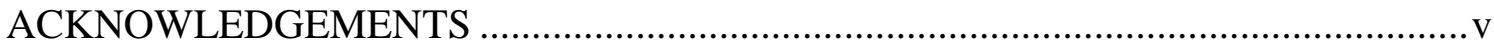

CONTRIBUTORS AND FUNDING SOURCES ................................................ vi

NOMENCLATURE .................................................................................... vii

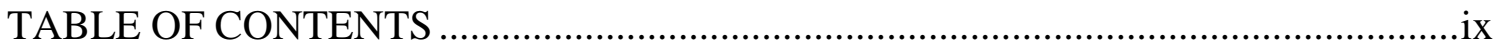

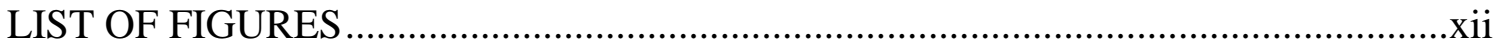

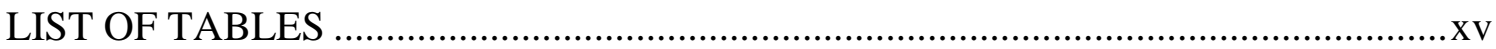

CHAPTER I INTRODUCTION ................................................................... 1

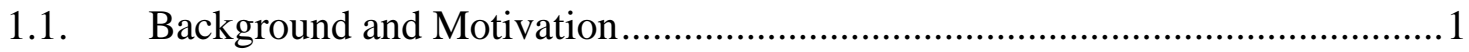

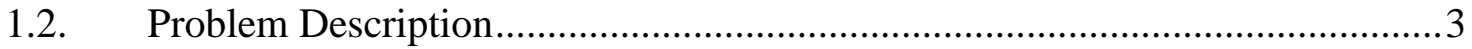

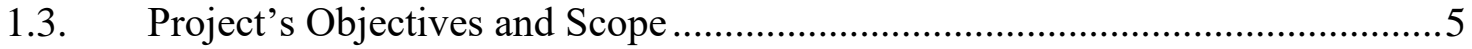

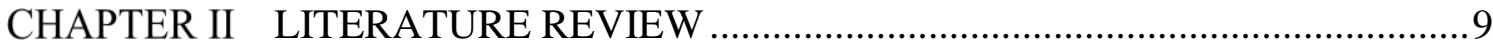

2.1. Wind Farms Technologies ...................................................................

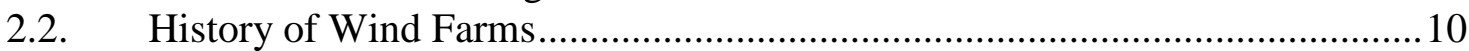

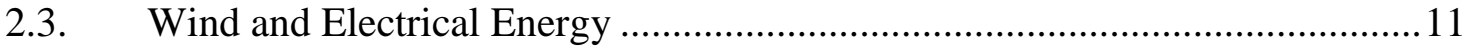

2.4. Wind Farm Locations and Importance ................................................... 17

2.4.1. Significance of the Wind Resource ........................................................ 17

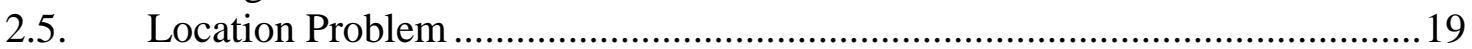

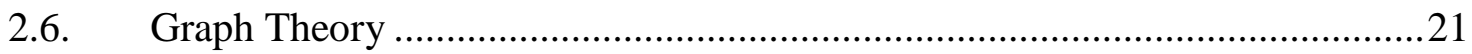

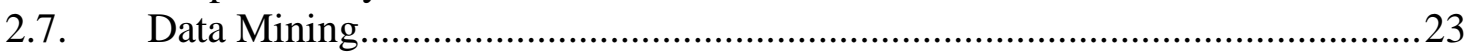

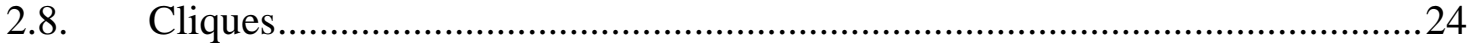

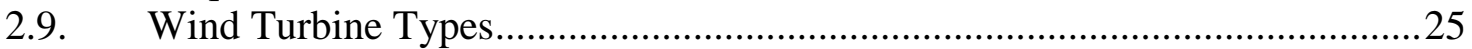

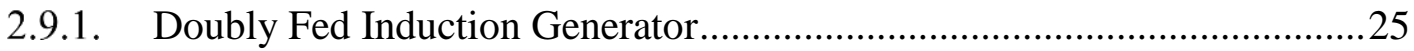

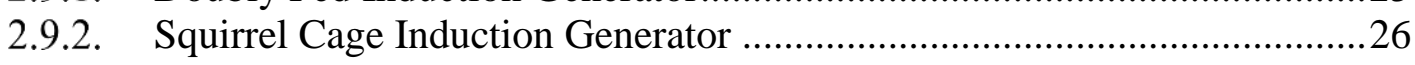

2.9.3. Permanent Magnet Synchronous Generator ..........................................2 27

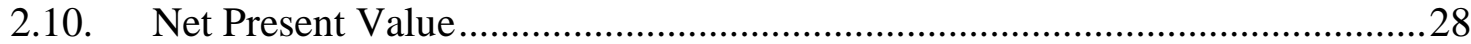

2.11. Internal Rate of Return .........................................................................29

2.12. Payback Period ........................................................................................... 30 
CHAPTER III WIND ENERGY GRAPH …………..............................................

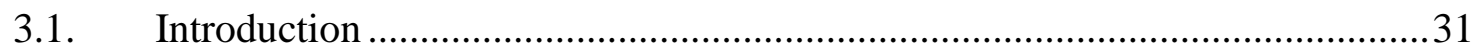

3.2. Correlation Coefficients ............................................................................

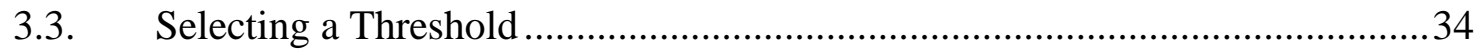

CHAPTER IV MAXIMUM CLIQUE ……………………....................................

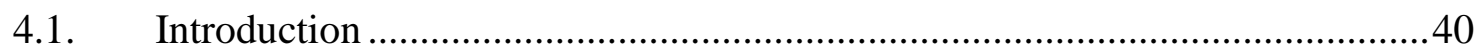

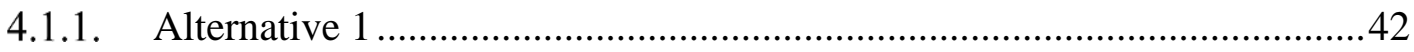

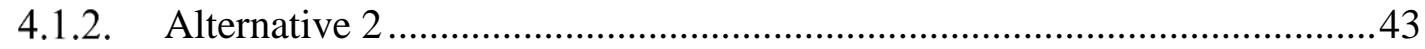

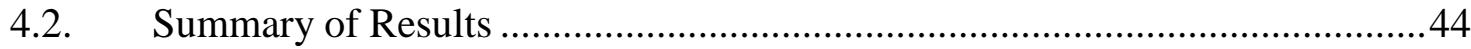

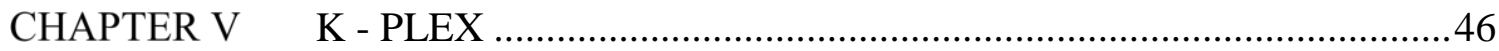

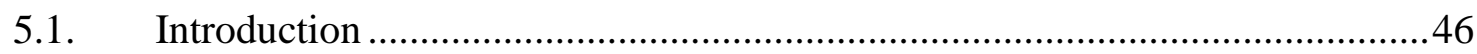

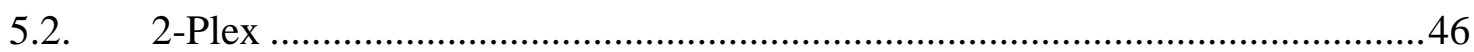

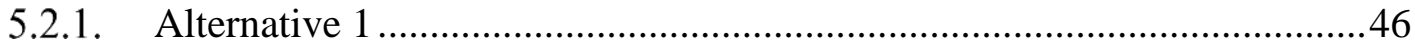

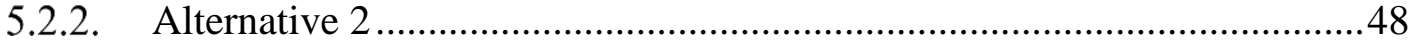

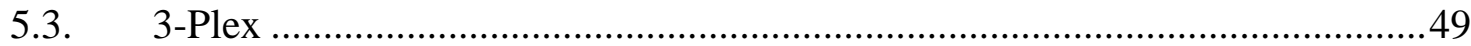

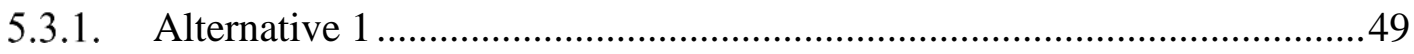

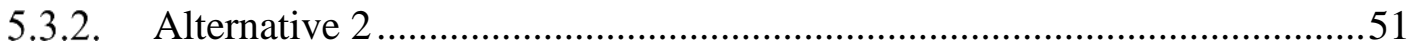

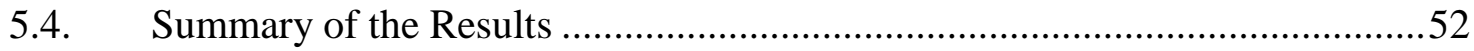

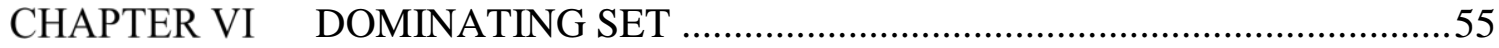

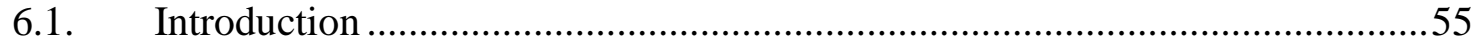

6.2. Wind Graph for Positive Correlations of Wind Speed Fluctuations .................56

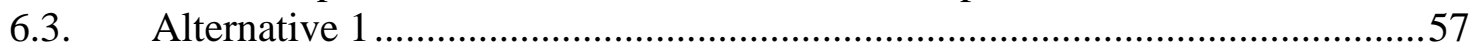

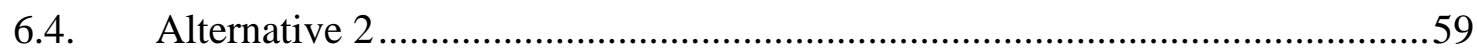

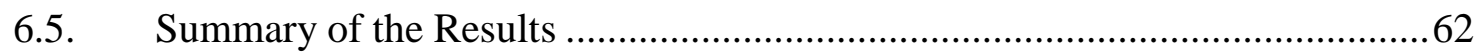

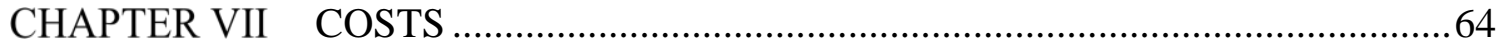

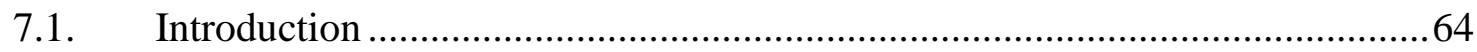

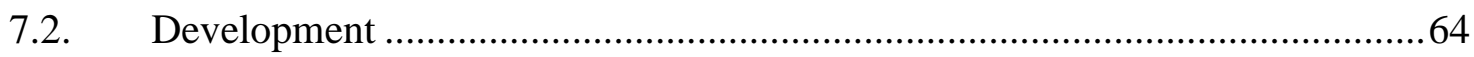

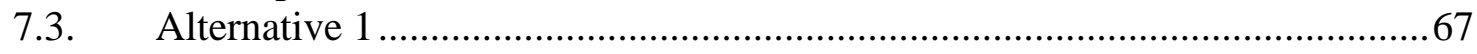

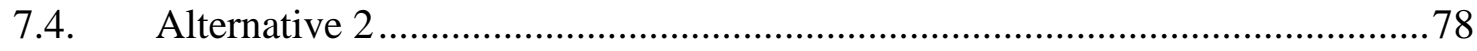

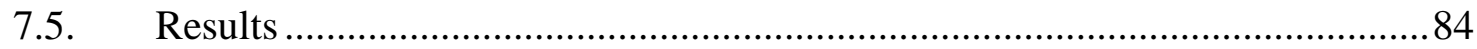

CHAPTER VIII CONCLUSIONS AND RECOMMENDATIONS ..............................86

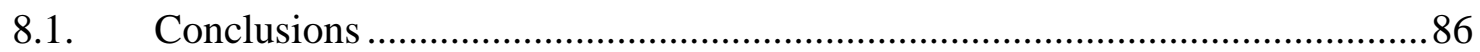

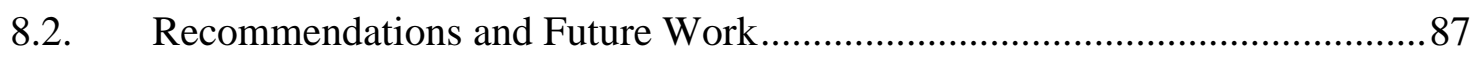




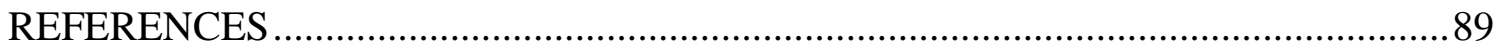

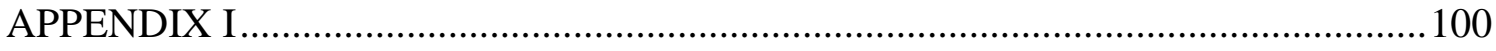

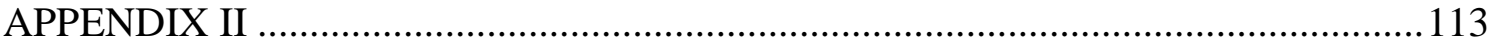




\section{LIST OF FIGURES}

Page

Figure 1: Global wind map, reprinted with permission from (Vaisala, 2017)................5

Figure 2: Actual wind mills, reprinted from (Pexels, 2017). .................................... 10

Figure 3: Wind mills used for drainage, reprinted from (Katicaj, 2016). .....................11

Figure 4: Graph example, adapted from (Legner, 2017).........................................22

Figure 5: Directed graph example, adapted from (Legner, 2017) ..............................22

Figure 6: Tree example, adapted from (Legner, 2017). .........................................23

Figure 7: Doubly Fed Induction Generator (DFIG), reprinted with permission from (Beainy, Maatouk, Moubayed, \& Kaddah, 2016).

Figure 8: Squirrel cage Induction Generator (SCIG), reprinted with permission from (Beainy, Maatouk, Moubayed, \& Kaddah, 2016).

Figure 9: Permanent Magnet Synchronous Generator (PMSG), reprinted with permission from (Beainy, Maatouk, Moubayed, \& Kaddah, 2016). .................28

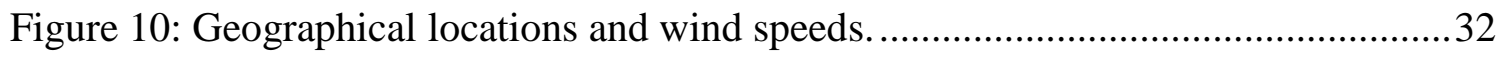

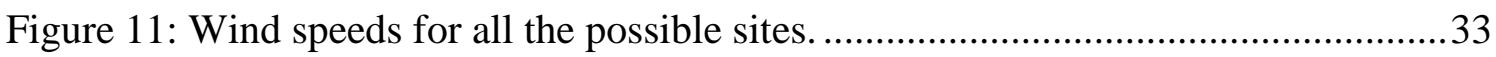

Figure 12: Distribution of correlation coefficient values....................................... 34

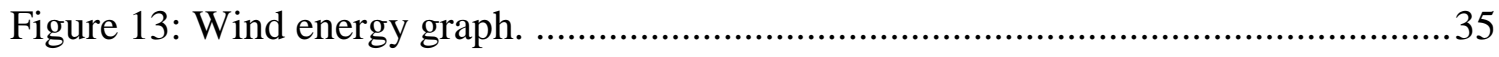

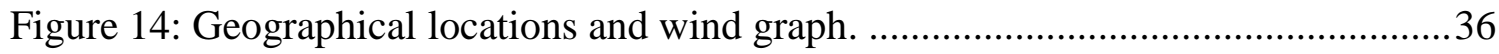

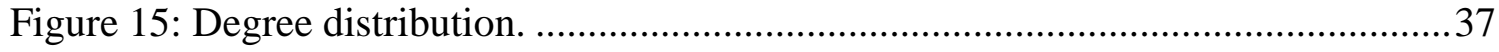

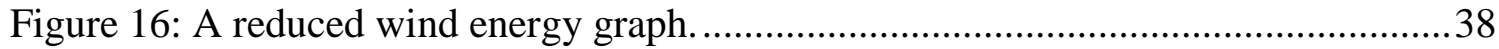

Figure 17: Typical wind turbine power output, adapted from (Wind Power Program,

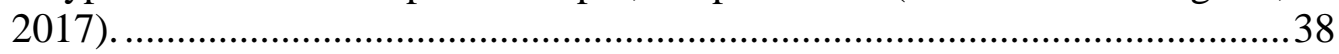

Figure 18: The degree distribution for the reduced wind energy graph........................39

Figure 19: The subgraph induced by the maximum clique in the wind energy graph.....43

xii 
Figure 20: The subgraph induced by the maximum weight clique of the wind energy graph.

Figure 21: Comparison of the monthly average wind speeds for the maximum weight clique, maximum clique, and the whole wind energy graph.

Figure 22: Maximum 2-plex wind graph.

Figure 23: The subgraph of the wind graph induced by the maximum weight 2-plex....49

Figure 24: Maximum 3-plex wind graph.

Figure 25: Maximum 3-plex weighted wind graph

Figure 26: Average monthly wind speeds comparison for the 2-plex solutions...............53

Figure 27: Average monthly wind speeds comparison for the 3-plex solutions...............54

Figure 28: MDS optimal solution for $\boldsymbol{\theta 1}=\mathbf{0 . 3 3}$ on the Bolivian map..........................58

Figure 29: Comparison of monthly average wind speeds for the MDS and the whole system.

Figure 30: MDS optimal solution for $\boldsymbol{\theta 2}=\mathbf{0 . 5}$ on the Bolivian map.

Figure 31: Comparison of monthly average wind speeds for the MDS and the whole system.

Figure 32: Comparison of monthly average wind speeds for the MDS and the whole system.

Figure 33: Vestas, wind classes 2.0 MW, reprinted from (Vestas, 2017).......................68

Figure 34: Annual energy production for V90, reprinted from (Vestas, 2017). .............69

Figure 35: Annual energy production for V100, reprinted from (Vestas, 2017). ............69

Figure 36: Annual energy production for V110, reprinted from (Vestas, 2017). ............70

Figure 37: Annual energy production for V116, reprinted from (Vestas, 2017). ............70

Figure 38: Annual energy production for V120, reprinted from (Vestas, 2017). ............70

Figure 39: Energy production equation based on V116 data...........................................71

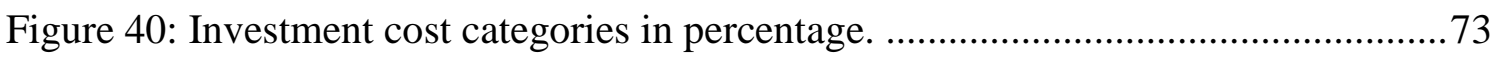


Figure 41: Operation cost categories in percentage. ............................................. 74

Figure 42: Cumulative discounted cash flow for Site 1 ........................................ 76

Figure 43: Cumulative discounted cash flow for Site 2. .......................................... 77

Figure 44: Cumulative discounted cash flow for Site 3 ...................................... 77

Figure 45: Vestas, wind classes 3.0 MW, reprinted from (Vestas, 2017).....................79

Figure 46: Annual energy production, V126, reprinted from (Vestas, 2017)................79

Figure 47: Annual energy production, V136, reprinted from (Vestas, 2017)................80

Figure 48: Energy production equation based on V136 data.................................... 80

Figure 49: Cumulative discounted cash flow for Site 1 .......................................... 83

Figure 50: Cumulative discounted cash flow for Site 2 ....................................... 84

Figure 51: Cumulative discounted cash flow for Site 3...................................... 84

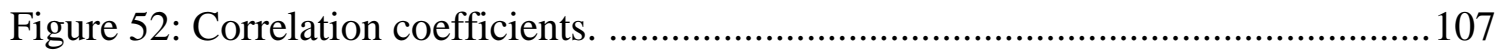

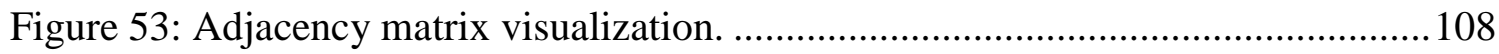

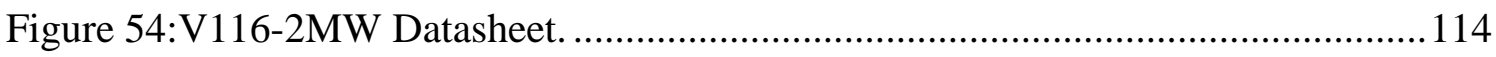

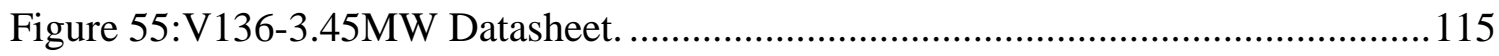




\section{LIST OF TABLES}

Page

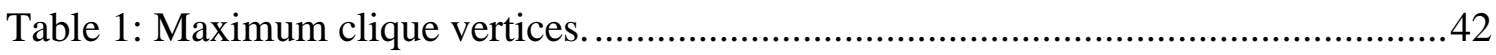

Table 2: The vertices of the maximum weight clique.............................................43

Table 3: Comparison of average wind speeds......................................................4

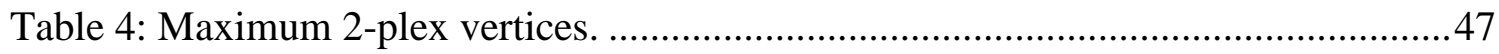

Table 5: Maximum weight 2-plex vertices. ..................................................... 48

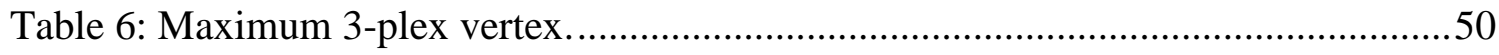

Table 7: Maximum 3-plex weighted vertex. ......................................................51

Table 8: Average wind speeds for obtained solutions................................................53

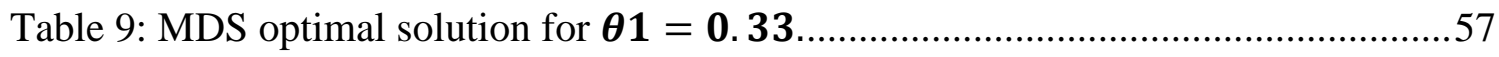

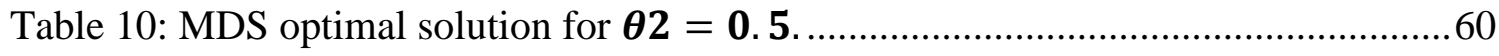

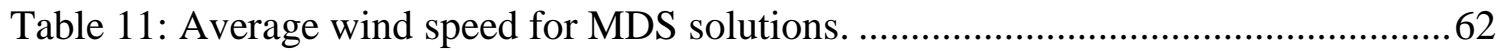

Table 12: Wind turbines comparison, adapted from (Beainy, Maatouk, Moubayed, \&

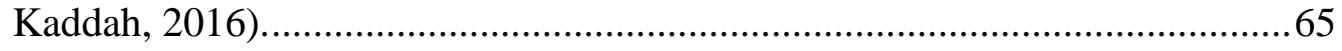

Table 13: Advantages and disadvantages of the three technologies, adapted from (Beainy, Maatouk, Moubayed, \& Kaddah, 2016)........................................66

Table 14: Vestas model type selection, 2.0 MW, adapted from (Vestas, 2017).............68

Table 15: Characteristics of the project........................................................... 72

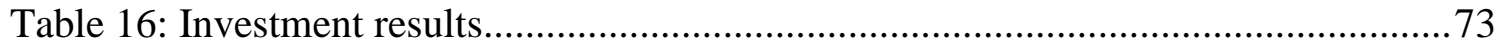

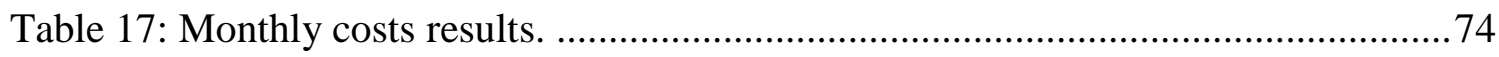

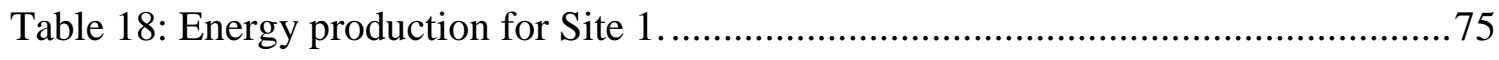

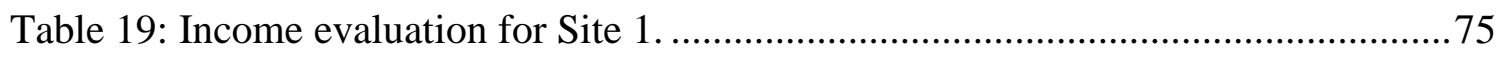

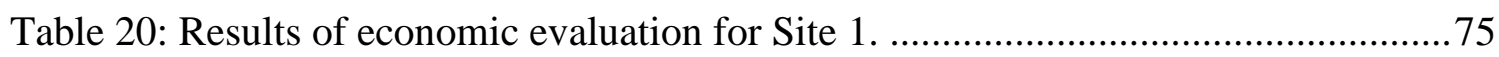




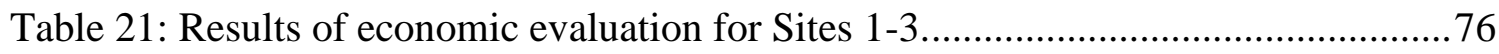

Table 22: Vestas, model type selection $3.45 \mathrm{MW}$, adapted from (Vestas, 2017)...........78

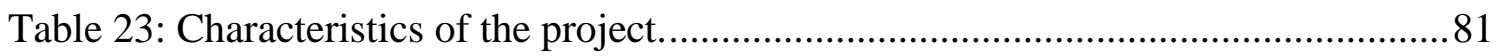

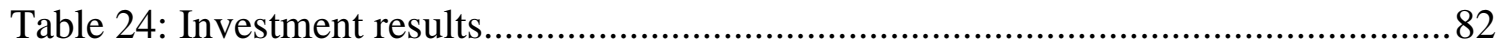

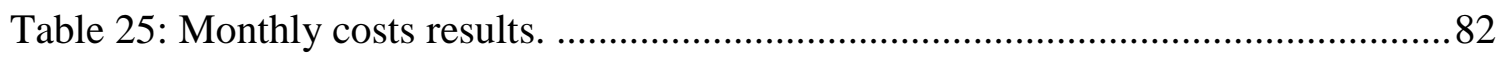

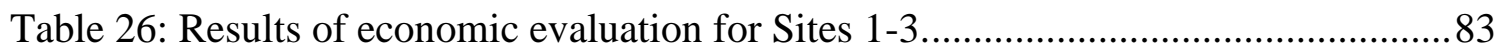

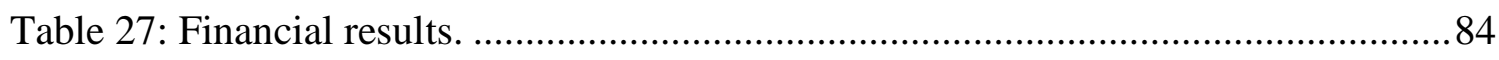

Table 28: The list of considered locations, with geographical coordinates and wind speed information. ........................................................................ 101

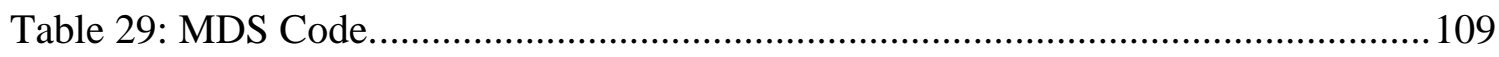

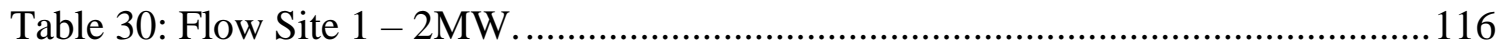

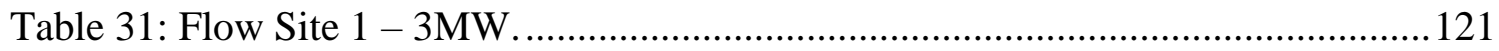




\section{CHAPTER I}

\section{INTRODUCTION}

\subsection{Background and Motivation}

This section briefly reviews some history behind the wind energy technology in general terms. Harvesting wind energy is not something new; it is one of the oldest sources of energy utilized by humans, along with thermal energy. Wind has been used since ancient times, as a driving force. It has moved ships; it has even operated mills machinery while moving its blades (Sathyajith, 2006). However, after an era in which it has been abandoned, from the eighties of the twentieth century, this type of clean energy is experiencing a resurgence in the world (Wind Energy Foundation, 2016).

Wind energy offers many advantages, making it one of the fastest-growing energy sources in the world nowadays. The boom in the increase of wind farms is due to favorable wind conditions, as well as improvements in costs and technology. (U.S. Departament of Energy, 2016) A wind farm is a grouping of wind turbines that transform wind energy into electricity. Wind farms can be located on land or on sea, the first being the most common, although offshore parks have experienced significant growth in recent years (European Wind Energy Association, 2012).

The number of wind turbines that make up a park or a wind farm is very variable, and depends mainly on the availability of surface and the characteristics of the wind in the location. Before setting up a wind farm, the wind is usually studied at the site chosen for more than one year (Southwest Power Pool, Inc., 2016). For this purpose, weather vane and anemometers are installed. With the data collected, a wind rose is drawn which 
indicates the prevailing directions of the wind and its speed (European Wind Energy Association, 2012).

Wind farms provide different amounts of energy depending on differences in design, turbine status, and the fact that older turbine designs were less efficient and able to adapt to changes in direction and wind speed (National Wind Watch, Inc., 2015). Although the environmental impact of wind power plants is relatively small, compared to other forms of generation, wind turbines produce acoustic and visual pollution. In addition, there may be a significant impact on wildlife since birds are not able to see the blades when they rotate (Lucas, 2006).

In addition, to install a wind farm, a thorough study of the area is required to make sure that windmills will be able to work efficiently and effectively. In particular, the following important aspects are taken into account (van Kuik, et al., 2016):

- The Environmental impact on the area. Even though wind power is one of the cleanest and therefore has only a minor impact on the environment, it is necessary not to forget that the size of the windmills is very large. In addition to changing the environment visually, it can adversely affect bird and animal traffic. Ideally, it should be installed in a wide area, without trees and not a place inhabited by birds, especially those species that are protected or in danger of extinction.

- Energy potential of the area. It is necessary to have a community close to the wind farms, or even electrical transmission lines, in order to have 
ideal conditions for consuming and making the generation of wind energy in the area commercially attractive.

- Behavior of the air. Wind is not nearly enough. It takes a lot of time of previous study of its direction, temperature and maximum generation capacity. In short, before giving green light to the installation of windmills, groundwork is performed for more than a year, which should involve a group of different professionals to determine if there are the necessary conditions to generate wind energy and make it profitable (Twenergy, 2014).

Substantial research efforts are put into addressing many challenges we face in order to increase the usage of wind energy (Fares, 2015). The challenges of high interest for wind power plant stakeholders and common investors include determining optimal sizing and locations of wind farms in order to maximize the wind power produced (van Kuik, et al., 2016). As wind is a stochastic source of energy, there exists uncertainty connected with the timing of wind capacity. Nevertheless, electric power output from geographically separate locations could be used to smoothen fluctuations in the amount of electrical power output and decrease the risk of wrong estimations (Milligan \& Artig, 1999).

\subsection{Problem Description}

Wind energy is one of the most important renewable sources that is abundant in nature. It could be an effective solution to the growing demand for energy resources around the world. However, one of the drawbacks of wind farms is the uncertainty associated with wind, which makes the supplies of wind energy difficult to predict. As a result, wind energy cannot be used as a single source of supply and must always be supplemented by 
other sources of energy with greater regulatory capacity. This leads to the dilemma of optimizing wind energy output while ensuring a steady supply whenever possible (Discovery Education, 2016).

In order to have a stable supply of energy, the wind energy system needs to figure out a way to balance speed diversification and overall energy production. This could be done by selecting wind farm locations that have negative correlations of wind speeds, where if one location's wind speed drops, the other locations will pick it up (World Nuclear Association, 2016).

This project deals with the problem of finding optimal locations for wind farms that maximize the overall energy output while ensuring a steady supply of energy by diversifying the wind farm locations.

Additionally, we consider the problem of determining a small number of locations that would be representative of the comportment of wind in the whole system.

The costs of setting up wind farms will be demonstrated based on the wind farm's size, the height of wind turbines, and geographical contemplations. High wind speeds are essential to get the maximum possible electrical power output in a wind farm. Alternatively, one needs to balance the wind energy supplies over time by picking different locations. These concerns will be addressed using network-based models. It is important to mention that real-life wind speed data will be applied to build the models.

Figure 1 shows the actual $5 \mathrm{~km}$ wind speed map of the world at 80 meters (Vaisala, 2017). 


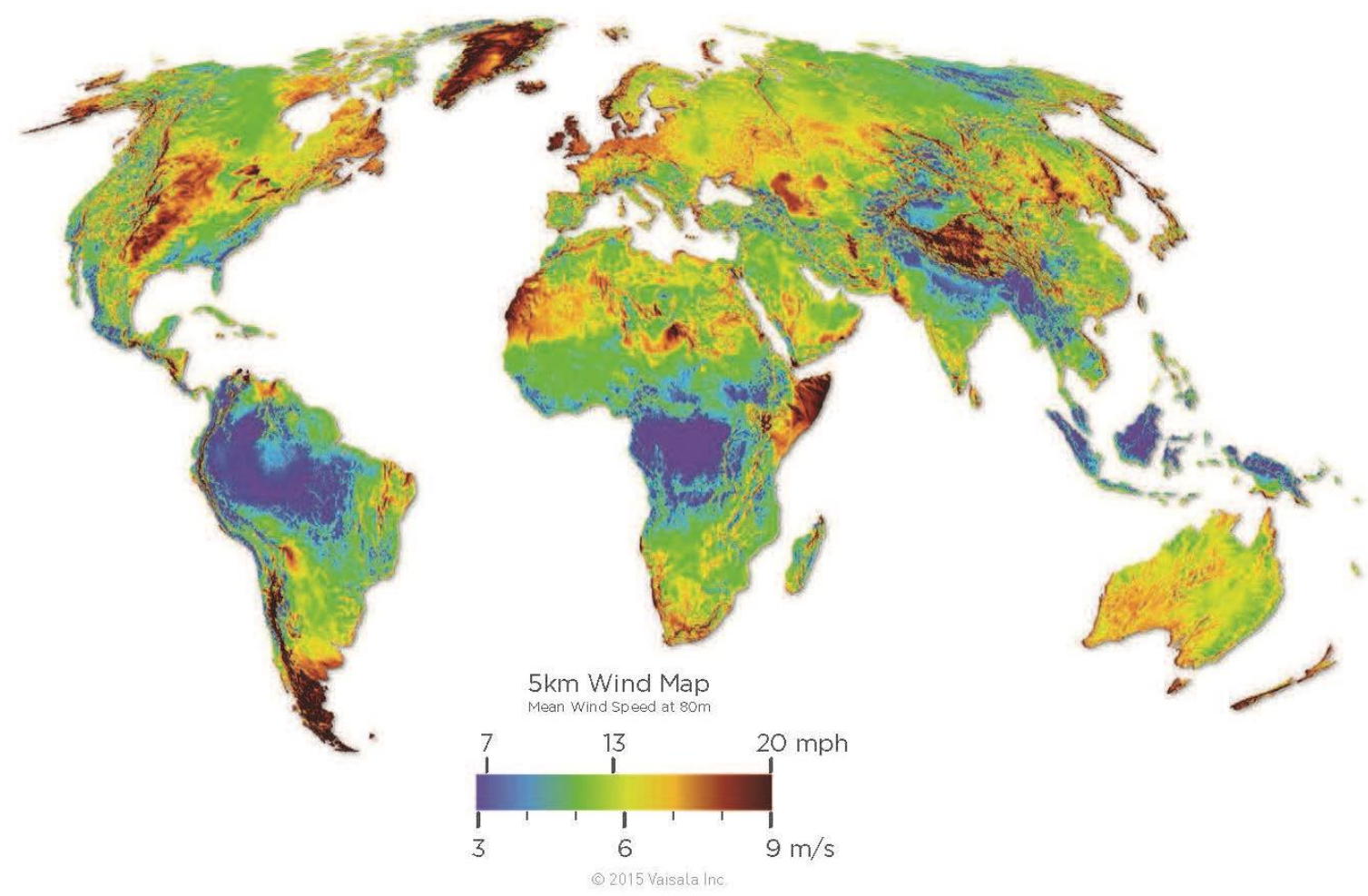

Figure 1: Global wind map, reprinted with permission from (Vaisala, 2017).

\subsection{Project's Objectives and Scope}

The main objective of this project is to investigate the wind energy system in order to determine optimal locations for windmills that would maximize the energy production while ensuring a steady supply. Thus, two important considerations associated with windmill locations are addressed, high overall energy production and wind speed diversification, which could be used to reduce risks associated with wind uncertainty for wind energy systems.

The specific steps employed to achieve the main objective include:

- Finding correlation coefficients of wind speeds.

- Selecting the cut-off correlation threshold indicating acceptable level of diversification. 
- Construction of the wind energy graph based on the selected threshold.

- Selecting a subset of nodes in the graph that maximizes energy while satisfying the restrictions placed on the structure of the corresponding sub graph to ensure the appropriate level of diversification.

- Selecting a subset of nodes in the graph for small dominating sets, while satisfying the limitations cited.

- Estimating the cost of setting up wind farms with desired characteristics.

We use real data from Bolivian studies of wind velocities around the whole country. To solve the central problem of the project, related to location decisions for wind farms technologies, network-based models and graph theoretical techniques are utilized. High wind speeds are essential to get the maximum possible power output in a wind farm, while controlling the effects of wind speed variability.

We use graph theory to model the problem of finding appropriate locations for wind mill farms that maximize the overall energy output, while controlling the effects of wind speed variability, to balance the wind energy supplies over time by selecting diverse locations. If the weights of vertices are given by the average wind speed at the corresponding locations, then the problem of finding appropriate sites, and locations for wind mill farms is formulated as the problem of finding a tightly knit cluster of vertices with high weights. We use cliques, 2-plexes, and 3-plexes to model the clusters.

To determining a small number of locations that would be representative of the overall behavior of wind speeds in the whole system, we search for small dominating sets in graphs representing the system. 
Lately, because of the growing information and technology world, one often finds serious challenges on processing huge data sets that arise in many different disciplines. Solving such interesting problems and extracting useful information from data sets has been one of the most exciting areas of research for many years (Boginski, Butenko, \& Pardalos, 2003). Particularly, there have been many studies on these systems using graph theory. Networks, also known as graphs, are the representation of real life structures that consists of vertices and edges connecting pairs of vertices. Graph is a simple and intuitive modeling tool that is convenient for study of objects from diverse origins. Specifically, graphs have been previously used in the analysis of the World Wide Web, the phone call records in telecommunications, social networks, and the stock market data among other applications (Bondy \& Murty, 2008). For example, in the Social Networking Graph, each individual person is represented as one vertex, and there is an edge between two people if and only if they know each other. An interesting assertion related to such networks, known as "six degrees of separation" argues that any two people on Earth are separated by at most six direct pairwise connections (Hayes, 2000). Likewise, in the Stock Market Graph, each financial instrument is represented as a vertex, and there is an edge between two instruments if they are correlated under certain conditions. The stock market obeys the power-law model, and the information in the stock market can be used to analyze the market behavior (Boginski, Butenko, \& Pardalos, 2003).

Following this general framework, in this project, a wind energy system is represented as a graph, where the vertices are the potential sites for windmills location, and there is an edge between two locations if the correlation coefficient of the corresponding pair over a 
specified period, is below a given threshold $\theta,-1 \leq \theta \leq 1$. This project studies the windmill system over a defined period, where it is possible to compare and contrast the behaviors of the wind data. Therefore, one could get useful information about the wind energy system.

While the problem of determining optimal locations for wind power plants has been studied in the literature (Milligan \& Artig, 1999), to the best of our knowledge, networkbased approaches like the one proposed in this thesis have not been considered previously (Bondy \& Murty, 2008). These. It should be noted that the approaches developed in this thesis can be applied to other renewable energy systems with high variability (e.g., solar energy). 


\section{CHAPTER II}

\section{LITERATURE REVIEW}

\subsection{Wind Farms Technologies}

Wind energy technologies use wind for different practical purposes, such as generating electricity, charging batteries, and pumping water. Wind energy is the result of the sun's irregular heating of the atmosphere, the earth's irregular surfaces and the planet's rotation around the sun, which all in association create wind with different speeds (U.S. Department of Energy, 2013).

Most wind energy technologies can be used as self-governing applications, connected to a utility power grid, also combined with different energy sources, like photovoltaic system. (Fares, 2015). For bigger megawatt sources of wind energy, a large number of turbines is usually built adjacent to each other to form a wind farm that provides electrical energy to the grid power system. Numerous electricity generators use wind farms to supply electrical power to their customers. Individual turbines are typically used for communications or water pumping. Nevertheless, landowners and agriculturalists in windy areas can also use minor wind energy systems to generate electricity. (U.S. Department of Energy, 2013).

Figure 2 shows a group of 80 meter wind mills. These type of mills are being widely used in the recent years (Pexels, 2017). 


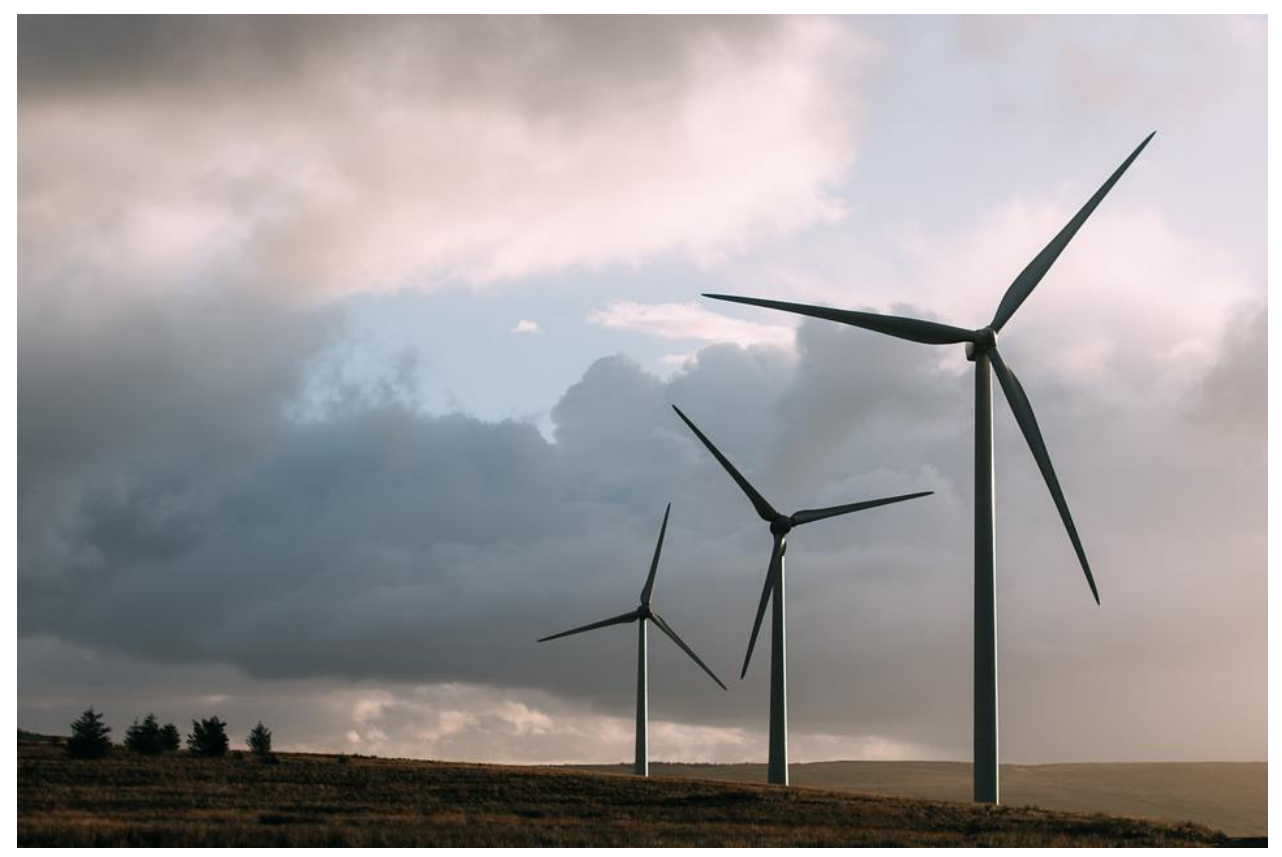

Figure 2: Actual wind mills, reprinted from (Pexels, 2017).

\subsection{History of Wind Farms}

Since early history, people have utilized wind energy. It propelled boats alongside the Nile River as early as 5,000 B.C., and helped Persians pump water and grind grain between 500 and 900 B.C. As cultures took advantage of the power that wind offered, the use of windmills propagated from Persia to different areas in the world, especially Middle East, where windmills were used in its majority for producing food (U.S. Department of Energy, 2013).

Eventually, around 1,000 A.D., wind power technology propagated to north European countries like Netherlands, which adjusted windmills to help drainage in lakes and marshes in the Rhine River Delta. Figure 3 shows a picture of this type of wind mills. Later on, the use of wind power has diminished, which was the case until the last century (Lynn, 1962). 


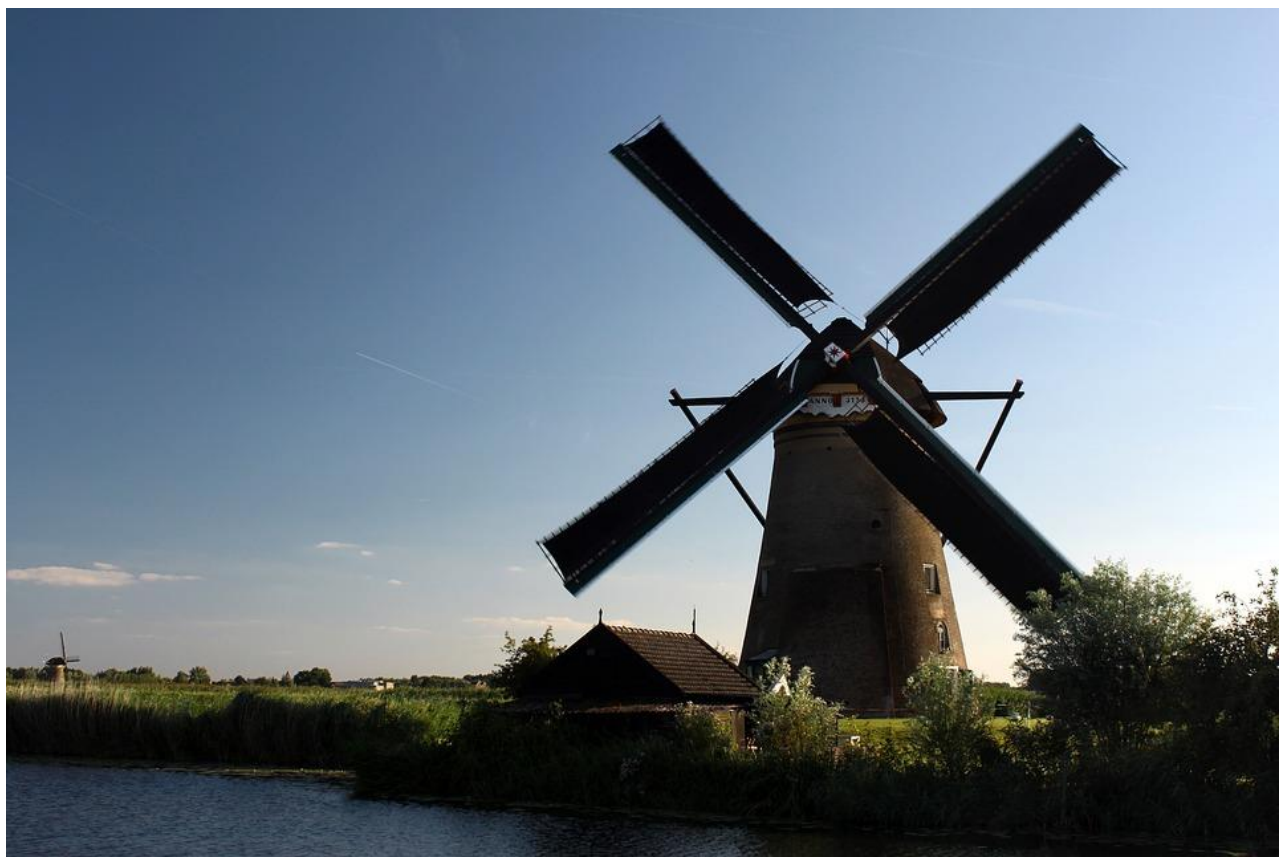

Figure 3: Wind mills used for drainage, reprinted from (Katicaj, 2016).

\subsection{Wind and Electrical Energy}

Mills powered by wind are being used for around 3000 years, principally for grinding grain or pumping water; while in ships the wind has been an essential source of power for a longer period. Since medieval times, horizontal axis windmills were an important part of the country economy and only fell into abandonment with the advent of inexpensive fossil-fueled engines and then the spread and growth of rural electrification (Musgrove, 2010). The usage of wind turbines to produce electricity can be tracked back to the late $19^{\text {th }}$ century with the $12 \mathrm{~kW}$ direct current windmill generator fabricated by Charles Brush in USA and the research carried out by Poul la Cour in Denmark. However, for much of the $20^{\text {th }}$ century there was slight interest in utilizing wind energy for electricity generation, other than for battery charging for remote houses; and these low power energy systems were quickly removed once access to electricity became available, thanks to grid expansion. One distinguished improvement was the $1250 \mathrm{~kW}$ Smith-Putnam wind turbine 
constructed in USA around the year 1941. This remarkable machine had a steel rotor of $53 \mathrm{~m}$ in diameter, flapping blades to decrease extra loads, and full span control of pitch. Although a blade arm failed devastatingly in 1945, since then, it has remained as the largest wind turbine ever constructed for at least 40 years (Putnam, 1948).

Golding in 1955, and Shepherd and Divone in 1994 provided a fascinating history of primary wind turbines manufacture. They recorded the $100 \mathrm{~kW}$, a $30 \mathrm{~m}$ diameter Balaclava wind turbine in the USSR in the year 1931, and the Andrea Enfield $100 \mathrm{~kW}$, a $24 \mathrm{~m}$ diameter pneumatic design produced in the UK in the early 1950s. In this turbine, resonating blades were used to draw air up over and through the tower where another turbine had driven the electrical generator.

In Denmark the $200 \mathrm{~kW}$, a 24 m diameter Gedser machine was built around 1956, while Electricite de France had tested the 1.1 MW, a 35 m diameter turbine around 1963. In Germany, Ulrich Hutter, developed a number of original, lightweight turbines during the 1950s and 1960s. In spite of these practical advances and enthusiasm that Golding had at the Electrical Research Association in UK, there was little continual interest in wind electrical generation until the price of oil rose dramatically around 1973.

The unexpected increase in the price of oil stimulated a number of considerable, government funded programs of research and development. In USA, this led to the construction of a series of different prototype turbines starting with the $38 \mathrm{~m}$ diameter $100 \mathrm{kWMod}-0$ in 1975 and ending in the 97.5 m diameter - 2.5 MWMod-5B during 1987. Similar programs were pursued in UK, Sweden and Germany. There was considerable uncertainty as to which architecture might demonstrate maximum cost effectiveness and 
more than a few innovative concepts were studied at large scale. In Canada, a $4 \mathrm{MW}$ vertical axis Darrieus wind turbine was erected and this concept was also studied in a 34 m diameter Sandia Vertical Axis test facility, in the USA. In the UK a substitute, vertical axis design using straight blades to giving an " $\mathrm{H}$ "' type rotor was suggested by Dr Peter Musgrove and a $500 \mathrm{~kW}$ model was constructed (Musgrove, 2010). By 1981 an advanced horizontal axis $3 \mathrm{MW}$ wind turbine was designed, built and tested in the USA. It used hydraulic transmission and as a different alternative to a yaw drive, the entire structure was orientated in direction to the wind. The best selection for the number of blades remained uncertain for some period, while and large horizontal axis turbines were constructed in different arrangements, with one, two or three types of blades.

After a certain period of research and development, several prototypes were created. Nevertheless, the difficulties of operating very large wind turbines in problematic wind climates were often undervalued and the reliability of the different prototypes was not good enough. At the same time as the multi megawatt prototypes were constructed by some private companies, often with considerable support from the state, were developing smaller, and simpler, turbines for commercial production and use. In particular the financial support mechanisms in California in the mid 1980s resulted in installation of a high number of small (less than $100 \mathrm{~kW}$ ) wind turbines. A number of these projects also suffered from various types of difficulties, but, being smaller, they were generally easier to modify and repair. The Danish wind turbine concept emerged of a three bladed, up wind stall regulated rotor and a fixed speed, induction generator drive train. This simple architecture proved to be extraordinarily successful and was implemented on turbines as 
large as $60 \mathrm{~m}$ in diameter and power at ratings of up to $1.5 \mathrm{MW}$. On the other hand, at large rotor diameters and generator ratings, the architecture terminated to be effective, as aerodynamic stall is difficult to predict, an induction generator no longer easily provides enough damping and torsional compliance in the drive train and the requirements of the electrical Transmission System Operators for connection to the electrical network. The Grid Norms and Codes were more difficult to meet. Hence, as the size of commercially available turbines came near or exceeded that of the large prototypes of the 1980s, the concepts of variable speed operation were investigated then, developing a full span control of the blade pitch. Some advanced materials were used progressively more by many designers.

In 1991, the very first offshore wind farm was erected at Vindeby. It consisted of eleven, $450 \mathrm{~kW}$ wind turbines situated up to $3 \mathrm{~km}$ offshore. During the course of the 1990s, small numbers of offshore wind turbines were placed really close to shore, while in 2002 the Horns Rev, a $160 \mathrm{MW}$ wind farm, approximately $20 \mathrm{~km}$ off the western coast close to Denmark, was constructed. This was the primary project to use an offshore substation, which raised the power and collection voltage of $30 \mathrm{kV}$ to $150 \mathrm{kV}$ for a transmission line to shore. In 2010 a 500MWwind offshore wind farm named Greater Gabbard was constructed near the coast of England with 1000MW. The wind turbines that have been installed in these types of offshore wind farms have been amplified versions of 3-bladed, upwind terrestrial designs. Conversely, the possibility of higher blade tip speeds, because of a reduced emphasis on visual appearance in sites far from land, and more comfortable 
noise constraints, are leading to an attention in the development of very large scale plants, lower solidity rotors with two or even one blade.

The incentive for the improvement of wind energy technology around 1973 was the increase in the price of oil and concerns about limited fossil fuel resources around the world. Since 1990, the main concern for using wind turbines to generate electrical power and produce electrical energy, was very low $\mathrm{CO} 2$ emissions, and the potential of wind energy to help mitigating climate change related to greenhouse gasses. Then since 2006 the increment of oil price and is derivatives, as well as concerns over security of energy provisions, leads to a further increase of interest in wind energy power. A succession of different policy measures were put in place in many countries to boost its usage. By 2007, the EU declared a policy setting the goal that $20 \%$ of all energy should be from renewable sources by the year 2020. Because of the difficulty of using renewable energy for transportation and heating, this implies that in some countries $30 \%$ to $40 \%$ of its electrical power usage should come from renewable resources, including wind energy, which plays an important role. Energy policies continue developing rapidly with many countries adopting ambitions to reduce greenhouse emissions by at least $80 \%$ by 2050 in order to alleviate climate change.

The expansion of wind energy in some countries has been quicker than in others and this difference cannot be explained simply by changes in wind speeds. Other important factors include financial support mechanisms for wind electricity, access to the electrical network, the process by which the local authorities give authorization for the production of wind farms, and the sensitivity of the population, predominantly with respect to visual and 
environmental impact. The development of offshore locations, although at high cost, responds to these concerns over the environmental impact of wind farms technologies.

As a comparatively new generation technology, wind energy requires some financial support to encourage its development and encourage investment from private corporations. This funding is sometimes provided in many countries and recognizes the contribution that wind generation makes to climate change and security of future energy provisions. There is currently an active discussion as to the best instrument of providing support so that it motivates the development of wind energy at lowest cost and without altering the electricity marketplace.

Feed in Tariffs are offered in a diverse number of countries. A fixed price is paid for each $\mathrm{kWh}$ generated from renewable sources with dissimilar rates for wind energy, photovoltaic solar energy and other kind of renewable energy system. This support instrument has the benefit of giving certainty of the income from a successful project and is credited by its supporters for the fast expansion of wind energy, as well as other renewables. An alternative approach is a quota or Renewable Portfolio system where the government places an obligation on electricity suppliers to source a definite segment of the energy they produce and supply from renewable energy sources. Also, renewable energy generators are awarded green certificates for energy generated from renewable sources.

Historically, Capacity Auctions have also been used as a good mechanism. The government regulates the volume of wind energy necessary and conducts an auction for a certain capacity on price. Capacity Auctions suffered from some wind farm designers bidding low to secure contracts and then not building projects. 
Even though the form of these support mechanisms, and particularly their stability, is important, it may be argued that some other factors including access to the energy in the electrical grid, speed of the planning system and public acceptance play a critical role in defining the rate of positioning wind energy. It is also possible that some extra international support, establishes different types of methods for small carbon electricity generation (Burton, Sharpe, Jenkins, \& Bossanyi, 2011).

\subsection{Wind Farm Locations and Importance}

Selecting an appropriate site is crucial to the success of any energy project, technically and financially. This idea applies to every project, from the smallest residential energy systems to the largest projects. It also applies to every renewable energy system technology, from wind to solar, and others. Selecting the proper location and designing a turbine selection to fit it are vital topics to ensuring performance of wind farms (Southwest Power Pool, Inc., 2016).

Site selection also plays an important part in financial returns, besides construction, current operations and maintenance, and general safety. An inappropriate site turbine array puts in danger the whole wind farm project (Tocco, 2013).

In the following, we consider some important key questions concerning wind farms.

\subsubsection{Significance of the Wind Resource}

For wind projects, understanding the available wind resource is crucial. It is also important to evaluate neighboring obstacles, which could cause disruption to airflow access and reduce life of the turbine (Fares, 2015). As a rule, distance between a turbine and the closest obstacle should be at most twice the height of the turbine, except if the turbine is more than twice the height of the obstacle, the distance can be less (Wind Energy the Facts, 
2017). Even though it may be evident, it is essential to note that locations such as inside a valley or the bottom of a hill are not the finest places for placing wind farms. The best locations in terms of wind supply are naturally high altitudes on mountains, on large open fields, and on the edge of water bodies (Cleveland , 2004).

It is also important to consider the wind cut on the proposed site. Turbines in particular can experience a high amount of wind cut, so it is imperative to design an appropriate arrangement that resists wind cut (Tocco, 2013) (Wind Energy the Facts, 2017).

There are technology specific questions that must be considered. For instance, we provide a brief checklist of the questions used when evaluating potential wind-energy sites defined by (HSH Nordbank, 2016).

- "Is it necessary to build a road to the site?".

- "What are the required hours for construction and O\&M?".

- "Are there access limitations to the site, such as it being locked during certain hours?".

- "Are there site operations that construction might hinder?" (Tocco, 2013).

- "Is there space for a staging area, which will most likely consist of a crane, construction trailers, dumpsters, various trucks, cement mixers, concrete pumps, and other equipment?".

- "Is there onsite access to electricity and water, or are a generator and water supply needed?".

- "How will workers access the site for future operations and maintenance? " (HSH Nordbank, 2016). 
While this list is neither exhaustive nor comprehensive, it provides an overview of key items to be considered at the beginning of the site selection process.

It is important to mention that one of the most crucial factors influencing the performance of wind mills and wind farms is the speed of the wind. Efforts to maximize energy power output are always related to length, quality and geographical coverage around wind farms (Wind Energy the Facts, 2017).

\subsection{Location Problem}

The location problem consists in determining the optimal location of one or multiple energy systems or resources centers (S\&C Electric Company, 2017), either in a coordinated space linked to a geographic location, or within a network with edges and nodes (which can represent an electric network, roads and cities, etc.) (Bondy \& Murty, 2008). The determination of the location of an electrical power plant depends on one or more factors that, for purposes of mathematical modeling of the problem, are represented in objective functions that must be maximized or minimized. It means that the specific place must have an objective function (Wind Energy Center, 2010).

Setting up a location model can be addressed in three stages, described as follows (Fernandez, 2011):

- Alternative localization: regardless of the type of mathematical modeling that would be performed for the problem, it is necessary to delimit the set of possible solutions, either by conformation of a finite set of locations or by geographical delimitation of possible locations. The mathematical model used will depend directly on the selection of different possible sites. 
- Evaluation of the alternatives: once the possible locations have been defined, the information describing each one of them must be gathered, according to the most relevant attributes related to the main objective, and then we need to compare them with each other. If necessary, a numerical quantification of qualitative attributes must be done, which should be determinant for the performance of each alternative.

- Selection of the localization: in this stage a mathematical model is used to determine the alternative that will be an optimal solution. This would be chosen in order to define a solution taking into account one or several criteria. Depending on the decision model, whether we deal with a single criterion or multiple criteria, an optimal solution or a set of "good solutions" would be obtained (Fernandez, 2011).

The problem of locating plants and resources has been addressed in various disciplines such as medicine, telecommunications and industry in general (Daskin, Snyder, \& Berger, 2003). There are different approaches to address the problem depending on needs. However, the basic approach to the localization problem is common to all areas, it is an optimization problem described as follows in ( 1 ):

$$
\begin{gathered}
\min (\max ) f(x)=\left[f_{1}(x), \ldots, f_{m}(x)\right] \quad x \in \Omega \\
\text { subject to: } c_{j}(x)=0 \quad j=1 \ldots n \\
h_{k}(x) \leq 0 \quad k=1 \ldots p
\end{gathered}
$$

Where $x$ represents the solution vector, $\Omega$ the solution domain, $f_{i}(x)$ denotes the objective function and $h_{k}(x)$ and $c_{j}(x)$ correspond to the constraints of equality and inequality type. Depending to the application, the problem may have one or more objective functions. 
Usually, the objective function represents some type of cost (associated with the installation to be located) or metric distance that is required to minimize or, alternatively, the utility to be maximized. Similarly, constraints on the problem relate to the maximum or minimum size of the plant, usage level, location of competitors and customers, as well as budget constraints and access to basic supplies (Grady, Hussaini, \& Abdullah, 2005).

\subsection{Graph Theory}

In discrete mathematics, particularly in graph theory, a graph is an assembly of a set of objects in which certain pairs are related (Harju, 2011). The objects correspond to mathematical concepts named vertices and each pair of related vertices is named an edge (Trudeau, 2012). Naturally, a graph is depicted in a form as a set of spots for the vertices, linked by lines for the edges. Graphs are a popular object of study in mathematics (Randic, Novic, \& Plavsic, 2016).

Edges could be directed or undirected. For instance, if vertices represent people at a conference, and there is an edge between two people if they shake hands, immediately this graph is undirected, because any person $B$ can shake hands with $A$ only if $A$ also shakes hands with $B$. In contraposition, if any edge from a person $B$ to a person $A$ corresponds to $B^{\prime} S$ admiring $A$, then this graph is called directed, since admiration is not necessarily reciprocated (Ruohonen, 2013). The former type of graph is named undirected graph and edges are called undirected, while the last type of graph is named directed graph and edges are called directed (Gross \& Yellen, 2004). Graph theory studies graphs. The term "graph" was introduced by (Sylvester, 1878). 
The common mathematical notation used to describe a graph is an ordered pair $G=(V$, $E$ ) where $V$ is the set of vertices and $E$ is the set of edges. Two vertices that are endpoints of the same edge are called adjacent or neighbors.

A graph is typically visualized as a collection of points or vertices that are connected with lines or edges (Caldwell, 1995). An example of an undirected graph is shown in Figure 4 (Dutta, 2012).

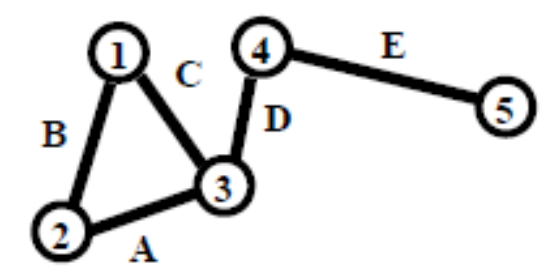

Figure 4: Graph example, adapted from (Legner, 2017).

A directed graph involving the same vertices and edges is shown in Figure 5 (Dutta, 2012).

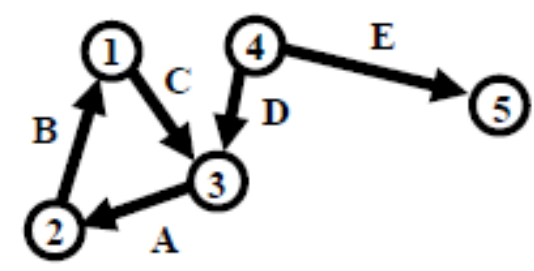

Figure 5: Directed graph example, adapted from (Legner, 2017).

A graph is called a tree if one and only one path exists amongst any two of its vertices. In other terms, a graph without any kind if loop is a tree. Figure 6 shows an example of a tree. For instance, the tree in this figure is a common example of a spanning tree, since it spans all of the vertices of the presented graph (Dutta, 2012). 


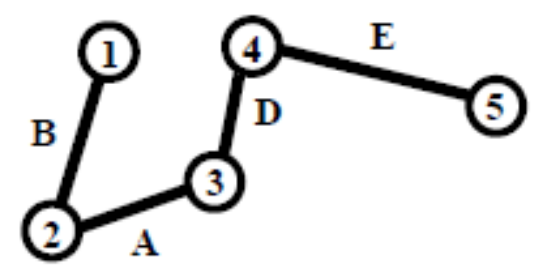

Figure 6: Tree example, adapted from (Legner, 2017).

Graph theory has found numerous applications in traditional power systems. Graph theoretic concepts are for example very useful in topological analysis of electrical power systems. Pai has studied this topic in his book on application of computer techniques in power analysis (Pai, 2006).

Another useful reference and literature on different power system applications of graph theory is a book by (Zhu, 2009). This book includes graph theoretic applications for electrical power flow calculations, classical financial power dispatch, security constrained monetary dispatch, multi area system monetary dispatch, reactive power optimization and pricing in multi area environment, hydro and thermal power system operation, power system state estimation, secure financial automatic generation control, automatic contingency selection, optimal load shedding, and distribution network optimization (Zhu, 2009). It is beyond the scope of this project to discuss all applications of graph theory in power systems.

\subsection{Data Mining}

Data mining, is the process of extracting information from huge data sets by utilizing methods referred as artificial intelligence or AI, machine learning, database systems, and statistics. A very essential idea is to discover patterns in the data and in general involves the following (Fayyad, Shapiro, \& Smyth, 1996): 
1. Anomaly detection identifies unusual data records that might be "interesting" or contain data errors.

2. Association rule learning also called dependency modeling, finds relationships between variables.

3. Clustering groups "similar" objects.

4. Classification generalizes known structures to apply to new data.

5. Regression finds a function while modeling available data with the least error.

6. Summarization provides a compact representation of the data set, including report generation and visualization (Fayyad, Shapiro, \& Smyth, 1996).

Data mining has been applied to numerous electrical power system applications (Saleh \& Laughton, 1985). Although, data mining techniques have been applied in different electrical power system applications, some of these methods have gained a renewed interest in the context of the growing Smart Grids technology, since combination and integration of data and information systems, is one of the key advantages of the Smart Grid technology (McGranaghan, 2010).

\subsection{Cliques}

The idea of a clique is somewhat simple. At the most universal and common level, a clique is a sub set of a network, in which the players are closely and intensely tied to one another, than they are to further members of the network. In general, terms of relationship ties, for instance, it is not unusual for people in human groups to form groups or cliques on the basis of ideology, religion, race, gender, age, and many other common things. The smallest cliques, groups, are composed of 2 actors: the dyad. Dyads can be extended to become more inclusive, forming closely connected regions and strong in graphs. A number of 
approaches to finding groups in graphs could be developed, by extending the close coupling of dyads to bigger configurations.

The formal definition of a clique, as it is used in analysis of networks is more narrow and specific, than the general notion of a local density. Officially, a clique is the maximum number of players who have all possible ties, present among themselves. A maximal complete sub graph is such an alliance, grouping, prolonged and extended to include as many players as possible (Hanneman \& Riddle, 2005).

\subsection{Wind Turbine Types}

\subsubsection{Doubly Fed Induction Generator}

DFIG is a wound- rotor induction generator. DFIG are the most commonly used in the wind industry. In the DFIG, the stator terminals are connected directly to the grid and the rotor across a partially rated convertor (Gerges, Ali, Moubayed, \& Outbib, 2007). A gearbox is necessary to couple the rotor to the generator due to the difference in the rotor and generator speed ranges. These convertors are usually of variable frequency (VFC) and back to back AC-DC-AC voltage source type (Sathiyanarayanan \& Senthil Kumar, 2014). They are made up of two IGBT types of side converters: rotor converter and grid converter, with a link connection in DC. This type of converter decouples the electrical grid frequency and the mechanical rotor frequency, which in turn enables variable speed operation. The rotor voltage is applied from the power converters. The Rotor Side Convertor (RSC) fully controls the generator like in the control of active and reactive powers, and controlling harmonics, while the Grid Side Converter (GSC) controls the power factor and ensures that it is high enough (Chakrawarti, 2015). A schematic of a DFIG is presented in Figure 7 (Solero, 2002). 


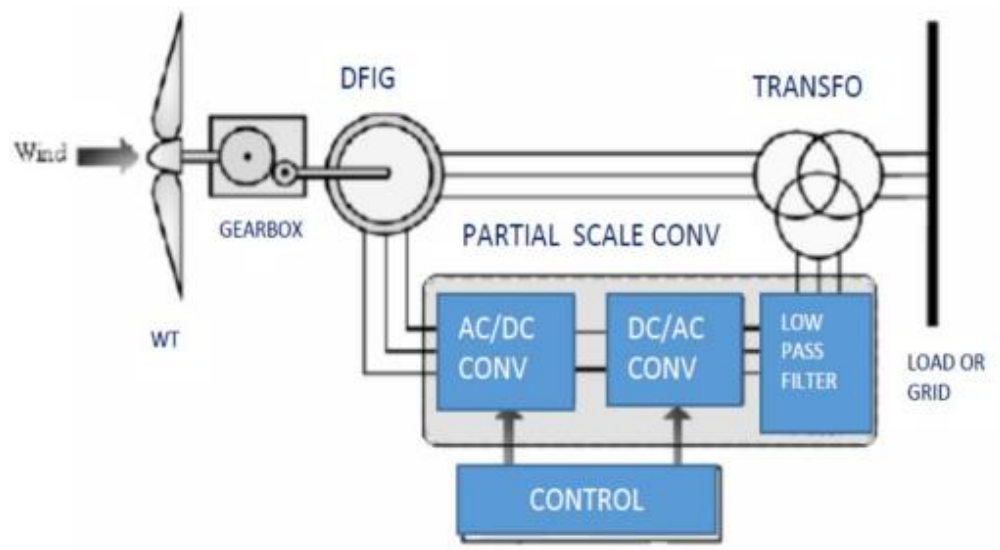

Figure 7: Doubly Fed Induction Generator (DFIG), reprinted with permission from (Beainy, Maatouk, Moubayed, \& Kaddah, 2016).

\subsubsection{Squirrel Cage Induction Generator}

The SCIG as shown in Figure 8, operates completely minimum ranges of wind speeds through a gearbox. Variations in the rotor speed of the SCIG are very small as the only speed variations that can occur are changes in the rotor slip. Due to this fact, the SCIG was widely considered as fixed-speed and was the basis of design for the first Danish WT (Hansen, et al., 2001).

It is very robust and little maintenance is needed only bearings lubrication. The rotor is composed of metallic bars that are very effective in resistive vibratory motion and dirt (Hasen, Blaabjerg, Christensen, \& Lindhard, 2001). In some cases, a SCIG may and it is been still used for variable-speed wind energy generation with a full-scale power electronic convertor (Patil \& Bhosle, 2013). To extract more power from the wind is difficult because this can cause generator overload. In order to achieve an optimal power extraction, pitch angle regulation is required. Figure 8 shows a schematic of the generator (Cardenas, Pena, Wheeler, Clare, \& Asher, 2009). 


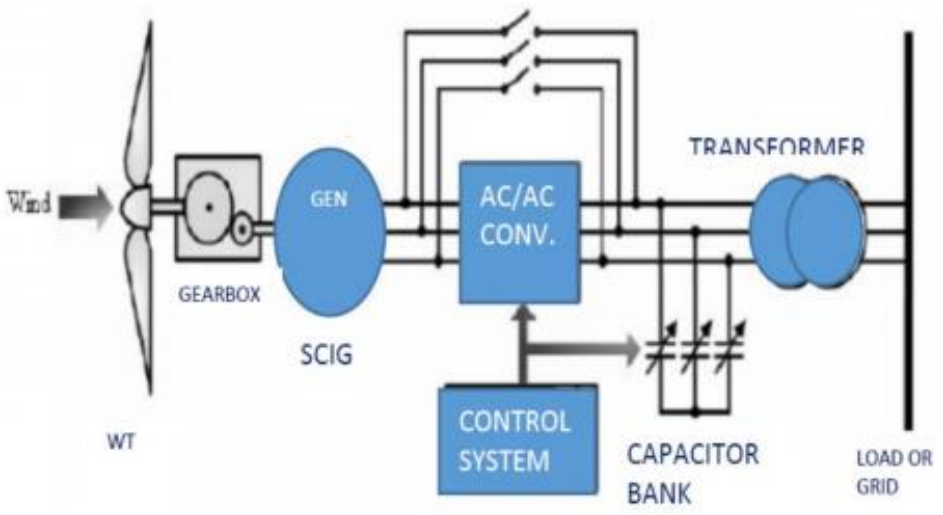

Figure 8: Squirrel cage Induction Generator (SCIG), reprinted with permission from (Beainy, Maatouk, Moubayed, \& Kaddah, 2016).

\subsubsection{Permanent Magnet Synchronous Generator}

To couple the slow spinning turbine rotor blade to generators like the DFIG and the SCIG, high speed multiple stage gearboxes (1:100), medium-speed single-stage gearboxes (1:10) are necessary. Direct-driven generators are system that do not need the gearbox altogether and these systems are based on the PMSG. Today's WTs high-speed multiple stage gearboxes have proven to be less reliable than expected by manufacturers thus requiring replacement at 5 to 7 years from beginning of operation, and that is a much earlier than their expected design life of 20 years (Musial, Butterfield, \& McNiff, 2007) (Tavner, Xiang, \& Spinato, 2007).

On shore-based wind turbines have a serious issue of decreased reliability and longevity, so this becomes a critical matter to look into for offshore installations. In this case, main WT manufacturing companies have started manufacturing WT with this type of generators for mainly offshore installations (Li \& Chen, 2008) (Dubois, 2004). This type is the most efficient generator with power losses of about $65 \%$ of that of a typical DFIG. A schematic of a PMSG is presented in Figure 9 (Polinde, can der Pijl, de Vilder, \& Tavner, 2005). 


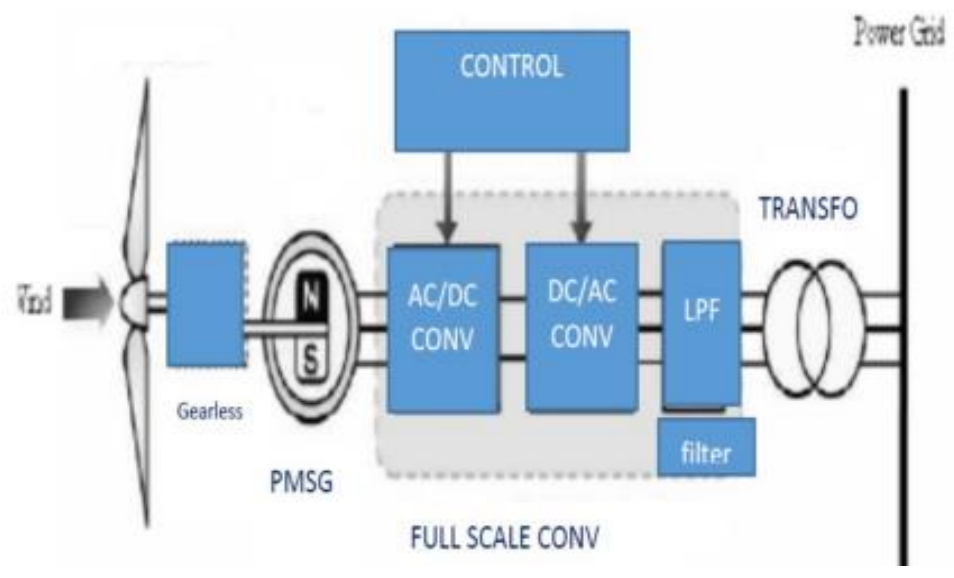

Figure 9: Permanent Magnet Synchronous Generator (PMSG), reprinted with permission from (Beainy, Maatouk, Moubayed, \& Kaddah, 2016).

\subsection{Net Present Value}

Net Present Value - NPV is the difference among the present value of cash inflows and the present value of cash outflows. It is frequent used in capital budgeting to analyze the profitability of a projected investment or project (Investopedia, 2017).

The formula ( 2 ) shows the equation for calculating "NPV":

$$
N P V=\sum_{t=1}^{T} \frac{C_{t}}{(1+R)^{t}}-C_{o}
$$

Where:

$C_{t}=$ net cash inflow, during period $t$

$C_{o}=$ total, initial investment costs

$r=$ discount rate

$t=$ number of periods, time

A positive net present value, indicates that the projected profits generated by a project or investment in dollars, exceeds the anticipated costs, also in dollars. Commonly, an investment with a positive NPV will be a profitable one than one with a negative NPV, 
which will result in a net loss. This theory is the main basis for Net Present Value Rule, which edicts that the only investments that should be faced, are those with positive NPV values (Investopedia, 2017).

\subsection{Internal Rate of Return}

Internal rate of return - IRR is a metric mostly utilized in capital budgeting measuring the profitability of profitable and potential types of investments. Internal rate of return is a discount rate that makes the net present value - NPV of all flows of from a specific venture equal to "0" zero. Internal rate of return calculations rely on the same formula as Net present value does (Investopedia, 2017).

To calculate the Internal rate of return using the formula, one would set Net present value equal to zero and solve for the discount rate $\mathrm{r}$, which is Internal rate of return here. Because of the nature of the formula, however, Internal rate of return cannot be calculated analytically, and must as a substitute be calculated either through trial and error or using some software programmed to calculate Internal rate of return.

Commonly talking, the higher a project's internal rate of return, the more required it is to assume the project. Internal rate of return is uniform for investments of varying types and, as such, Internal rate of return can be used to rank numerous prospective projects a firm is bearing in mind on a comparatively even basis. Assuming the costs of investment are similar or equal among the various projects, the project with the highest ranked Internal rate of return would probably be considered the best and undertaken first (Moten \& Thron, 2013). 


\subsection{Payback Period}

The payback period is the span of time required to recuperate the cost of an investment. The payback period of an established investment or project is an important factor of whether to undertake the project or position, as longer payback periods are typically not desirable for venture positions. The payback period normally ignores the value of money over time, unlike other complex methods of capital budgeting, for instance net present value, internal rate of return or discounted cash flow (Investopedia, 2017).

When cash inflows are uneven, we need to compute the cumulative net cash flow for each period and then use the formula ( 3 ) for payback period considering the time value of money (Jan, 2013):

$$
P B P=A+\frac{B}{C}
$$

Where:

$A=$ Last period with negative cumulative flow

$B=$ Absolute value of cumulative cash flow at the end of the period A

$C=$ Total cash flow during the period A 


\section{CHAPTER III}

\section{WIND ENERGY GRAPH}

\subsection{Introduction}

The wind speed and direction change continuously. Nevertheless, while processing wind data for wind power applications it is finally reduced to statistics, for instance, average speeds and altitudes. It is important to mention that the distribution of wind speed over a certain time is usually categorized by the Weibull function (Piacquadio \& De la Barra, 2014).

To construct the wind graph, we need to consider a number of geographically diverse locations as potential places for harvesting wind energy.

\subsection{Correlation Coefficients}

The wind energy graph is constructed based on the data of the study developed by "Transportadora de Electricidad S.A." (TDE) in Bolivia. In particular, the considered data set contains real wind speed measurements in a number of locations around the country. More specifically, TDE developed a technical document summarizing historical records of wind speeds in 201 meteorological stations distributed all around the Bolivian territory (GeoBolivia, 2008).

In the study realized by TDE, the data has been taken from meteorological stations, for ten years in a row, at 10 meters above surface level of the ground. The information collected was represented in monthly charts, correcting the variation of the data in air density, height and temperature depending on the location, due to the variation related of the altitude in comparison to the sea level (Transportadora de Electricidad S.A.). 
For each of the 201 potential windmill locations used in this study, there is a data file created that lists the wind speed data and the corresponding energy output.

We used ArcGis to create a map showing the 201 locations with their corresponding wind speeds; see Figure 10. The size of the blue disks corresponds to different ranges of velocities.

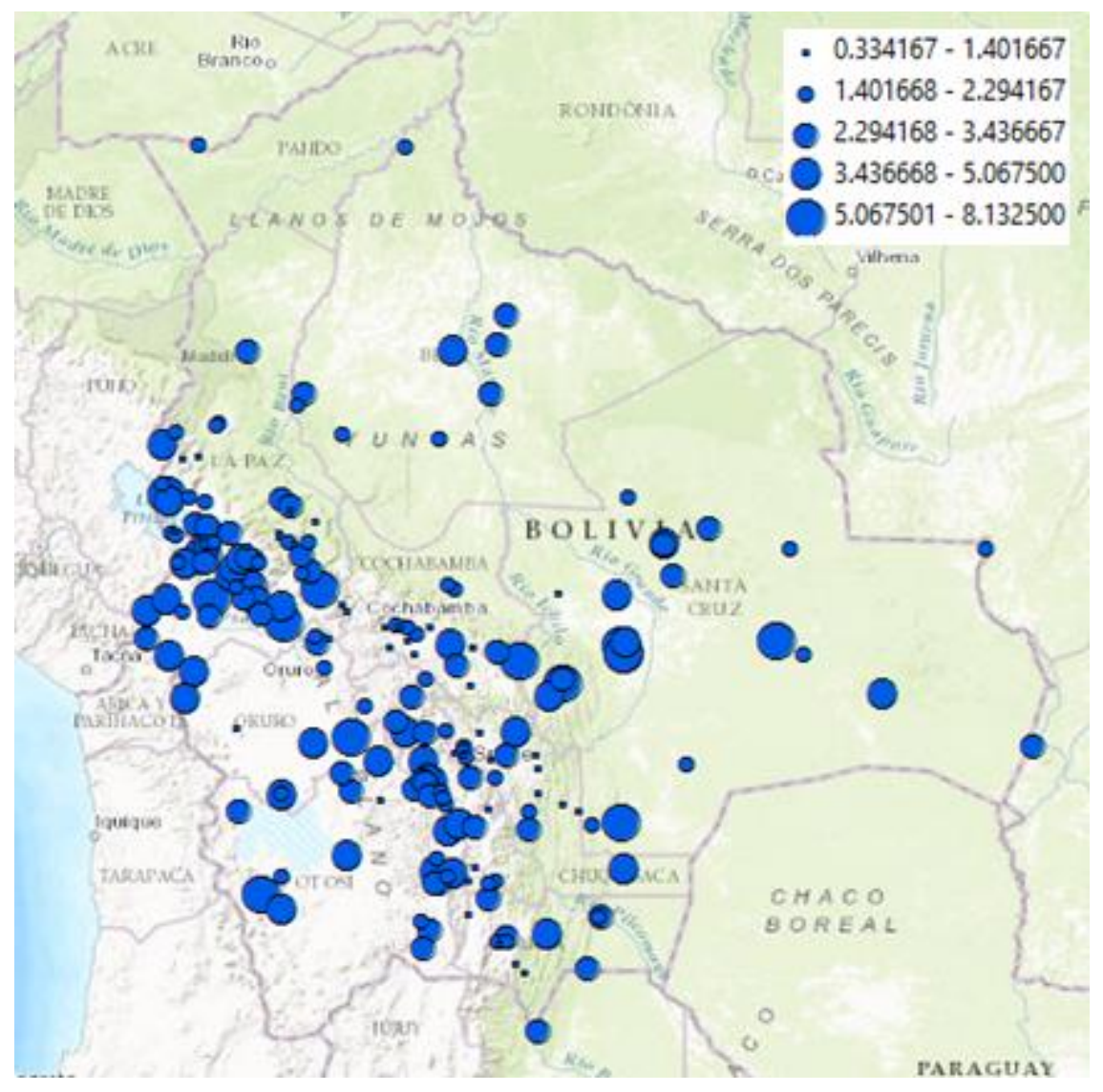

Figure 10: Geographical locations and wind speeds.

Figure 11 shows the wind speeds for all the studied sites, at $10 \mathrm{~m}$ height. The average speed is $2.70 \mathrm{~m} / \mathrm{s}$. 


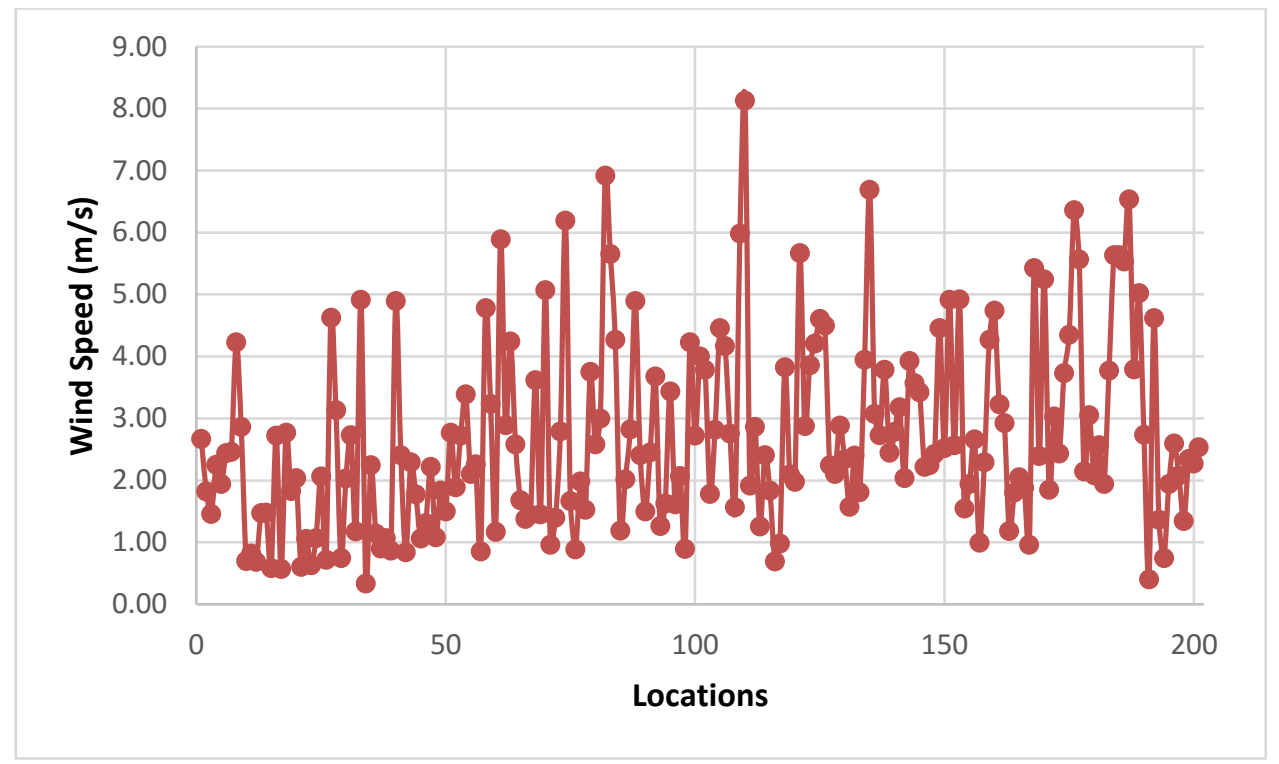

Figure 11: Wind speeds for all the possible sites.

Based on the data files, we calculated the cross correlation coefficient between each pair of windmill sites using the following formula as suggested in the market graph described as follows (Butenko, 2003):

$$
C i j=\frac{\left(R_{i} R_{j}\right)-\left(R_{i}\right)\left(R_{j}\right)}{\sqrt{\left(R_{i}^{2}-\left(R_{i}\right)^{2}\right)\left(R_{j}^{2}-\left(R_{j}\right)^{2}\right)}}
$$

Here $R i(t)=\ln \left(\frac{S i(t)}{S i(t-1)}\right)$ is the fluctuation of wind speed for the $i^{\text {th }}$ site at a specific interval of time.

Computing the correlation coefficient for each pair of sites, we will have the total of

$$
\frac{|V|(|V|-1)}{2}
$$

correlation coefficients, where $|V|$ is the number of vertices (i.e., locations) (Coleman $\&$ Moré, 1983). This is also the maximum possible number of edges in a graph with $|V|$ vertices. For our data $|V|=201$, so we have 20100 pairs of correlation coefficients. We 
can calculate the edge density $D$ for a simple undirected graph using the following formula (Diestel, 2005):

Here $|E|$ is the number of edges.

$$
D=\frac{2|E|}{|V|(|V|-1)}
$$

\subsection{Selecting a Threshold}

We will build a wind energy graph based on a correlation threshold $\theta$ as follows: If $C_{i j} \leq$ $\theta$ then we place an edge between the vertices $i$ and $j$; otherwise, we do not. Determining an appropriate correlation threshold $\theta$ is an important task, since it will have a strong influence on the structural properties of the resulting graph (Lee $\&$ Streinu, 2008). For this purpose, we analyze the distribution of correlation coefficients, which is visualized in Figure 12.

The most frequently occurring correlation coefficient values are around 0.33 , the average correlation coefficient value is approximately 0.27 , and the median is around 0.3 .

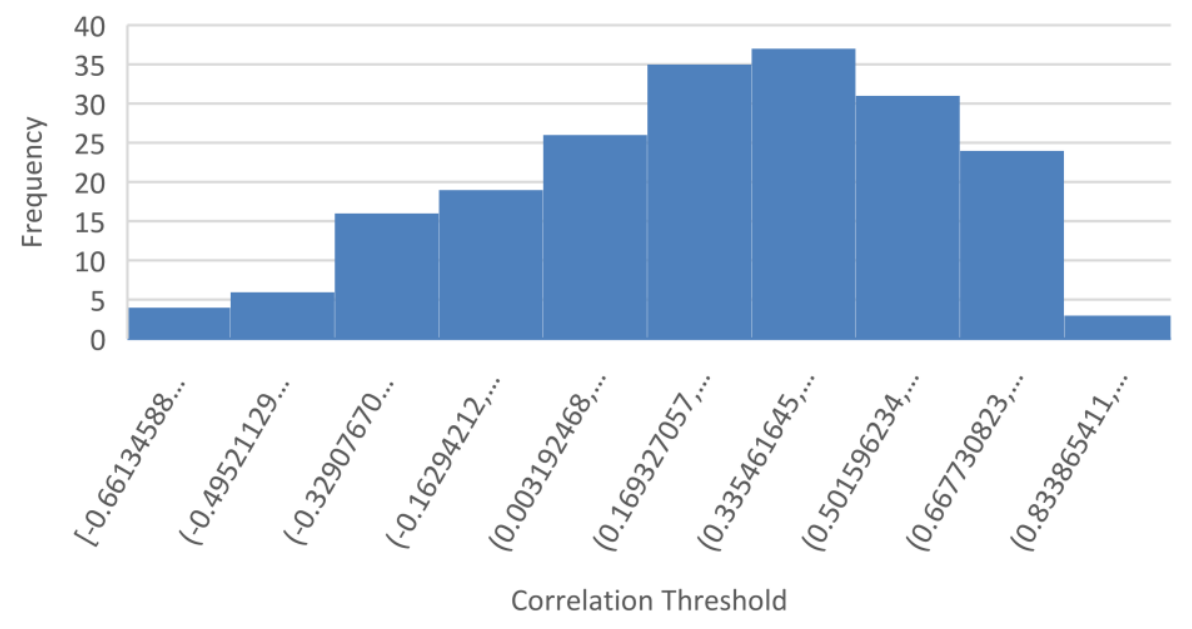

Figure 12: Distribution of correlation coefficient values.

To minimize the effects of wind speed variability, it is desirable that wind farms be located and set at places that have a negative correlation, below "0" zero with each other in terms 
of wind speed over time (Sethuraman \& Butenko, 2015). Hence, $\theta=0$ is selected as the threshold correlation value for this project. The number of edges we have with $\theta=0$ is 4,811 , which corresponds to the edge density of 0.239353 .

We created the adjacency matrix for the obtained graph, which is defined as follows: For a simple graph with vertex set $V$, the adjacency matrix is a square $|V| \times|V|$ matrix $A$ such that its element $A i j$ is one when there is an edge from vertex $i$ to vertex $j$, and zero when there is no edge (Biggs, 1993). The diagonal elements of the matrix are all zero, since edges from a vertex to itself, called loops, are not allowed in simple graphs. It is also occasionally useful in algebraic graph theory to replace the non-zero elements with some algebraic variables (Harary, 1962). To visualize the obtained graph, we used the Gephi software. The graph is shown in Figure 13.

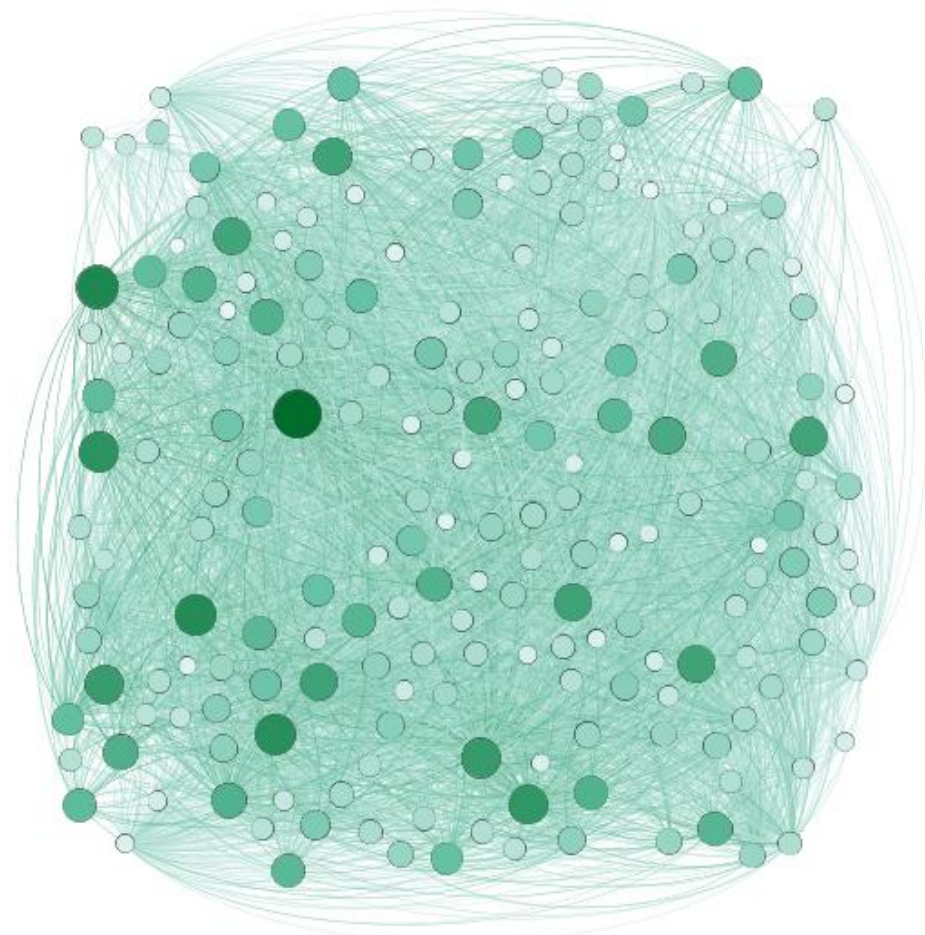

Figure 13: Wind energy graph. 
The radius of a disk representing a vertex is proportional to the average wind speed for the corresponding location. Figure 14 shows the same wind energy graph as in Figure 13, but with the nodes pictured according to their actual geographical locations.

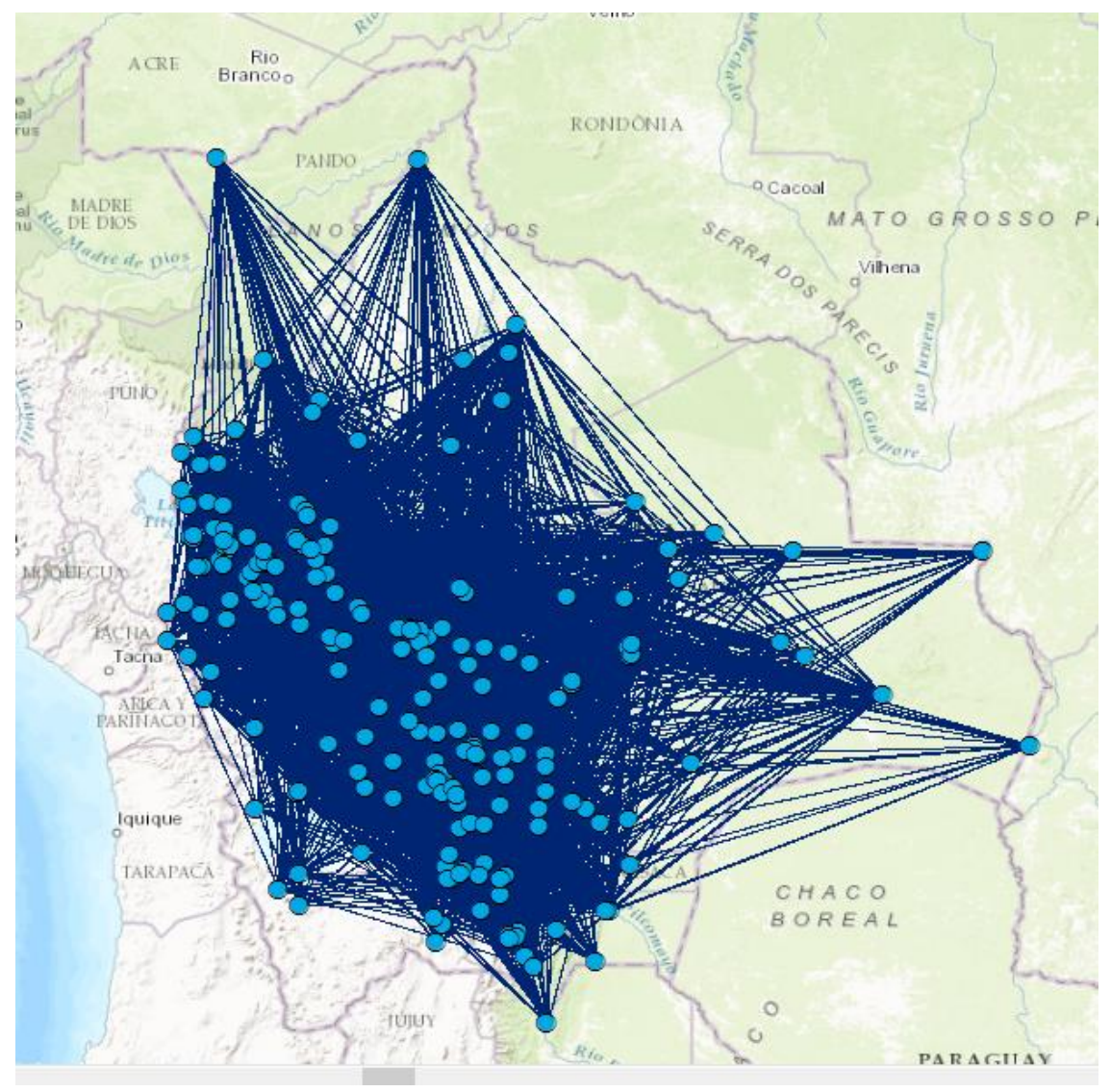

Figure 14: Geographical locations and wind graph. 
Figure 15 shows the degree distribution diagram. The average degree of a vertex is 23.935 .

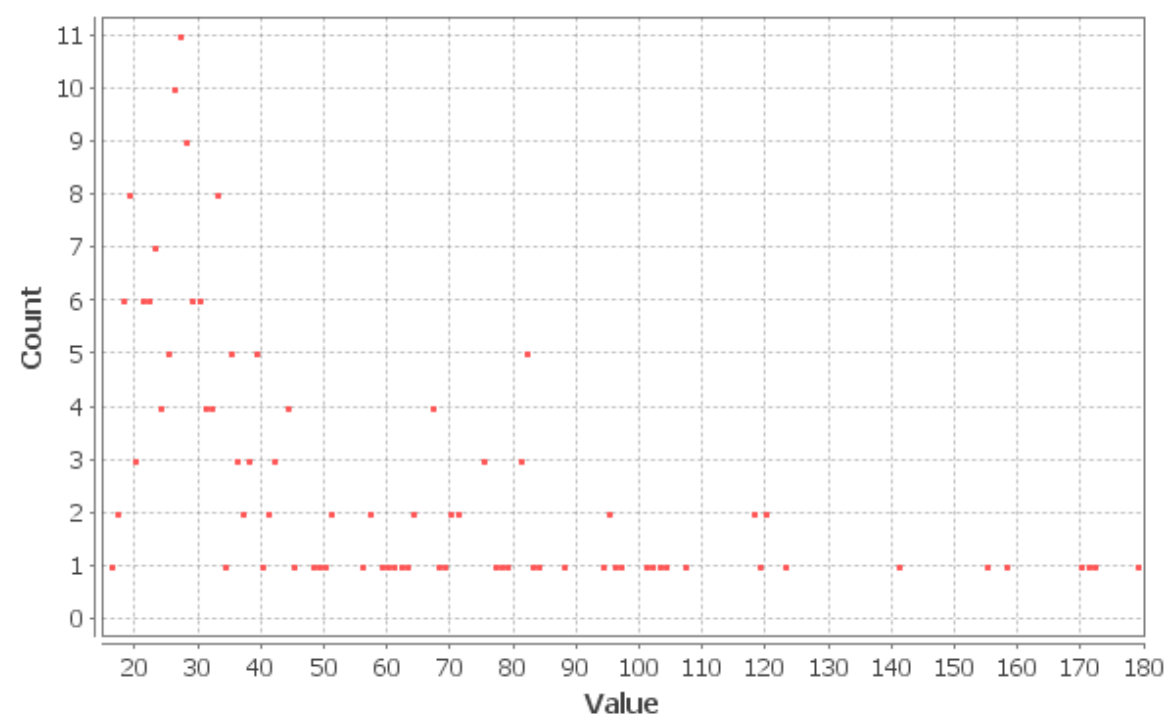

Figure 15: Degree distribution.

Furthermore, Figure 16 shows a reduced wind energy graph, which is a subgraph of the wind energy graph induced by vertices corresponding to the locations with the average wind speeds above $3 \mathrm{~m} / \mathrm{s}$ and below $25 \mathrm{~m} / \mathrm{s}$. Notice the sparsity of the new graph compared to the original one. We selected these values $(3 \mathrm{~m} / \mathrm{s}$ to $25 \mathrm{~m} / \mathrm{s}$ ) because they are the minimum and maximum velocities for generating electricity with wind turbines. More specifically, at very low wind speeds there is insufficient torque utilized by the wind on the turbine blades to make them rotate. Nonetheless, as the speed increases, the wind turbine will begin to rotate and generate power, as electrical type of energy. The rapidity at which the turbine first starts to rotate and generate power is frequently called the cut-in speed and is usually between 3 and 4 meters per second (Wind Power Program, 2017). As the speed, the forces on the turbine structure continue to rise and at some point, and at some point the chance of damage to the rotor becomes high. As a result, a braking system 
is engaged to bring the rotor to a full stop. This is frequently called the cut-out speed and is habitually around 25 meters per second (Wind Power Program, 2017); see Figure 17.

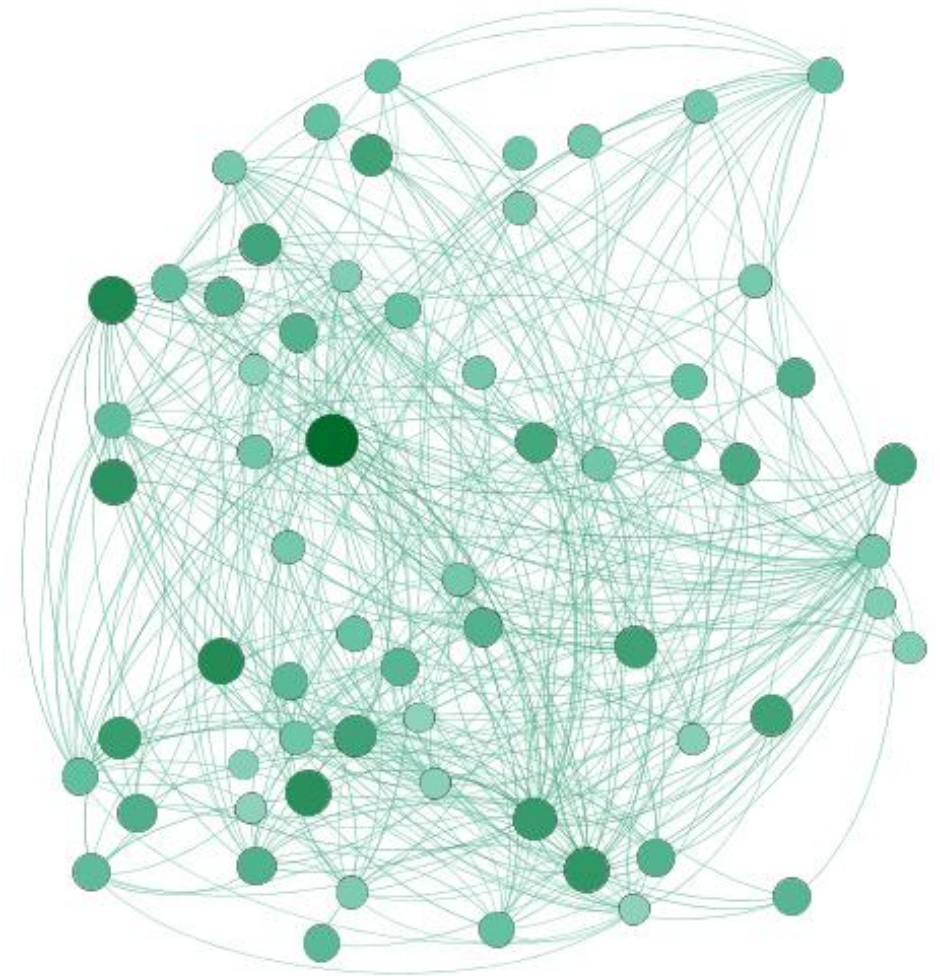

Figure 16: A reduced wind energy graph.

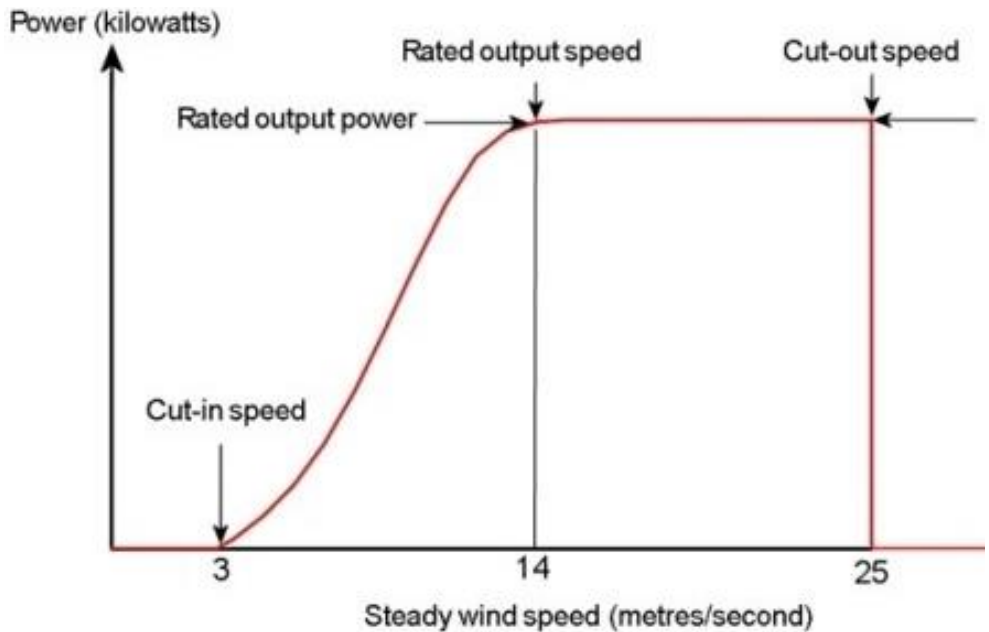

Figure 17: Typical wind turbine power output, adapted from (Wind Power Program, 2017). 
The reduced wind energy graph has 63 vertices and 371 edges, so the edge density is around 0.19 . Figure 18 shows the degree distribution diagram for this graph. The average degree is 5.889 in this case.

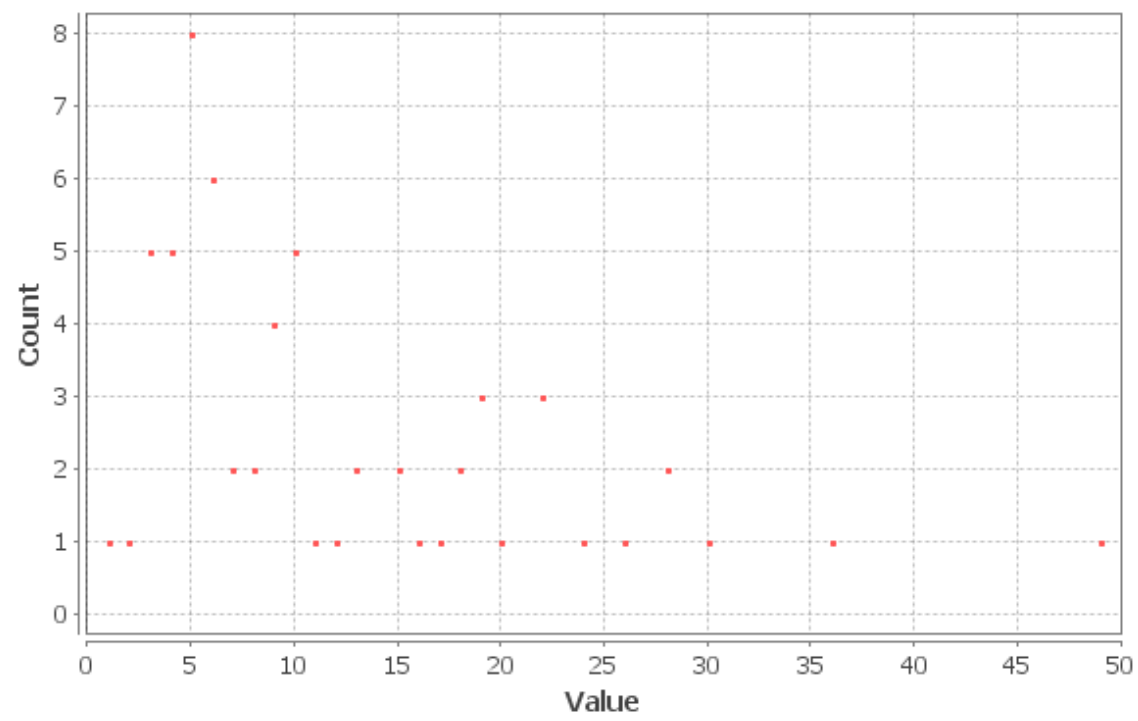

Figure 18: The degree distribution for the reduced wind energy graph.

It should be noted that since the measurements were taken at the $10 \mathrm{~m}$ height, but a typical wind turbine is operated at a height of $80 \mathrm{~m}$ or $100 \mathrm{~m}$, where the wind speeds are higher. According to the wind profile power law relationship (Touma, 1977), we have

$$
u=u_{r}\left(\frac{z}{z_{r}}\right)^{\alpha},
$$

where $u$ is the wind speed (in $\mathrm{m} / \mathrm{s}$ ) at height $z$ (in $\mathrm{m}$ ), and $u_{r}$ is the known wind speed at a reference height $z_{r}$. The friction coefficient $\alpha$ depends on the type of the location and ranges between 0.1 for lakes, ocean and smooth hard ground and 0.4 for city areas with high-rise buildings (Bañuelos-Ruedas, Rios-Marcuello, \& Camacho, 2011). Therefore, in our further investigation we take into account all 201 considered locations. 


\section{CHAPTER IV}

\section{MAXIMUM CLIQUE}

\subsection{Introduction}

We would like to find appropriate locations for wind farms, which would combine to provide a stable supply of energy. Maximizing the overall energy output produced per dollar invested can be modeled as the problem of finding a maximal clique, where the vertices of the graph represent different possible wind farm configurations for the prospective locations and sites of interest, and the edges correspond to pairs of locations with negatively correlated wind speeds. Then a maximum ratio maximal clique has the highest value of the ratio of the net wind speed to the net cost (Butenko, 2003).

The maximum clique will be studied in order to determine the possible energy sources for generating electricity. We will study 2 alternatives, the first one would be maximum clique and the second one will be the maximum weighted clique.

First, we recall some definitions and notations. We deal with a simple, undirected, finite graph $G=(V, E)$ with the set $V=\left\{v_{1}, \ldots, v_{n}\right\}$ of $n$ vertices and the set $E \subseteq\left\{\left\{v_{i}, v_{j}\right\}: i \neq\right.$ $\left.j, v_{i}, v_{j} \in V\right\}$ of $m$ edges. It is assumed that a positive real weight $w(v)$ is associated with each vertex $v$. If $\left\{v_{i}, v_{j}\right\} \in E$ we call the vertices $v_{i}$ and $v_{j}$ adjacent or neighbors. In addition, we call the edge $\left\{v_{i}, v_{j}\right\}$ incident to vertices $v_{i}$ and $v_{j}$. The set of all neighbors of the vertex $v \in V$ is denoted by $N_{G}(v)$ and its cardinality $d_{G}(v)=\left|N_{G}(v)\right|$ is called the degree of vertex $v$. The minimum and maximum degree of a vertex in $G$ is denoted by $\delta(G)$ and $\Delta(G)$, respectively. A graph $G^{\prime}=\left(V^{\prime}, E^{\prime}\right)$ is a subgraph of a graph $G=(V, E)$ if $V^{\prime} \subseteq V$ and $E^{\prime} \subseteq E$. Given a subset of vertex $S \subseteq V$ the corresponding induced 
subgraph is the graph obtained from $G$ by deleting all vertex in $V \backslash S$ together with their incident edges.

A graph property $\Pi$ said to be nontrivial, if every graph with one vertex satisfies $\Pi$ and not every graph satisfies $\Pi$, and interesting, if there are graphs with arbitrary large number of vertices satisfying $\Pi$. Most of the meaningful graph properties are nontrivial and interesting (Lykhovyd \& Butenko, 2017).

A clique is a subset of vertices inducing a complete sub graph. A maximal clique is a clique that is not a subset of a greater clique, and a maximum clique is a clique with the maximum possible number of vertices in the present graph (Ruzzo, 2001). Given a nonnegative weight wi associated with each vertex $i \in V$, the maximum weight clique problem is to find a clique that maximizes the sum of its vertex weights. Then, the case where $w_{i}=1 \forall i \in V$ corresponds to the classical maximum clique problem (Sethuraman \& Butenko, 2015).

The size of the maximum clique is known as a graph's clique number, and the problem of finding the clique number for a graph $G$ is an NP-hard problem (Skiena, 1997).

To find a maximum clique, one can systematically inspect all subsets of vertices in the graph, but this brute force search is too time consuming in order to be practical for networks of large size. Even though no polynomial time algorithm is known for this type of problem, more efficient algorithms than the brute force are known (Bomze, Budinich, Pardalos, \& Pelillo, 1999).

To find a maximum weight clique, we applied the algorithm called RDS, Russian Doll Search, in implementation developed by (Lykhovyd \& Butenko, 2017). This framework 
provides an attractive option for solving the class of problems characterized by heredity in the induced subgraphs. The $\mathrm{C}++$ implementation developed by (Lykhovyd \& Butenko, 2017) can be used to find maximum vertex weight structures for any hereditary property, as long as one can provide an efficient feasibility verification procedure for a subgraph obtained from a feasible subgraph by adding a new vertex (Lykhovyd \& Butenko, 2017). As the weight of each vertex in the wind energy graph, we will use the average wind speed for the corresponding site.

The code used was programed in the software Xcode, and Code::Blocks, utilizing C++.

\subsubsection{Alternative 1}

For the first alternative, we applied the code to solve the maximum clique problem in the wind energy graph. The maximum clique found consisted of 6 vertices. Table 1 and Figure 19 show the corresponding sites and their location in the Bolivian map, respectively. The average wind speed for this subgraph is $2.36 \mathrm{~m} / \mathrm{s}$.

Table 1: Maximum clique vertices.

\begin{tabular}{|c|c|c|c|c|}
\hline$\#$ & Vertex & Location & Latitude & Longitude \\
\hline 1 & 111 & TAQUIRI & -16.28416667 & -68.67194444 \\
\hline 2 & 123 & SAUNAS DE G. MENDOZA & -19.64916667 & -67.6825 \\
\hline 3 & 129 & COLQUECHACA & -18.68333333 & -66.16666667 \\
\hline 4 & 183 & SANTA ANA & -18.35 & -64.15 \\
\hline 5 & 191 & EL PUENTE & -21.23333333 & -65.2 \\
\hline 6 & 198 & TARIQUIA & -22 & -64.46666667 \\
\hline
\end{tabular}




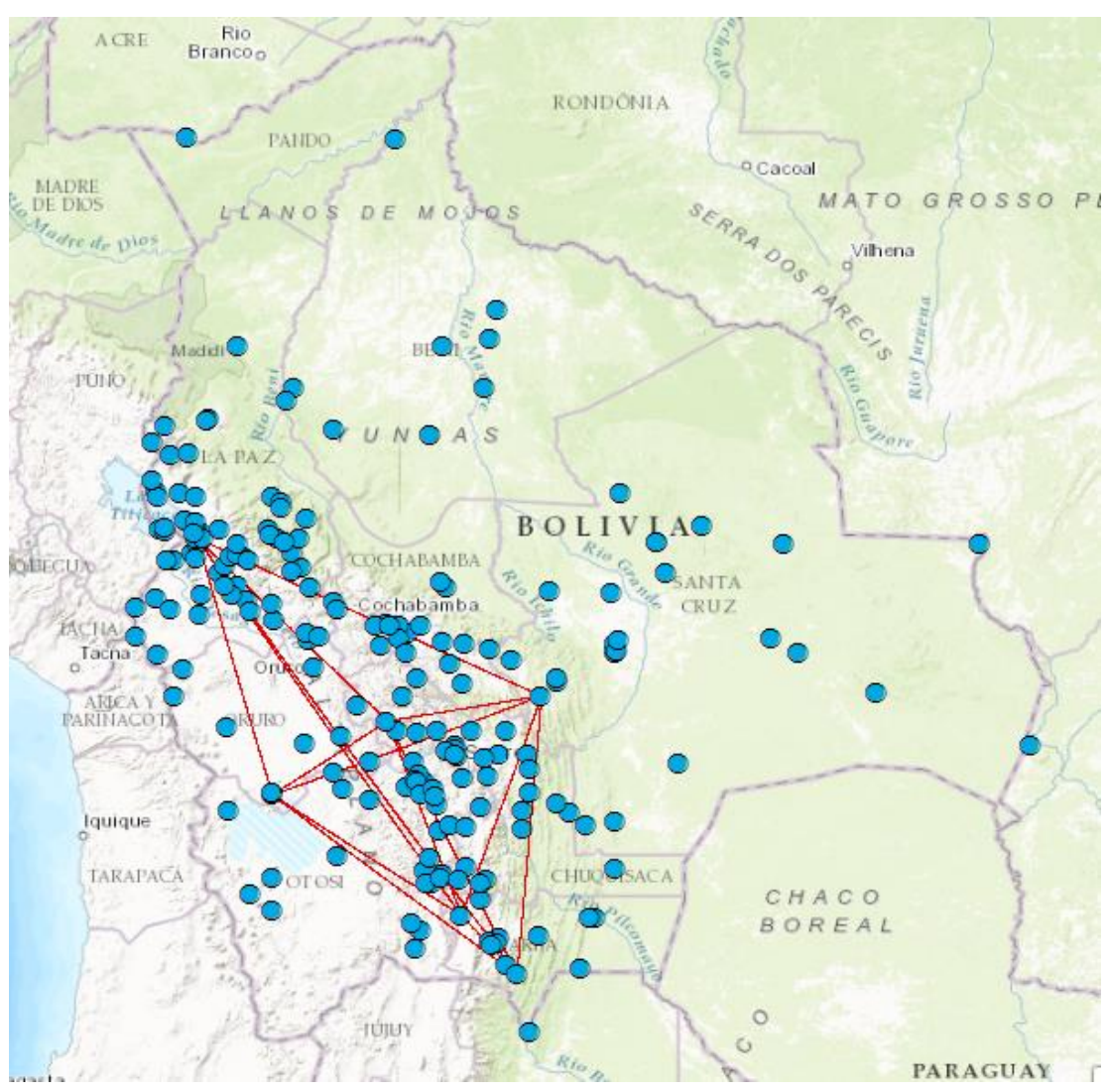

Figure 19: The subgraph induced by the maximum clique in the wind energy graph.

\subsubsection{Alternative 2}

For the second alternative, we considered the maximum weight clique problem. In this case, we obtain a slightly smaller clique (5 vertices), however, the corresponding average wind speed is much higher than for the unweighted maximum clique $-4.53 \mathrm{~m} / \mathrm{s}$.

Table 2 and Figure 20 show the results obtained.

Table 2: The vertices of the maximum weight clique.

\begin{tabular}{|c|c|c|c|c|}
\hline$\#$ & Vertex & Location & Latitude & Longitude \\
\hline 1 & 31 & CHILCARA & -21.0167 & -64.9333 \\
\hline 2 & 40 & REDENCION & -18.8167 & -64.6 \\
\hline 3 & 82 & HUACULLANI & -16.4667 & -68.7333 \\
\hline 4 & 175 & ROBORE & -18.3167 & -59.75 \\
\hline 5 & 183 & SANTA ANA & -18.35 & -64.15 \\
\hline
\end{tabular}




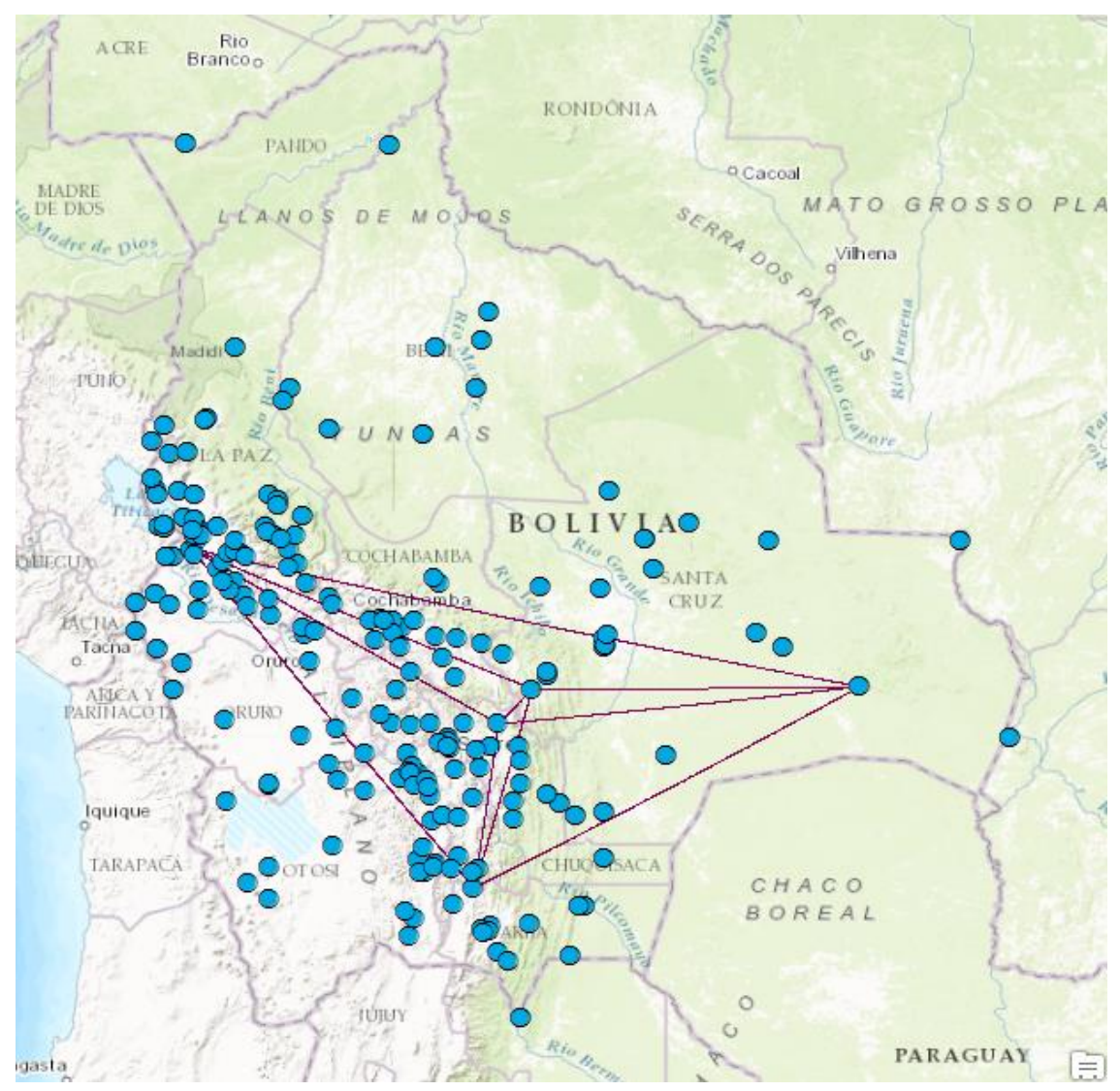

Figure 20: The subgraph induced by the maximum weight clique of the wind energy graph.

\subsection{Summary of Results}

We can see that the proposed method ensures a diversified selection of places for installing new wind farms, spanning the whole Bolivian territory. Regarding the two alternatives studied, we can notice that the second alternative is better, since it gives a better wind speed average for the selected locations. Table 3 compares the average wind speeds for the whole graph, the maximum clique, and the maximum weight clique.

Table 3: Comparison of average wind speeds.

\begin{tabular}{|l|l|}
\hline Graph/solution & Average Wind Speed \\
\hline Wind energy graph & $2.70 \mathrm{~m} / \mathrm{s}$ \\
\hline Maximum clique & $2.36 \mathrm{~m} / \mathrm{s}$ \\
\hline Maximum weight clique & $4.53 \mathrm{~m} / \mathrm{s}$ \\
\hline
\end{tabular}


Figure 21 provides a comparison among the average wind speed from both method utilized for a 12-month period. In the figure, the $\mathrm{x}$ axis corresponds to the months and the $\mathrm{y}$ axis corresponds to wind speeds at $10 \mathrm{~m}$ height, additionally the blue line represents the average monthly wind speeds for the maximum weight clique, the red line represents the same for the maximum clique, and the green line represents the average monthly wind speed data for the whole wind energy graph studied. We can see that the maximum weight clique approach yields superior results.

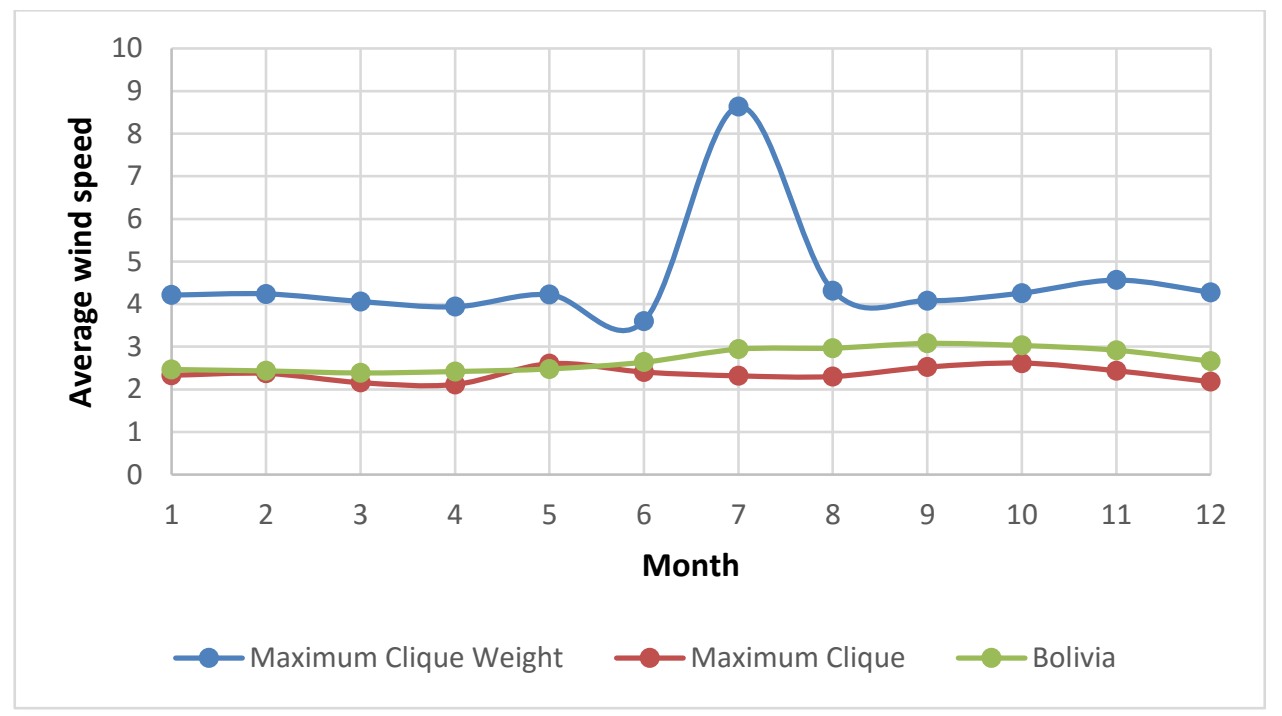

Figure 21: Comparison of the monthly average wind speeds for the maximum weight clique, maximum clique, and the whole wind energy graph. 


\section{CHAPTER V}

$$
\text { K - PLEX }
$$

\subsection{Introduction}

Next, we consider the maximum $k$-plex problem in order to determine more locations for installing different wind farms. In particular, we study the maximum weight 2-plex and 3plex problems on the wind energy graph. The $k$-plex based approach provides more flexibility compared to the clique-based approach, which is rather restrictive, since it requires negative correlation for every pair of locations. Namely, the $k$-plex model allows some wind sites to be members of the selected group even if they have some non-neighbors in the group, but the number of allowed non-neighbors cannot exceed $k$ (Hanneman \& Riddle, 2005) (Borgatti, 2000).

Formally, a $k$-plex is a subset of vertices such that each vertex in the subset is adjacent to all but at most $k$ others vertices in the subset (Seidman \& Foster, 1978).

To solve the maximum $k$-plex problems, we again use the RDS algorithm used for finding the maximum clique. We studied the unweighted and weighted versions of maximum 2plex and 3-plex in the wind graph.

\subsection{2-Plex}

When $k=2$, every vertex in the subset $\mathrm{S}$ of vertices defining a 2-plex will have at most one non-neighbor.

\subsubsection{Alternative 1}

For the first alternative, we solve the unweighted version of the maximum 2-plex problem for the wind energy graph. It turned out that there are 9 vertex or possible sites with 36 edges in the corresponding induced subgraph. 
Table 4 shows the locations corresponding to the 9 vertices in the maximum 2-plex and their characteristics, which include the average wind speed and the number of neighbors in the maximum 2-plex. Figure 22 shows these locations on the Bolivian map.

Table 4: Maximum 2-plex vertices.

\begin{tabular}{|c|c|c|c|c|c|c|}
\hline$\#$ & Vertex & Location & Latitude & Longitude & $\begin{array}{c}\text { Average Wind } \\
\text { Speed }\end{array}$ & $\begin{array}{c}\text { Number of } \\
\text { Neighbors }\end{array}$ \\
\hline 1 & 26 & VINTO & -17.4167 & -66.3167 & 0.720833333 & 7 \\
\hline 2 & 34 & EL VILLAR & -19.6167 & -64.3 & 0.334166667 & 8 \\
\hline 3 & 40 & REDENCION & -18.8167 & -64.6 & 4.8975 & 7 \\
\hline 4 & 51 & ZUDANEZ & -19.1167 & -64.7 & 2.77 & 7 \\
\hline 5 & 54 & ALCOCHE & -15.7333 & -67.6667 & 3.388333333 & 7 \\
\hline 6 & 85 & HUATAIATA & -16.2167 & -68.7 & 1.188333333 & 7 \\
\hline 7 & 152 & TARAPAYA & -19.45 & -65.8 & 2.565833333 & 7 \\
\hline 8 & 183 & SANTA ANA & -18.35 & -64.15 & 3.773333333 & 7 \\
\hline 9 & 191 & EL PUENTE & -21.2333 & -65.2 & 0.401666667 & 7 \\
\hline
\end{tabular}

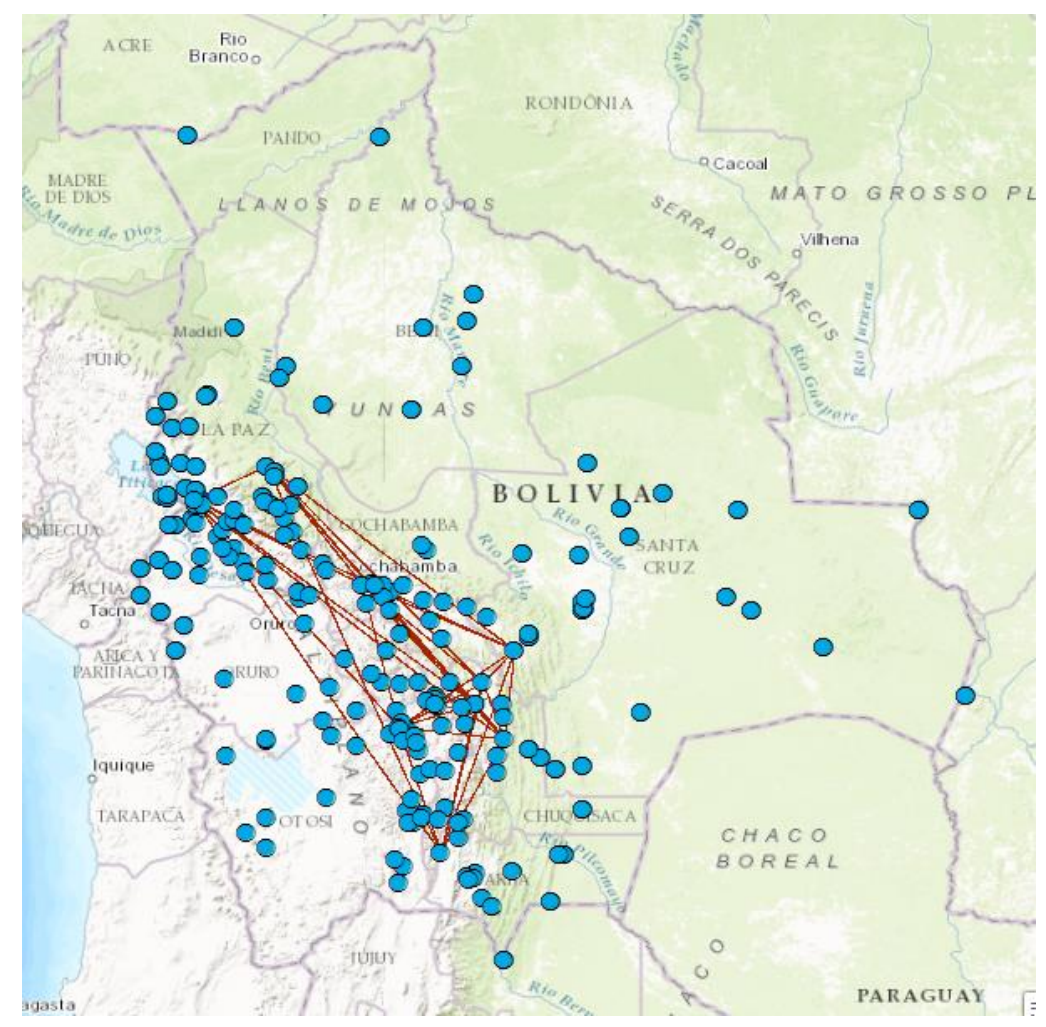

Figure 22: Maximum 2-plex wind graph. 
The average wind speed for this subgraph is $2.22 \mathrm{~m} / \mathrm{s}$. We can also notice that some the wind speeds obtained in the clique, are not as high as we expected it to be.

\subsubsection{Alternative 2}

For the second alternative, we used the RDS algorithm to solve the maximum weight 2plex problem for the wind energy graph. As before, the weights used were the average wind speeds for each location. The optimal solution has 6 vertices and the corresponding induced subgraph has 12 edges. Table 5 shows the solution.

Table 5: Maximum weight 2-plex vertices.

\begin{tabular}{|c|c|c|c|c|c|c|}
\hline$\#$ & Vertex & Location & Latitude & Longitude & $\begin{array}{c}\text { Average Wind } \\
\text { Speed }\end{array}$ & $\begin{array}{c}\text { Number of } \\
\text { Neighbors }\end{array}$ \\
\hline 1 & 51 & ZUDANEZ & -19.1167 & -64.7 & 2.77 & 4 \\
\hline 2 & 105 & ULLA ULLA & -15.0167 & -69.25 & 4.4575 & 4 \\
\hline 3 & 109 & VILLA PUNI & -15.6667 & -69.2 & 5.985 & 4 \\
\hline 4 & 110 & CALAMARCA & -16.9 & -68.1167 & 8.1325 & 4 \\
\hline 5 & 176 & SAMAIPATA & -18.1667 & -63.95 & 6.360833333 & 4 \\
\hline 6 & 183 & SANTA ANA & -18.35 & -64.15 & 3.773333333 & 4 \\
\hline
\end{tabular}


Figure 23 shows the maximum weight 2-plex vertices on the Bolivian map.

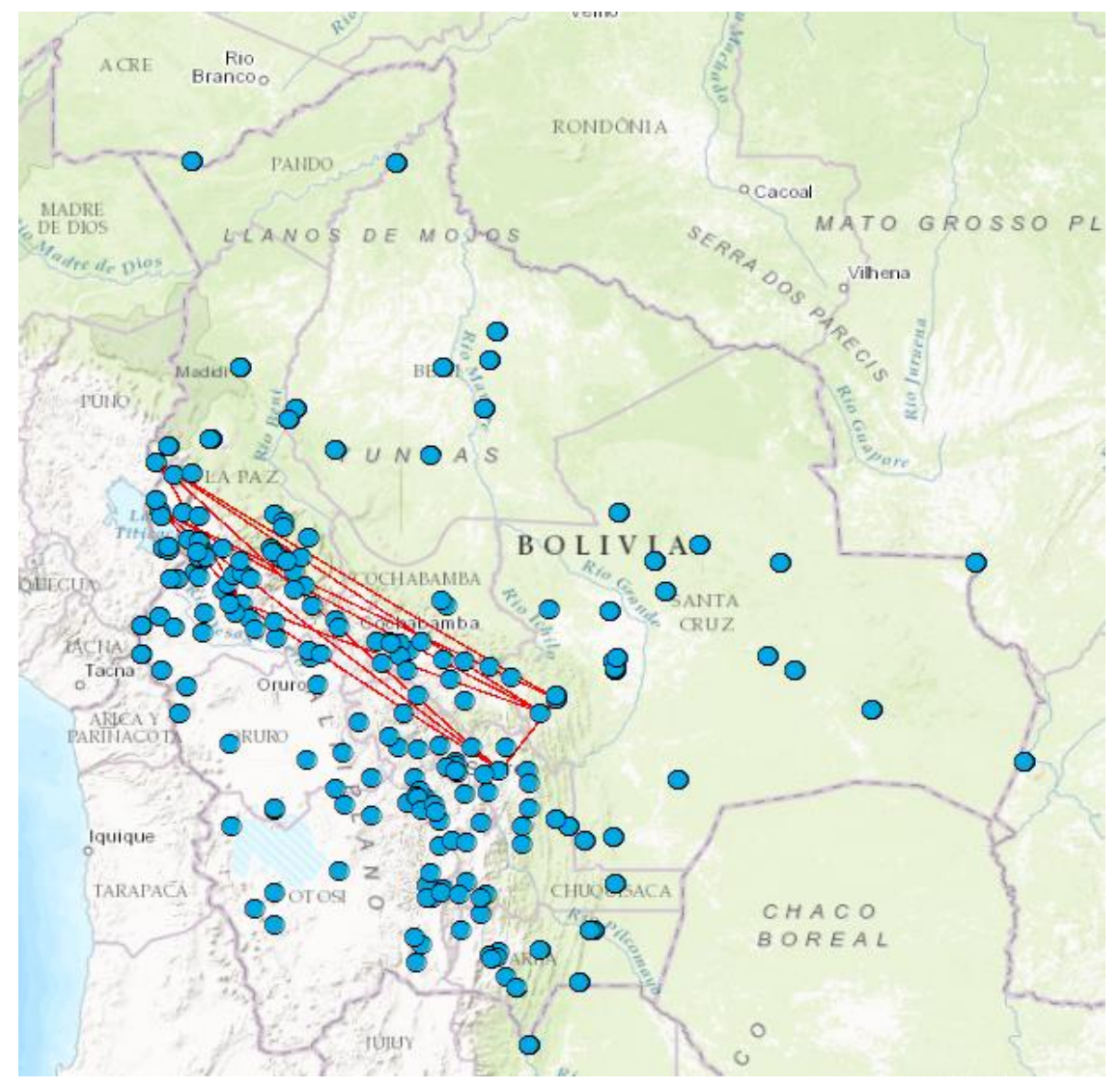

Figure 23: The subgraph of the wind graph induced by the maximum weight 2-plex.

\subsection{3-Plex}

Next, we will study the unweighted and weighted maximum 3-plex problem. For $k=3$, every vertex in the subset $\mathrm{S}$ will have at most two non-neighbors within the subset.

\subsubsection{Alternative 1}

The results for the maximum 3-plex problem are presented in Table 6 and Figure 24. 
Table 6: Maximum 3-plex vertex.

\begin{tabular}{|c|c|c|c|c|c|c|}
\hline$\#$ & Vertex & Location & Latitude & Longitude & $\begin{array}{c}\text { Average } \\
\text { Wind Speed }\end{array}$ & $\begin{array}{c}\text { Number of } \\
\text { Neighbors }\end{array}$ \\
\hline 1 & 26 & VINTO & -17.4167 & -66.3167 & 0.720833333 & 9 \\
\hline 2 & 34 & EL VILLAR & -19.6167 & -64.3 & 0.334166667 & 9 \\
\hline 3 & 51 & ZUDANEZ & -19.1167 & -64.7 & 2.77 & 10 \\
\hline 4 & 96 & PELECHUCO & -14.8167 & -69.0833 & 1.616666667 & 9 \\
\hline 5 & 110 & CALAMARCA & -16.9 & -68.1167 & 8.1325 & 9 \\
\hline 6 & 124 & CHACHACOMANI & -18.3592 & -68.9489 & 4.208333333 & 9 \\
\hline 7 & 144 & PALCA DE & -20.7 & -65.4333 & 3.5675 & 9 \\
\hline 8 & 152 & TARAPAYA & -19.45 & -65.8 & 2.565833333 & 9 \\
\hline 9 & 183 & SANTA ANA & -18.35 & -64.15 & 3.773333333 & 10 \\
\hline 10 & 191 & EL PUENTE & -21.2333 & -65.2 & 0.401666667 & 9 \\
\hline 11 & 196 & TARIJA AASANA & -21.5333 & -64.7 & 2.593333333 & 9 \\
\hline 12 & 198 & TARIQUIA & -22 & -64.4667 & 1.344166667 & 9 \\
\hline
\end{tabular}

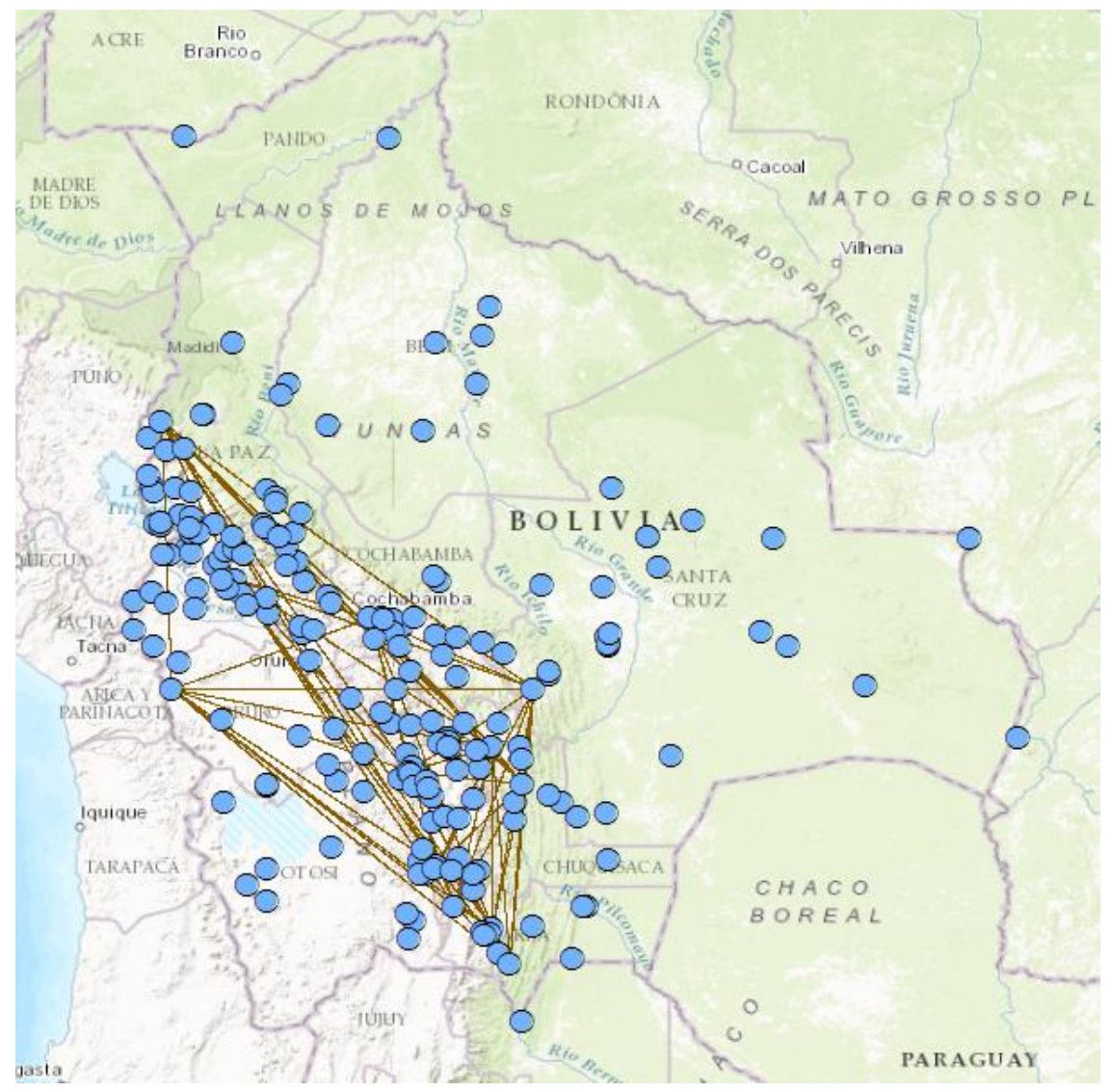

Figure 24: Maximum 3-plex wind graph. 
The average wind speed for this subgraph is $2.67 \mathrm{~m} / \mathrm{s}$. We can also notice that some of the wind speeds obtained in the clique, are not as high as we expected it to be.

\subsubsection{Alternative 2}

The optimal solution for the maximum weight 3-plex problem is shown in Table 7 and Figure 25 .

Table 7: Maximum 3-plex weighted vertex.

\begin{tabular}{|c|c|c|c|c|c|c|}
\hline$\#$ & Vertex & Location & Latitude & Longitude & $\begin{array}{c}\text { Average } \\
\text { Wind } \\
\text { Speed }\end{array}$ & $\begin{array}{c}\text { Number of } \\
\text { Neighbors }\end{array}$ \\
\hline 1 & 51 & ZUDANEZ & -19.1167 & -64.7 & 2.77 & 7 \\
\hline 2 & 105 & ULLA ULLA & -15.0167 & -69.25 & 4.457 & 6 \\
\hline 3 & 109 & VILLA PUNI & -15.6667 & -69.2 & 5.985 & 6 \\
\hline 4 & 110 & CALAMARCA & -16.9 & -68.1167 & 8.1325 & 6 \\
\hline 5 & 120 & $\begin{array}{c}\text { SALINAS DE G. } \\
\text { MENDOZ }\end{array}$ & -19.6333 & -67.6667 & 1.978 & 7 \\
\hline 6 & 144 & $\begin{array}{c}\text { PALCA DE } \\
\text { HIGUERAS }\end{array}$ & -20.7 & -65.4333 & 3.5675 & 6 \\
\hline 7 & 170 & EL VALLECITO & -17.7667 & -63.15 & 5.246 & 6 \\
\hline 8 & 183 & SANTA ANA & -18.35 & -64.15 & 3.773 & 6 \\
\hline 9 & 186 & $\begin{array}{c}\text { SANTA CRUZ } \\
\text { VIRU VIRU }\end{array}$ & -17.6667 & -63.1833 & 5.534 & 6 \\
\hline
\end{tabular}




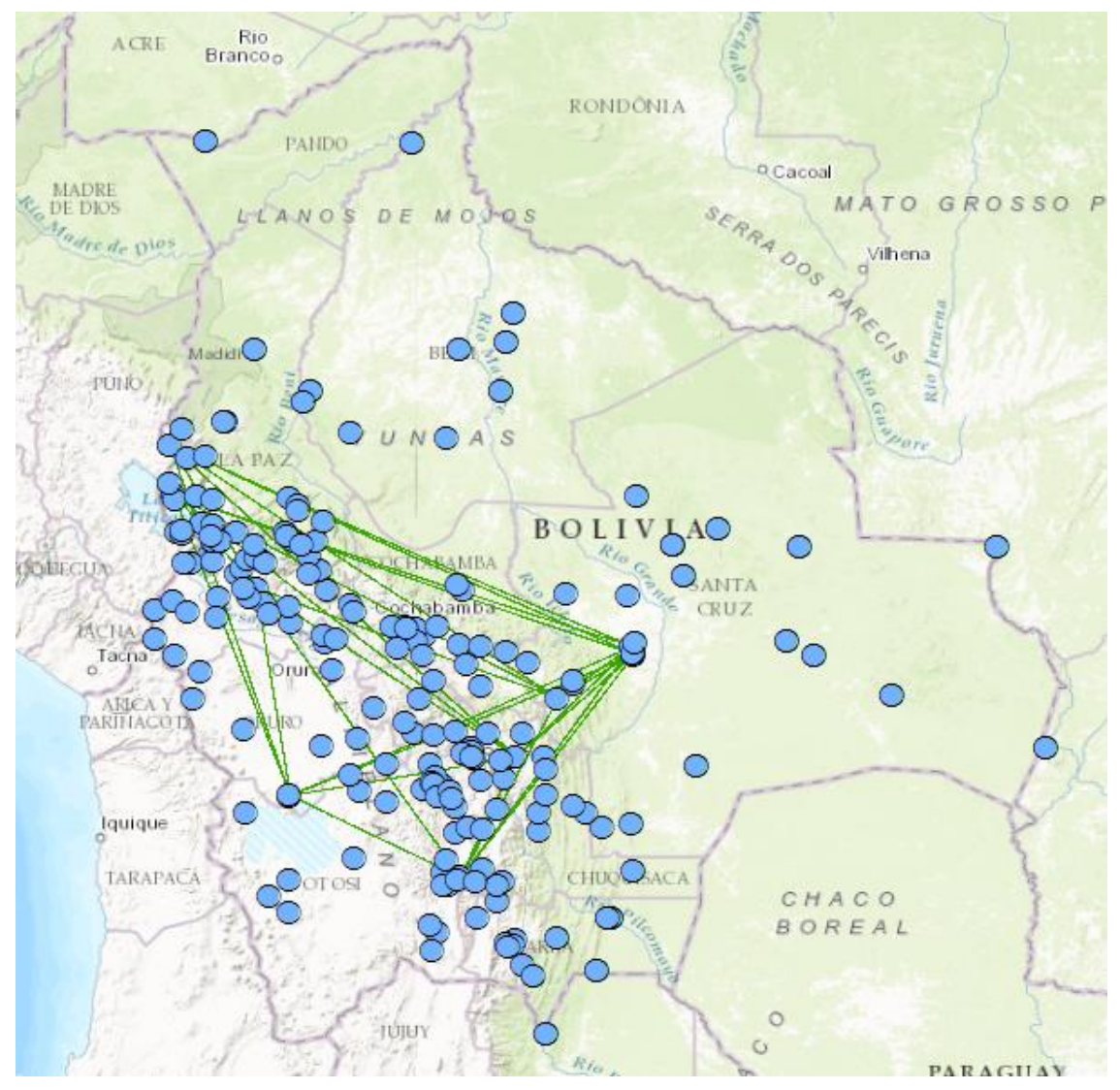

Figure 25: Maximum 3-plex weighted wind graph.

\subsection{Summary of the Results}

From Figure 22, Figure 23, Figure 24 and Figure 25, we could see that the selected sites are located from west to east on the Bolivian territory. These locations are spread out, ensuring a high diversification of the wind speed.

In addition, the selected sites from the maximum weight 2-plex and 3-plex problems have high overall energy productions, as can be seen by comparing the average wind speed of the picked sites and the average wind speed of the all the sites. Obviously, we assume that higher wind speed implies the higher wind energy output.

Table 8 summarizes the average wind speeds for all the obtained solutions. 
Table 8: Average wind speeds for obtained solutions.

\begin{tabular}{|l|l|}
\hline Graph/Solution & Average Wind Speed \\
\hline Wind energy graph & $2.70 \mathrm{~m} / \mathrm{s}$ \\
\hline 2-plex & $2.22 \mathrm{~m} / \mathrm{s}$ \\
\hline 2-plex weighted & $5.25 \mathrm{~m} / \mathrm{s}$ \\
\hline 3-plex & $2.67 \mathrm{~m} / \mathrm{s}$ \\
\hline 3-plex weighted & $4.60 \mathrm{~m} / \mathrm{s}$ \\
\hline
\end{tabular}

Figure 26 and Figure 27 show the comparison of the average monthly wind speeds for the 2-plex and 3-plex solutions found, similarly to how it was done for the clique solutions in the previous chapter.

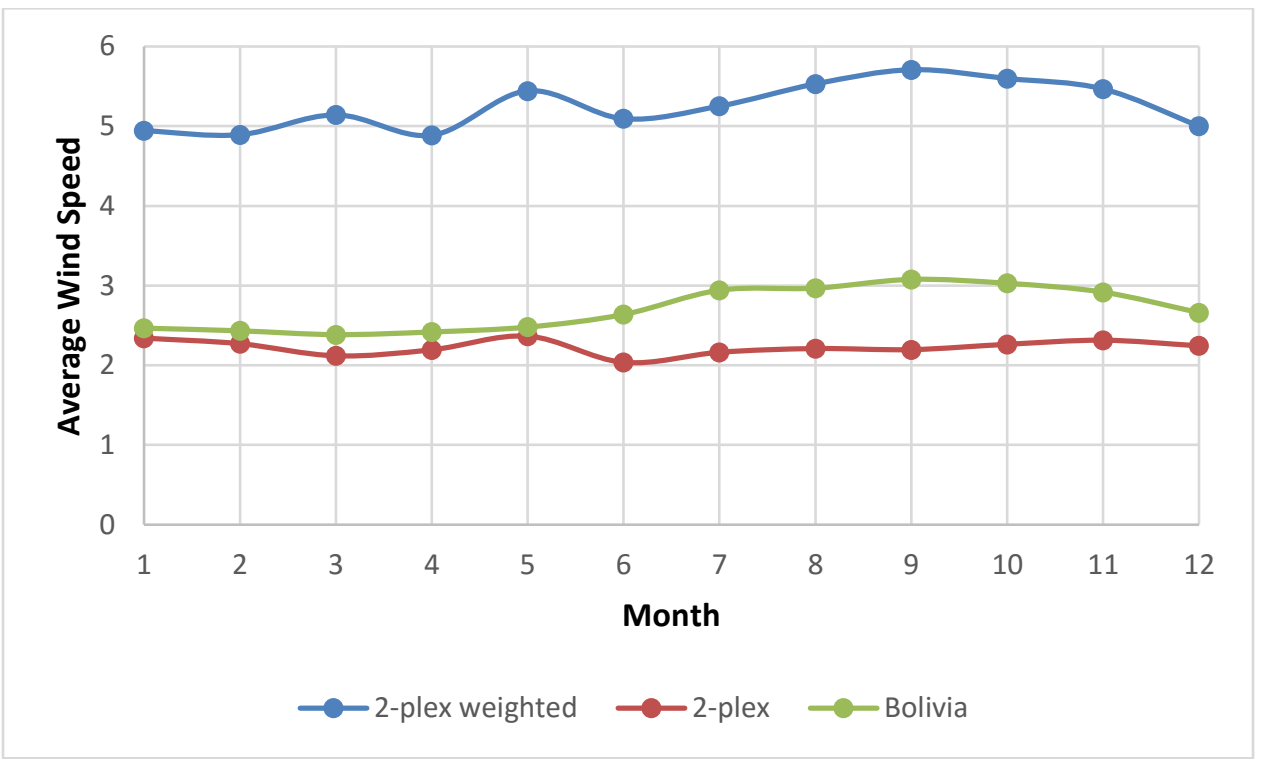

Figure 26: Average monthly wind speeds comparison for the 2-plex solutions. 


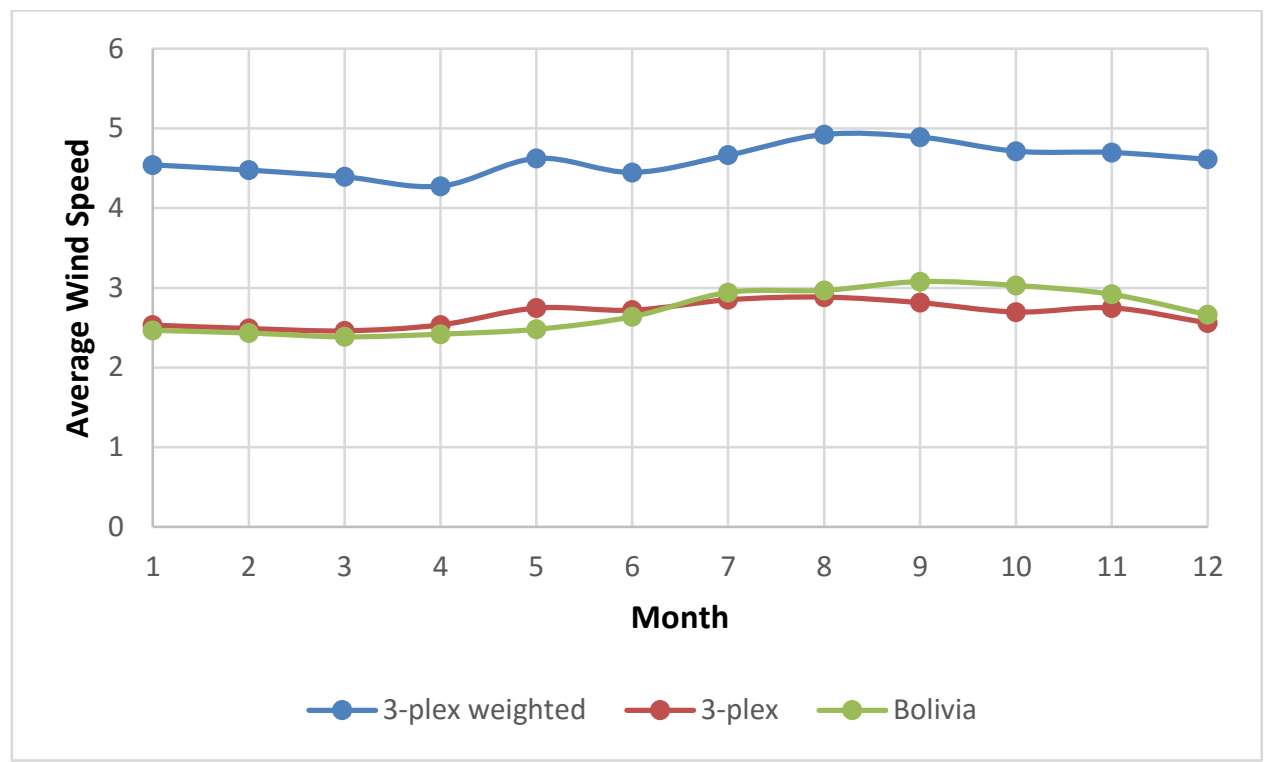

Figure 27: Average monthly wind speeds comparison for the 3-plex solutions.

As we can to see, the maximum 2-plex and maximum 3-plex resemble the overall wind graph in terms of average monthly speeds. On the other hand, the results obtained for the maximum weight 2-plex and 3-plex solutions are by far superior. Therefore, solving the maximum weight 2-plex and 3-plex problems provide a good method that can be utilized to select the potential wind farm locations. These solutions achieve a good balance between wind speed diversification and overall energy production.

In addition, as we could see, compared to the maximum 2-plex problem, the maximum 3plex problem has one more degree of relaxation, so the 3-plex solutions typically have more nodes than 2-plex solutions for the same graph. We can see that both structures give a good method for balancing the high diversification with overall energy output. In case we want to obtain more locations for possible wind farms, the 3-plex approach will be preferred. 


\section{CHAPTER VI}

\section{DOMINATING SET}

\subsection{Introduction}

In this chapter, we use the minimum dominating set problem to find a small subset of locations that would be representative of the behavior of the whole system in terms of the wind behavior. This problem is one of the classical problems in graph theory.

Given a graph $G=(V, E)$, a dominating set is a subset of vertices $D$ such that every vertex $v$ not in $D$ is adjacent to at least one member of $D$. The minimum dominating set (MDS) problem asks for a dominating set of minimum size in G. MDS and the closely related minimum set cover problem are two of the first problems that have been shown to be NP-hard (Karp, 1972). The domination number; $\gamma(G)$ is the number of vertices in a minimum dominating set for a graph $G$ (Garey \& Johnson, 1979).

To find a minimum dominating set, we used a standard integer programming formulation for the MDS problem (Kuhn \& Wattenhofer, 2003). Let $S \subseteq V$ denote a subset of vertices of $G$. For each $i \in V$, we define a binary decision variable $x_{i}$ such that $x_{i}=1 \Leftrightarrow v_{i} \in$ $S$. For $S$ to be a dominating set, we require that for each node $v_{i} \in V$, either $v_{i} \in S$ or at least one of its neighbors is in $S$. Let $N$ denote the adjacency matrix with ones added to its diagonal, that is,

$$
N=A+I_{n}
$$

where $A$ is the adjacency matrix of the graph and $I_{n}$ is the $n \times n$ identity matrix and $n$ is the number of vertices in the graph. Then the MDS problem could be formulated as the following integer program: 


$$
\begin{gathered}
\min \sum_{i=1}^{n} x_{i} \\
\text { Subject to: } N x \geq 1 \\
x \in\{0,1\}^{n}
\end{gathered}
$$

We solved this integer program using CPLEX solver for the wind graph built based on positive correlations of wind speed fluctuations. The entire code can be found in the Appendix I.

\subsection{Wind Graph for Positive Correlations of Wind Speed Fluctuations}

Since dominating sets are meant to be representative of the whole system in this study, the way we define the wind graph is now different compared to that we used in the previous two chapters. Here the edges will correspond to pairs of vertices with correlations of wind speed fluctuations above a given positive threshold. Based on the plot for correlations distribution in Figure 12, we tried several different threshold and analyzed the results in terms of how well the corresponding average wind speeds represented the average over all the considered locations. Below we report the outcomes for two threshold values that yielded the most meaningful results, $\theta_{1}=0.33$ (Alternative 1) and $\theta_{2}=0.5$ (Alternative 2). 


\subsection{Alternative 1}

For the first alternative, with $\theta_{1}=0.33$, the corresponding wind graph has 201 vertices and 10025 edges. We obtained a minimum dominating set consisting of 6 vertices.

Table 9 shows the optimal solution found, including the vertex number, the coordinates of its location in the Bolivian map, average wind speed for the corresponding location over the considered period, and the number of neighbors the vertex has.

Table 9: MDS optimal solution for $\theta_{1}=0.33$.

\begin{tabular}{|r|l|r|r|r|r|}
\hline & \multicolumn{1}{|c|}{ Location } & \multicolumn{1}{c|}{ Lat. } & \multicolumn{1}{c|}{ Lon. } & \multicolumn{1}{c|}{$\begin{array}{c}\text { Average } \\
\text { Wind } \\
\text { Speed }\end{array}$} & $\begin{array}{c}\text { Number } \\
\text { of } \\
\text { Neighbors }\end{array}$ \\
\hline 12 & CAPINOTA & -17.7 & -66.25 & 0.688333 & 75 \\
\hline 27 & J.MOLINO-PILANCHO & -17.65 & -65.45 & 4.625 & 151 \\
\hline 93 & MINACHI (COROICOJ & -16.1667 & -67.7167 & 1.2625 & 17 \\
\hline 105 & ULLA ULLA & -15.0167 & -69.25 & 4.4575 & 84 \\
\hline 108 & VIVERO SAPECHO & -16.2833 & -67.3167 & 1.569167 & 18 \\
\hline 158 & UNCIA & -18.4667 & -66.5667 & 2.294167 & 72 \\
\hline
\end{tabular}

Figure 28 shows the optimal solution on the Bolivian map, with the green triangles representing the 6 locations obtained. It should be noted that the locations are not connected to each other with an edge, that is, they form an independent dominating set. 


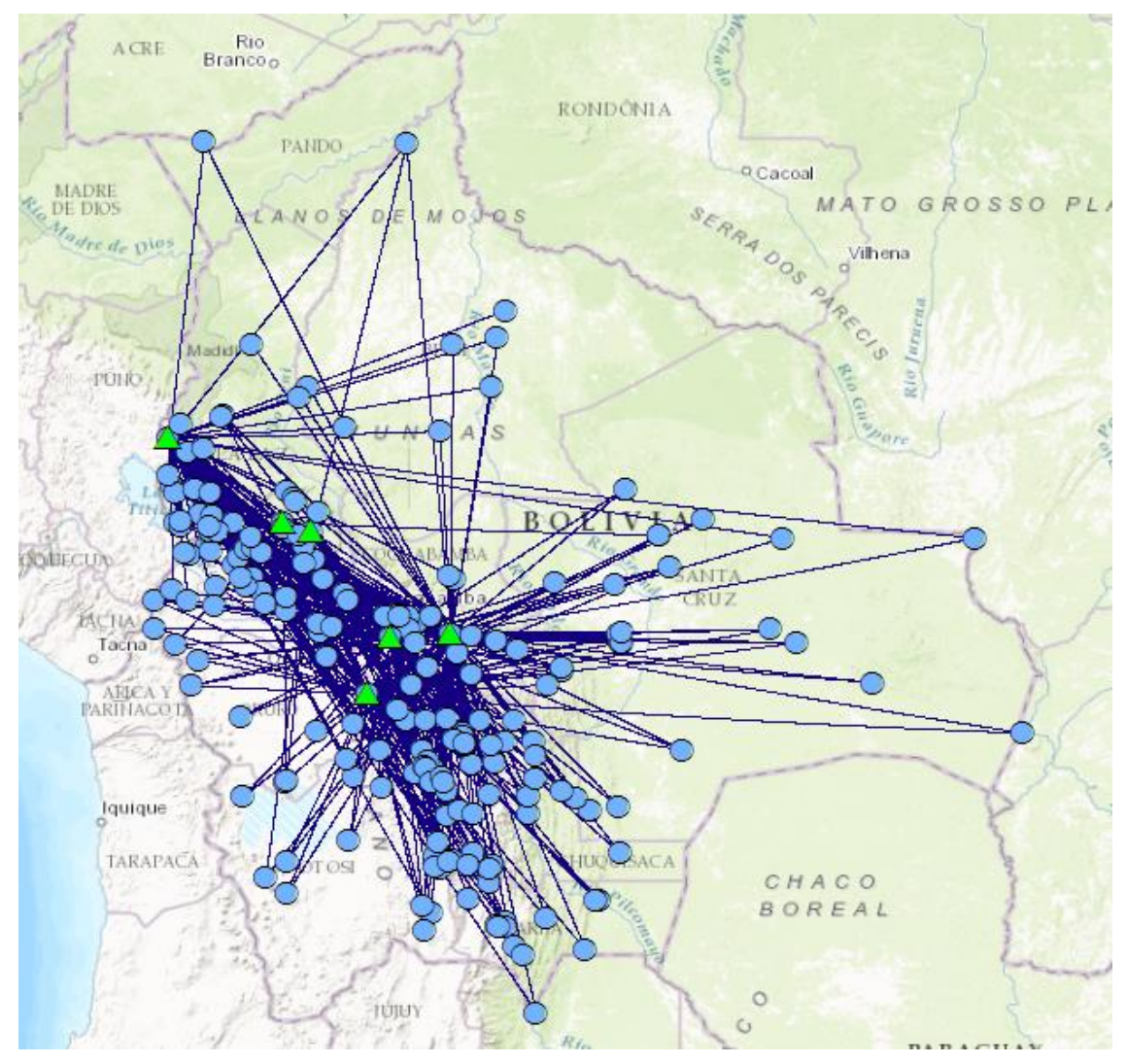

Figure 28: MDS optimal solution for $\theta_{1}=0.33$ on the Bolivian map.

Figure 29 compares average monthly speeds for the MDS and all the vertices in the graph. As we can notice from the graph, the 6 locations in MDS are representative of the overall behavior of wind speeds for the 201 considered locations across Bolivia. We can tell that these locations are diversely distributed on the map, while their collective behavior of the wind speeds is very similar that for the entire Bolivian monthly average. The overall average wind speed for the MDS is $2.48 \mathrm{~m} / \mathrm{s}$, on the other hand the average for the whole graph is $2.7 \mathrm{~m} / \mathrm{s}$. 


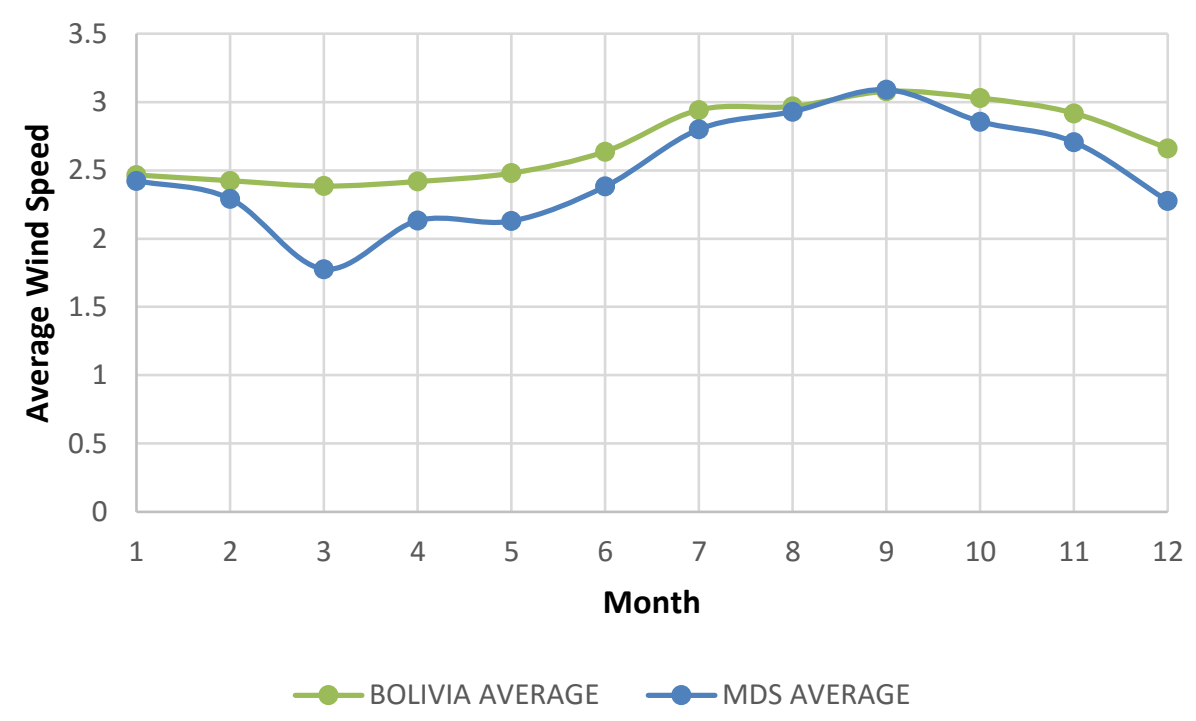

Figure 29: Comparison of monthly average wind speeds for the MDS and the whole system.

\subsection{Alternative 2}

For the second alternative, with $\theta_{2}=0.5$, the corresponding wind graph has 201 vertices and 6815 edges. We obtained a minimum dominating set consisting of 13 vertices.

Table 10 shows the optimal solution found, including the vertex number, the coordinates of its location in the Bolivian map, average wind speed for the corresponding location over the considered period, and the number of neighbors the vertex has. 
Table 10: MDS optimal solution for $\boldsymbol{\theta}_{2}=\mathbf{0 . 5}$.

\begin{tabular}{|r|l|r|r|r|r|}
\hline Vertex & \multicolumn{1}{|c|}{ Name } & \multicolumn{1}{c|}{ Lat } & \multicolumn{1}{c|}{ Long } & \multicolumn{1}{c|}{$\begin{array}{c}\text { Average Wind } \\
\text { Speed }\end{array}$} & $\begin{array}{c}\text { Number of } \\
\text { Neighbors }\end{array}$ \\
\hline 2 & RIBERALTA & -11.05 & -66.05 & 1.825 & 73 \\
\hline 11 & ANZALDO & -17.7833 & -65.9167 & 0.818333 & 3 \\
\hline 24 & TOTORA & -17.6833 & -65.15 & 1.066667 & 60 \\
\hline 26 & VINTO & -17.4167 & -66.3167 & 0.720833 & 2 \\
\hline 51 & ZUDANEZ & -19.1167 & -64.7 & 2.77 & 0 \\
\hline 62 & CARANAVI & -15.8167 & -67.5667 & 2.893333 & 64 \\
\hline 68 & COPAN CARA & -16.2167 & -68.65 & 3.616667 & 74 \\
\hline 108 & VIVERO SAPECHO & -16.2833 & -67.3167 & 1.569167 & 2 \\
\hline 110 & CALAMARCA & -16.9 & -68.1167 & 8.1325 & 55 \\
\hline 158 & UNCIA & -18.4667 & -66.5667 & 2.294167 & 39 \\
\hline 163 & YURA & -19.7167 & -66.3833 & 1.185833 & 53 \\
\hline 190 & BERMEJO & -22.7667 & -64.3 & 2.739167 & 81 \\
\hline 194 & SAN ANDRES & -21.6167 & -64.8 & 0.748333 & 5 \\
\hline
\end{tabular}

Figure 30 shows the optimal solution on the Bolivian map, with the green triangles representing the 6 locations obtained. It should be noted that the locations are not connected to each other with an edge, that is, they form an independent dominating set. 


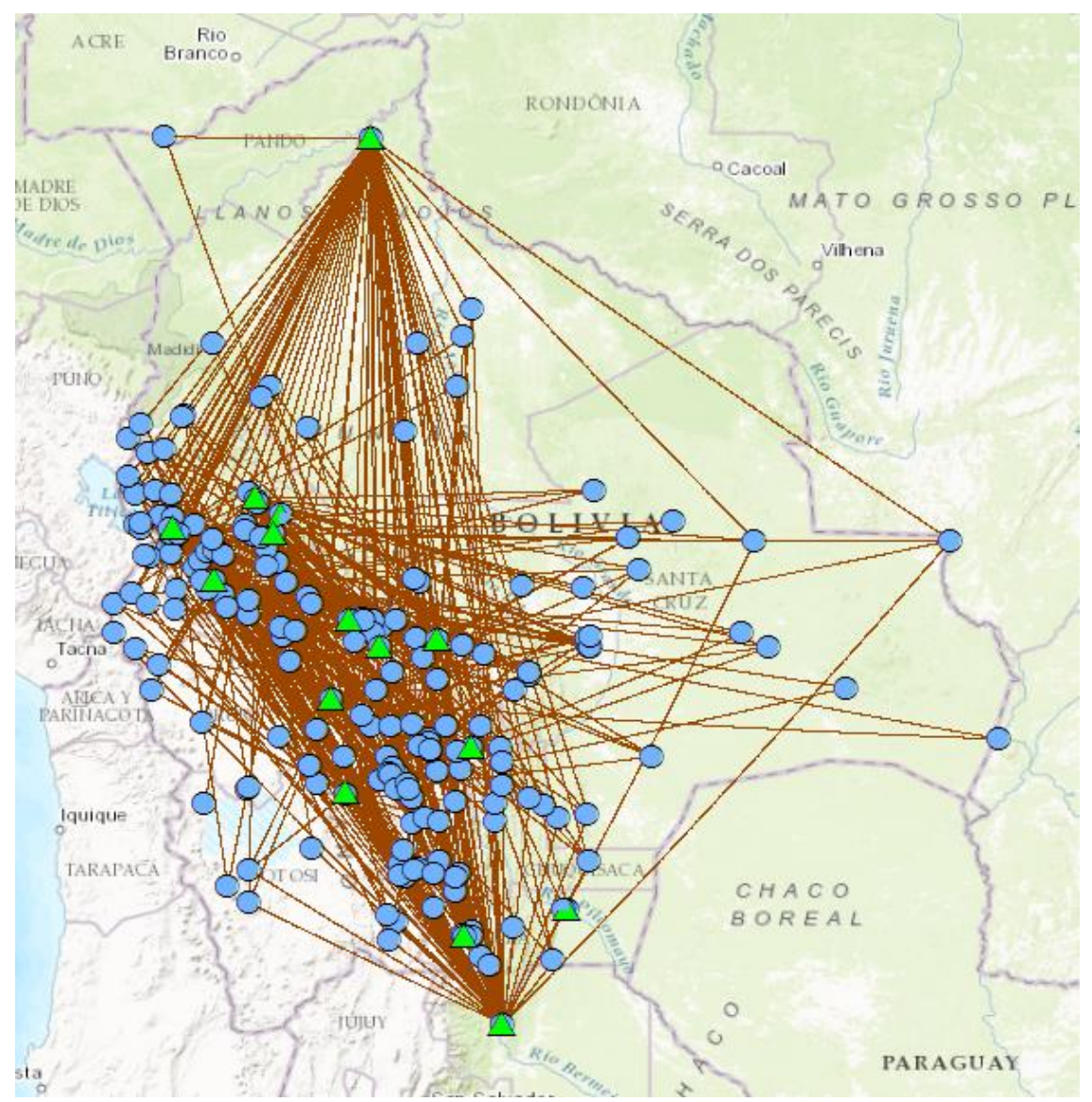

Figure 30: MDS optimal solution for $\boldsymbol{\theta}_{2}=0.5$ on the Bolivian map.

Figure 31 compares average monthly speeds for the MDS and all the vertices in the graph. As we can notice from the graph, the 6 locations in MDS are representative of the overall behavior of wind speeds for the 201 considered locations across Bolivia. We can tell that these locations are diversely distributed on the map, while their collective behavior of the wind speeds is very similar that for the entire Bolivian monthly average. The overall average wind speed for the MDS is $2.34 \mathrm{~m} / \mathrm{s}$, on the other hand the average for the whole graph is $2.7 \mathrm{~m} / \mathrm{s}$. 


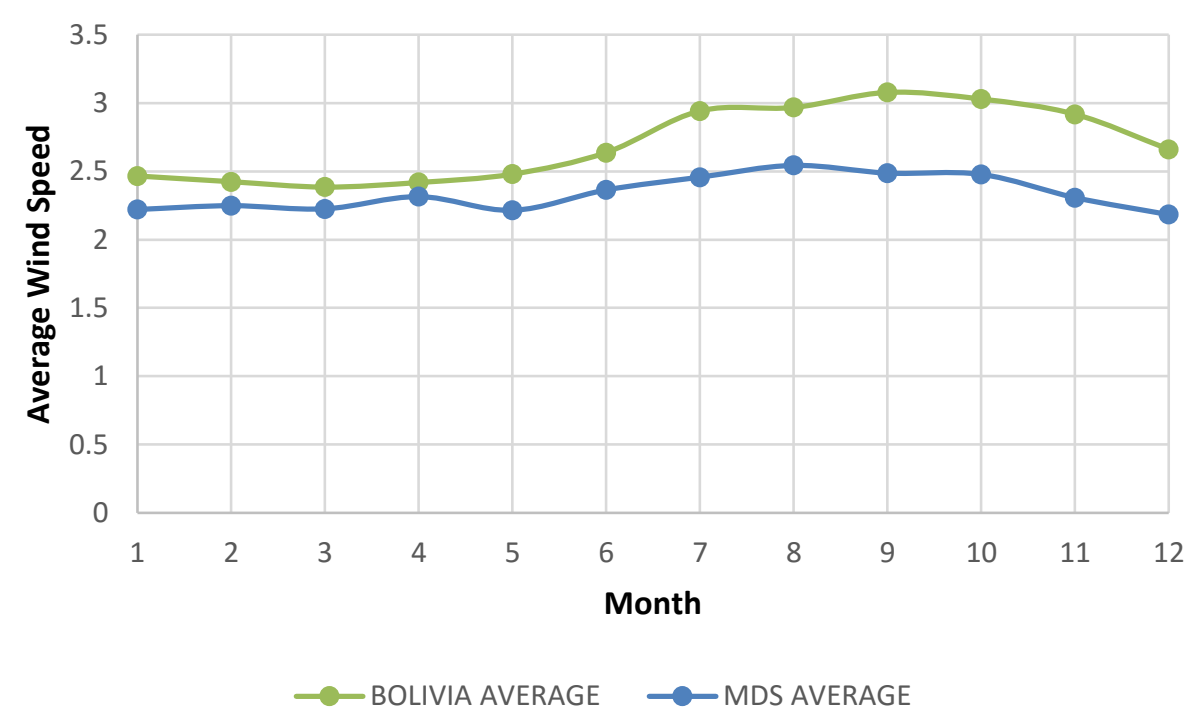

Figure 31: Comparison of monthly average wind speeds for the MDS and the whole system.

\subsection{Summary of the Results}

We studied the MDS solutions for several values of the correlation threshold in order to determine a small subset of locations that would be representative of the whole system. We concluded that using the correlation thresholds of 0.33 and 0.5 yielded very reasonable results, with just 6 and 13 vertices, respectively. Table 11 and Figure 32, summarizes the average wind speeds over the considered 10-year period for the obtained solutions.

Table 11: Average wind speed for MDS solutions.

\begin{tabular}{|c|c|c|}
\hline Location & Vertex & Average wind speed $(\mathbf{m} / \mathbf{s})$ \\
\hline Alternative 1 & 6 & 2.482777778 \\
\hline Alternative 2 & 13 & 2.336923077 \\
\hline Bolivia Wind & 201 & 2.700323383 \\
\hline
\end{tabular}




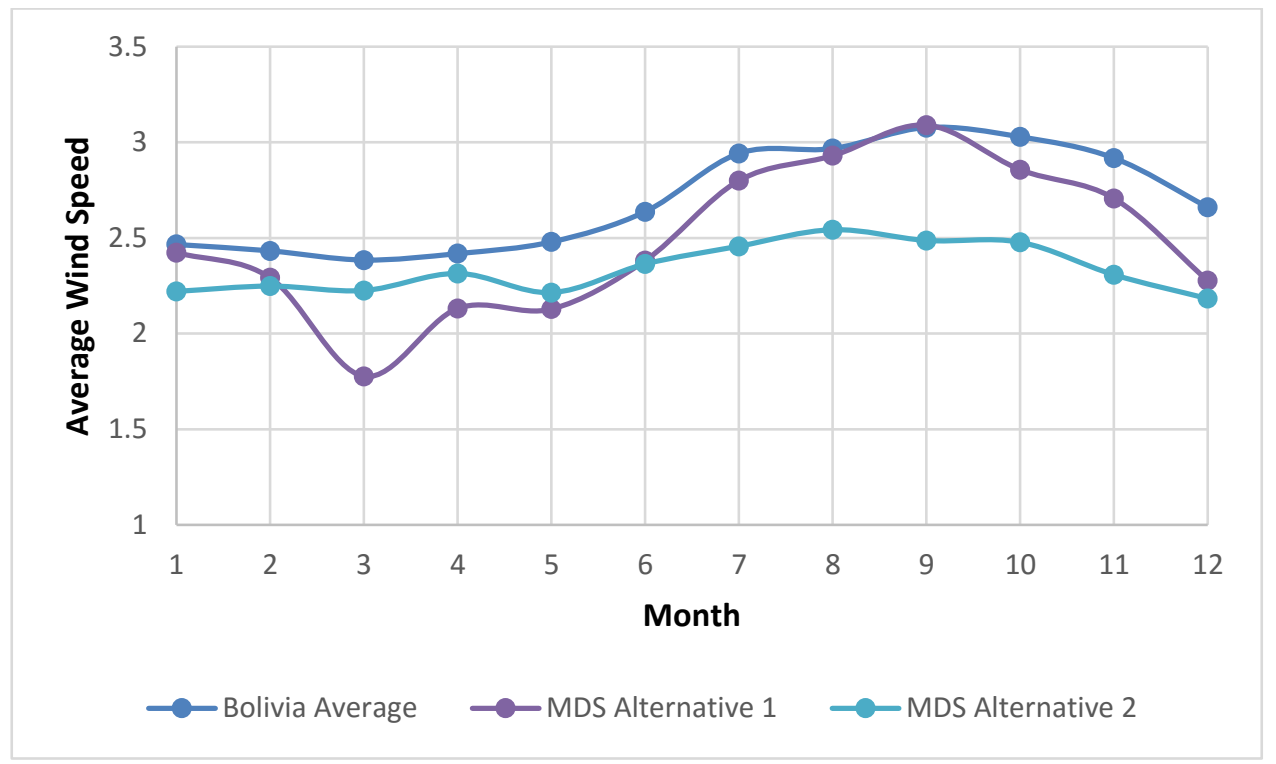

Figure 32: Comparison of monthly average wind speeds for the MDS and the whole system.

We can see, that even though both solution represent the behavior of the system reasonably well, the average wind speeds for the MDS are not as high as one would want to see in wind farm locations. Hence, the dominating set approach is only reasonable for finding a small "replicating portfolio" of locations that would be indicative of the overall dynamics of the considered system, which was exactly the goal of the part of work described in this chapter. To select a balanced set of locations with superior performance one could use the maximum weighted clique or $k$-plex models discussed in the previous two chapters. It should also be noted that the maximum clique solution obtained in the previous chapter provides an attractive alternative to the dominating sets as it replicates the behavior of the whole system rather well. 


\section{CHAPTER VII}

\section{COSTS}

\subsection{Introduction}

Renewable power generation can help many countries meeting their sustainable development goalmouths through provision of access to clean, reliable, secure, and affordable energy. Renewable energy has been mainly used for added capacity in power generation today. Many watts of wind, hydropower, and solar photovoltaic capacity are mounted worldwide every year in the renewable energy sector.

It is significant to mention that detailed financial analysis of project economics is not sufficient for evaluating projects, nevertheless, they do provide simple and clear metrics based on reliable information which can be used to evaluate costs and performance of different types of renewable power and generation systems or technologies (IRENA Secretariat, 2012).

This study would help to inform the current examination of renewable wind power generation and assist governments and key decision makers to make knowledgeable decisions on policy and investment. Additionally, we can understand if the project is feasible to implement from the financial perspective, and if it is, determine the magnitude of the project with respect to investment, cash flow and lifespan that would be optimal in terms of profitability. Hence, we evaluate the project in terms of NPV, IRR and the PBP (Cheremushkin, 2008).

\subsection{Development}

We perform the analysis for the case of building some wind farms in three locations with highest average wind speeds obtained in the maximum weight clique solution, which 
provided good results in terms of the possible energy output, while ensuring a high level of diversification among all the possible sites studied.

As an example, we will consider a method for determining the overall cost of installing a $30 \mathrm{MW}$ wind farm in each of the three selected locations from this clique. First, we made a comparison among different manufacturers and wind turbines technologies available in market today; this was made in order to find the best one for our project. It is important to mention that we will only consider onshore turbines. Table 12 presents the results of the comparison.

Table 12: Wind turbines comparison, adapted from (Beainy, Maatouk, Moubayed, \& Kaddah, 2016).

\begin{tabular}{|c|c|c|c|c|c|c|}
\hline Type & Manufacturer & Power & Converter & $\begin{array}{l}\text { Power } \\
\text { control } \\
\text { features }\end{array}$ & Efficiency & Comments \\
\hline SCIG & $\begin{array}{l}\text { Siemens } \& \\
\text { wind power }\end{array}$ & $\begin{array}{l}3.6 \\
\text { MW }\end{array}$ & Frequency & $\begin{array}{l}\text { Active } \\
\text { stall }\end{array}$ & $\begin{array}{l}\text { Low- } \\
\text { medium }\end{array}$ & $\begin{array}{l}\text { Variable speed } \\
\text { multiple-stage } \\
\text { gearbox with } \\
\text { full-scale power } \\
\text { converter }\end{array}$ \\
\hline \multirow[t]{5}{*}{ DFIG } & Vestas & $\begin{array}{l}4.5 \\
\mathrm{MW}\end{array}$ & \multirow[t]{5}{*}{ Frequency } & \multirow[t]{5}{*}{ Pitch } & \multirow[t]{5}{*}{ Medium } & \multirow{5}{*}{$\begin{array}{l}\text { Variable speed } \\
\text { multiple-stage } \\
\text { concept with } \\
\text { partial-scale } \\
\text { power converter }\end{array}$} \\
\hline & Nordex & $\begin{array}{l}2.5 \\
\text { MW }\end{array}$ & & & & \\
\hline & Ecotecnia & $3 \mathrm{MW}$ & & & & \\
\hline & GE wind & $\begin{array}{l}3.6 \\
\text { MW }\end{array}$ & & & & \\
\hline & Gamesa & $2 \mathrm{MW}$ & & & & \\
\hline \multirow[t]{2}{*}{ PMSG } & Enercon & $6 \mathrm{MW}$ & \multirow{2}{*}{$\begin{array}{l}\text { Rectifier \& } \\
\text { frequency }\end{array}$} & \multirow[t]{2}{*}{ Pitch } & \multirow[t]{2}{*}{ High } & \multirow{2}{*}{$\begin{array}{l}\text { Variable speed } \\
\text { direct-drive with } \\
\text { full-scale power } \\
\text { converter }\end{array}$} \\
\hline & Zypheros & $2 \mathrm{MW}$ & & & & \\
\hline
\end{tabular}

In Table 13, present a comparison of the three technologies studied. 
Table 13: Advantages and disadvantages of the three technologies, adapted from (Beainy, Maatouk, Moubayed, \& Kaddah, 2016).

\begin{tabular}{|c|c|c|}
\hline Type & Advantages & Disadvantages \\
\hline SCIG & $\begin{array}{l}\text {-This machine is a very popular for its } \\
\text { mechanical simplicity and robust } \\
\text { construction. } \\
\text {-A SCIG requires no brushes for operation, } \\
\text { which are sometimes necessary for the } \\
\text { operation of DFIG. } \\
\text {-Metallic rotor bars are very well resistant to } \\
\text { vibrations and dirt. } \\
\text {-Completely decoupled from the grid for } \\
\text { variable speed operations. } \\
\text {-SCIG based WT have the advantage of } \\
\text { avoiding short circuit power from the grid } \\
\text { because the control system limits any fault } \\
\text { current from the grid side convertor going into } \\
\text { the system. }\end{array}$ & $\begin{array}{l}\text {-Two full scale converters are } \\
\text { required for operation. } \\
\text {-It does not have the advantage using } \\
\text { reduced size power converters as in } \\
\text { the DFIG, for variable speed } \\
\text { operation. } \\
\text {-It can't function as a multi-pole } \\
\text { direct drive mode (gearless). }\end{array}$ \\
\hline DFIG & $\begin{array}{l}\text { - Mechanically and electrically simpler than } \\
\text { other generator types. The } 3 \text {-stage geared } \\
\text { DFIG is the lightest and low cost solution. } \\
\text { - Converter Rating is only } 25 \% \text { to } 30 \% \text { in } \\
\text { DFIG, as compared to } 100 \% \text { of nominal } \\
\text { power of the generator. } \\
\text { - Rugged and brushless. } \\
\text { - Can reach to about } 30 \% \text { of synchronous } \\
\text { speed, thus has a wide range of speeds. } \\
\text { - The converter compensates the reactive } \\
\text { power and ensures smooth grid integration. } \\
\text { - High efficiency and energy yield. }\end{array}$ & $\begin{array}{l}\text { - For WTs based on DFIGs, } \\
\text { gearboxes are still a necessity since a } \\
\text { multiple pole DFIG with low-speed is } \\
\text { not yet technically available. } \\
\text { - Difficulties associated in complying } \\
\text { with grid-fault ride-through. } \\
\text { - Medium reliability and reduced } \\
\text { longevity due to bearings and gear } \\
\text { faults. }\end{array}$ \\
\hline PMSG & $\begin{array}{l}\text { - Lower maintenance cost due to absence of } \\
\text { gearbox. } \\
\text { - Improved reliability and longevity comes } \\
\text { with the elimination of the gears and bearings, } \\
\text { which are by themselves the main cause of } \\
\text { faults in the generators. } \\
\text { - Lower weight. } \\
\text { - High efficiency and energy yield. }\end{array}$ & $\begin{array}{l}\text { - High cost. } \\
\text { - The outer diameter of the direct } \\
\text { drive PMSG is almost twice the size } \\
\text { of that of the conventional geared- } \\
\text { drive SCIG. } \\
\text { - Low maturity as it being a new } \\
\text { technology. } \\
\text { - Increased mass and weight that can } \\
\text { reach to critical proportions } \\
\text { especially for WT above 3MW. }\end{array}$ \\
\hline
\end{tabular}

Based on these comparisons, we selected DFIG as he best technology for our requirements, for which Vestas is the preeminent manufacturer. 
We will study two different alternatives for the two locations in order to compare different types of wind turbines and technologies from the manufacturer selected. We will compare the $2 \mathrm{MW}$ turbine and the $3.45 \mathrm{MW}$ turbine (Vestas, 2017).

\subsection{Alternative 1}

For the first alternative and according to the information and the literature review defined by the manufacturer, we selected the best type and model of turbine for our location and geographic conditions, Vestas model V116-2.0 MWTM. Table 14 and Figure 33 present the comparison (Vestas, 2017). 
Table 14: Vestas model type selection, 2.0 MW, adapted from (Vestas, 2017).

\begin{tabular}{|c|c|c|}
\hline Model & Tower & Operating Data \\
\hline V90-1.8/2.0 MW & $\begin{array}{l}\text { Hub heights: } \\
\text { - } 80 \text { m (IEC IIA). } \\
\text { - } 95 \text { m (IEC IIA). } \\
\text { - } 105 \text { m (IEC IIA). }\end{array}$ & $\begin{array}{l}\text { Rated power } 1,800 / 2,000 \mathrm{~kW} \text {. } \\
\text { Cut-in wind speed } 4 \mathrm{~m} / \mathrm{s} \text {. } \\
\text { Cut-out wind speed } 25 \mathrm{~m} / \mathrm{s} \text {. } \\
\text { Re cut-in wind speed } 23 \mathrm{~m} / \mathrm{s} \text {. } \\
\text { Wind class IEC IIA/IEC IIIA. }\end{array}$ \\
\hline V100-2.0 MW & $\begin{array}{l}\text { Hub heights: } \\
\text { - } 80 \text { m (IEC IIB). } \\
\text { - } 95 \text { m (IEC IIB). }\end{array}$ & $\begin{array}{l}\text { Rated power } 2,000 \mathrm{~kW} \text {. } \\
\text { Cut-in wind speed } 3 \mathrm{~m} / \mathrm{s} \text {. } \\
\text { Cut-out wind speed. } 22 \mathrm{~m} / \mathrm{s} \text {. } \\
\text { Re cut-in wind speed } 20 \mathrm{~m} / \mathrm{s} \text {. } \\
\text { Wind class IEC IIB. }\end{array}$ \\
\hline V110-2.0 MW & $\begin{array}{l}\text { Hub heights: } \\
\text { - } 75 \text { m (IECIIIA). } \\
\text { - } 80 \text { m (IEC IIIA). } \\
\text { - } 95 \text { m (IEC IIIA/IEC IIIB). } \\
\text { - 110,120,125 m (IEC IIIB). }\end{array}$ & $\begin{array}{l}\text { Rated power } 2,000 \mathrm{~kW} \text {. } \\
\text { Cut-in wind speed } 3 \mathrm{~m} / \mathrm{s} \text {. } \\
\text { Cut-out wind speed } 21 \mathrm{~m} / \mathrm{s} \mathrm{b} \text {. } \\
\text { Re cut-in wind speed } 18 \mathrm{~m} / \mathrm{s} \text {. } \\
\text { Wind class IEC IIIA. }\end{array}$ \\
\hline V116-2.0 MW & $\begin{array}{l}\text { Hub heights: } \\
\text { Site and country specific. }\end{array}$ & $\begin{array}{l}\text { Rated power } 2,000 \mathrm{~kW} \text {. } \\
\text { Cut-in wind speed } 3 \mathrm{~m} / \mathrm{s} \text {. } \\
\text { Cut-out wind speed } 20 \mathrm{~m} / \mathrm{s} \mathrm{b} \text {. } \\
\text { Re cut-in wind speed } 18 \mathrm{~m} / \mathrm{s} \text {. } \\
\text { Wind class IEC IIB. }\end{array}$ \\
\hline V120-2.0 MW & $\begin{array}{l}\text { Hub heights: } \\
\text { Site and country specific. }\end{array}$ & $\begin{array}{l}\text { Rated power } 2,000 \mathrm{~kW} \text {. } \\
\text { Cut-in wind speed } 3 \mathrm{~m} / \mathrm{s} \text {. } \\
\text { Cut-out wind speed } 18 \mathrm{~m} / \mathrm{s} \mathrm{b} \text {. } \\
\text { Re cut-in wind speed } 16 \mathrm{~m} / \mathrm{s} \text {. } \\
\text { Wind class IEC IIB. }\end{array}$ \\
\hline
\end{tabular}

\begin{tabular}{|c|c|c|c|}
\hline TURBINE TYPE & IECIII $(6.0-7.5 \mathrm{~m} / \mathrm{s})$ & IECII (7.5 - $8.5 \mathrm{~m} / \mathrm{s})$ & $\operatorname{IECI}(8.5-10.0 \mathrm{~m} / \mathrm{s})$ \\
\hline \multicolumn{4}{|l|}{2 MW TURBINES } \\
\hline \multicolumn{4}{|l|}{ V90-1.8/2.0MW* IEC IIA/IEC \|IA } \\
\hline \multicolumn{4}{|l|}{ V100-2.0MW*IECIIB } \\
\hline \multicolumn{4}{|l|}{ V110-2.0 MW•IEC IIIA } \\
\hline \multicolumn{4}{|l|}{ V116-2.0 MW' ${ }^{\mathrm{TM}}$ IEC IIB } \\
\hline V120-2.0 MW' IECIIIB/IECS & & & \\
\hline
\end{tabular}

Figure 33: Vestas, wind classes 2.0 MW, reprinted from (Vestas, 2017). 
In Figure 34, Figure 35, Figure 36, Figure 37, and Figure 38, we can see the energy production for each type of turbine studied. Here the $\mathrm{x}$-axis represents the average wind speed at the 10-meter height and y-axis shows a yearly output in GWh (Bañuelos-Ruedas, Rios-Marcuello, \& Camacho, 2011).

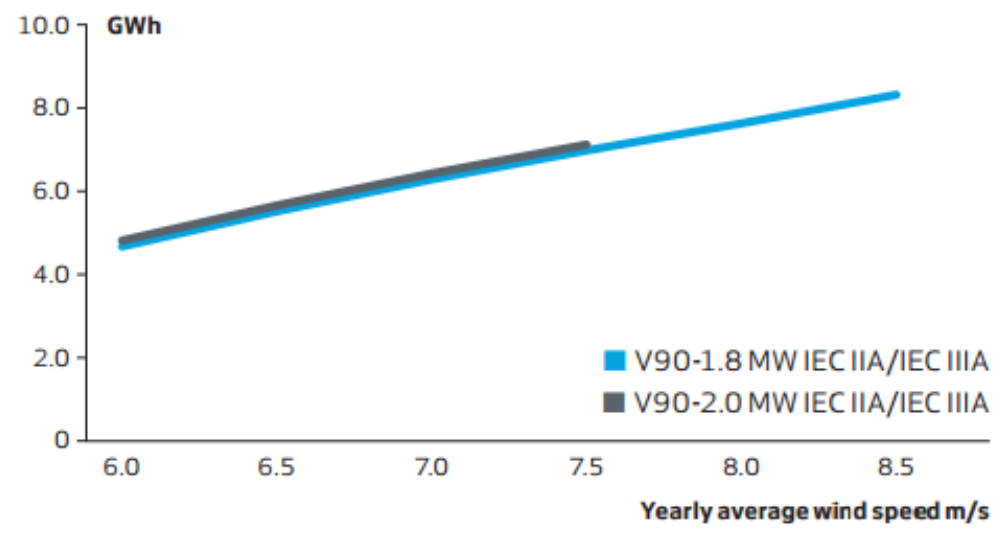

Figure 34: Annual energy production for V90, reprinted from (Vestas, 2017).

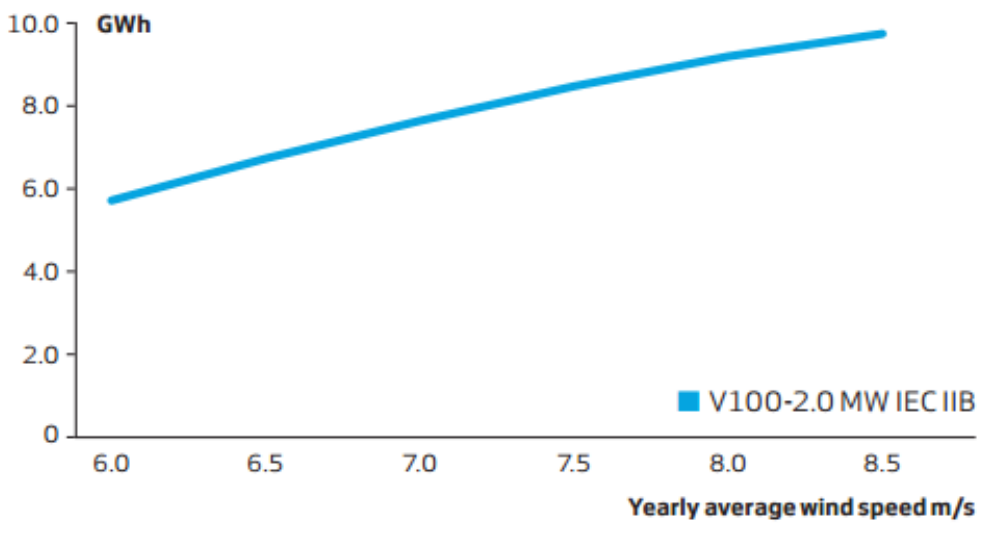

Figure 35: Annual energy production for V100, reprinted from (Vestas, 2017). 


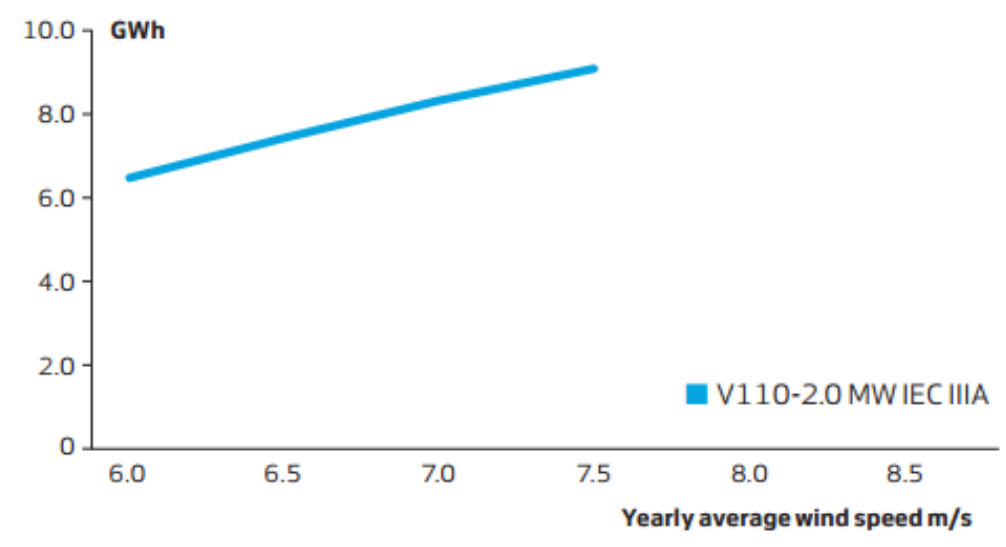

Figure 36: Annual energy production for V110, reprinted from (Vestas, 2017).

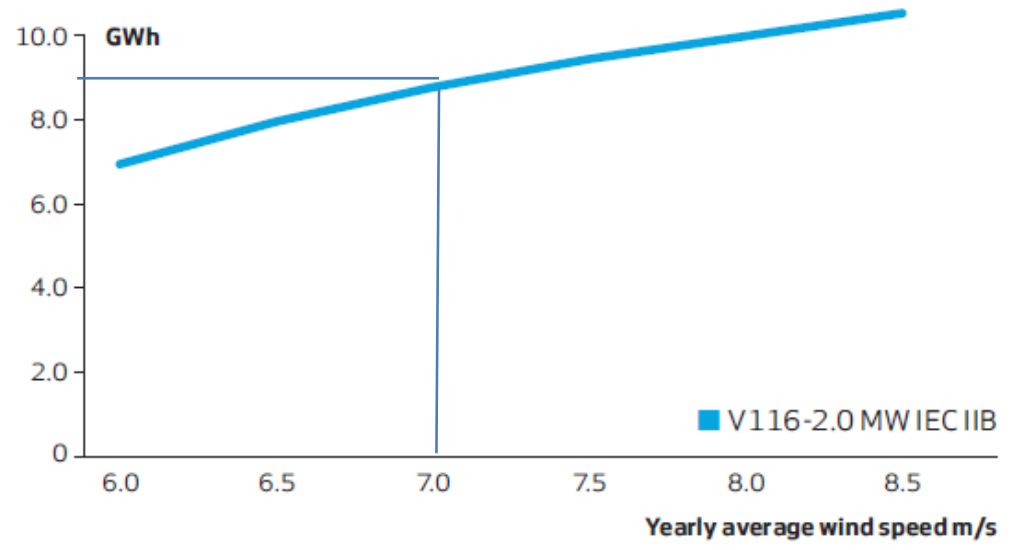

Figure 37: Annual energy production for V116, reprinted from (Vestas, 2017).

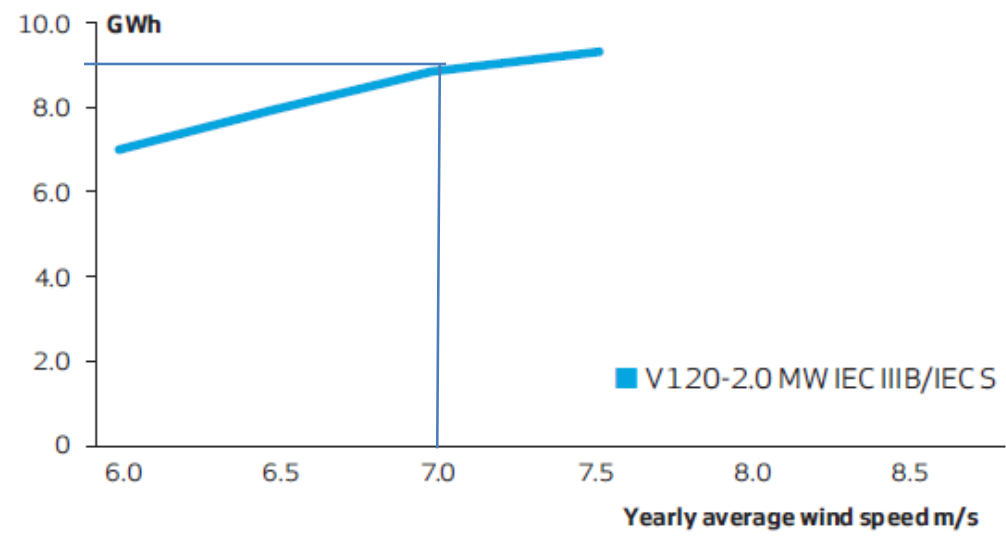

Figure 38: Annual energy production for V120, reprinted from (Vestas, 2017). 
More information on characteristics and comparisons of each model of turbines can be found in Appendix II.

For the turbine selected, we approximated an equation that relates the inputs and outputs (Viera da Rosa, 2012).

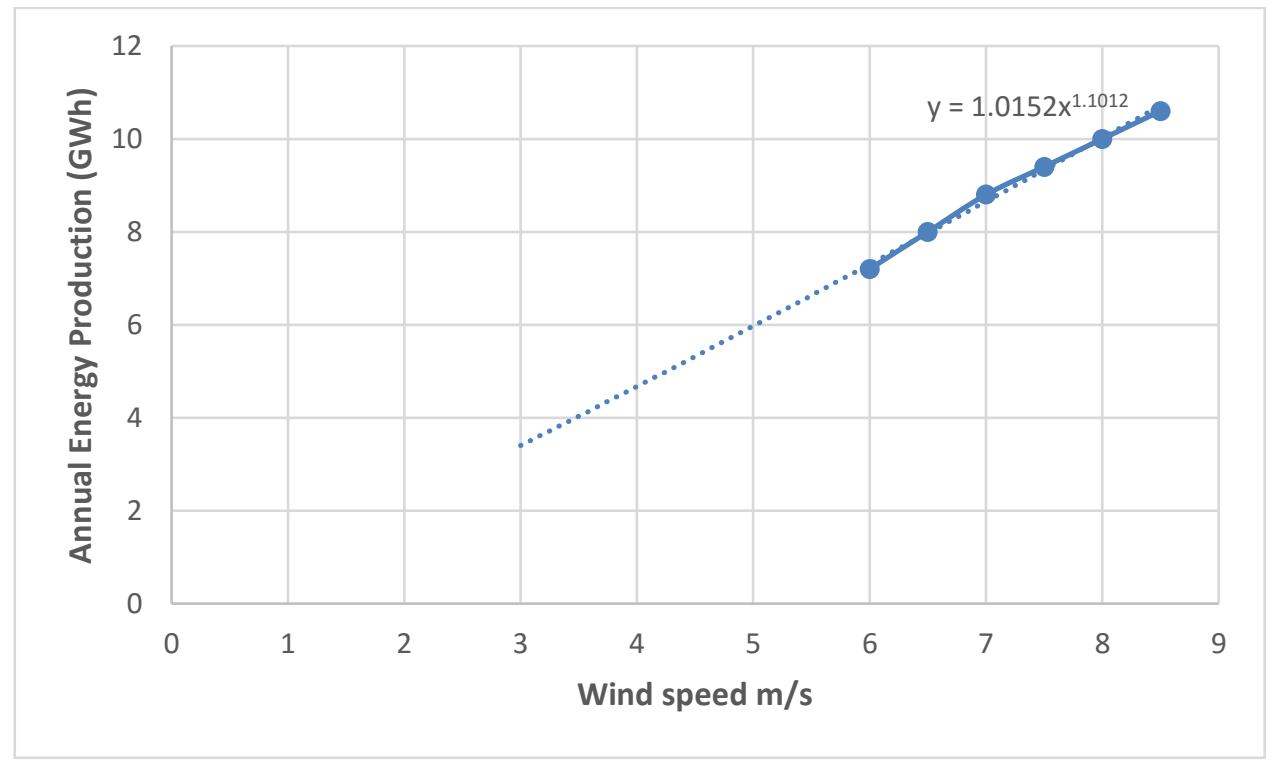

Figure 39: Energy production equation based on V116 data.

The equation obtained is given by:

$$
y=1.0152 * x^{1.1012}
$$

where $\mathrm{y}$ is the output (in GWh per year) and $x$ is the average wind speed over the year at $10 \mathrm{~m}$ height.

Using all the data presented, we calculated NPV, IRR and PBP of the wind farm in order to determine the feasibility of the project.

Table 15 shows some important information used for each wind farm studied. 
Table 15: Characteristics of the project.

\begin{tabular}{|l|r|l|}
\hline Wind Process & \multicolumn{2}{|l|}{} \\
\hline Operation Time & 8760 & Hours/Year \\
\hline Generator Capacity & 2 & MW \\
\hline Rated Power & 2000 & kW \\
\hline Rotor Diameter & 116 & meter \\
\hline & 380.57744 & feet \\
\hline Plant Factor & 60 & $\%$ \\
\hline Performance Coefficient & 59 & $\%$ \\
\hline Number of Generators & 15 & Units \\
\hline Total Power Output & 30 & MW \\
\hline Life Time & 25 & Years \\
\hline Discount Rate & 10 & $\%$ \\
\hline
\end{tabular}

In this table, we used the information from the manufacturer regarding the capacity of the generator, rated power, rotor diameter, and lifetime of the generator (Vestas, 2017). The operation time corresponds to a year of working expressed in hours. Performance coefficient is defined by (Viera da Rosa, 2012) and represents the available power density from the wind. Plant factor corresponds to how much electricity a power plant actually produces compared to how much it would produce if it operated at full capacity (Shahan, 2012). We selected the discount rate of $10 \%$, which is defined for all electrical projects, especially renewables (Obdam, Braam, van de Pieterman, \& Rademakers, 2011).

As for the number of generators, we defined it as an average for small-medium wind farm complexes. This number is based on the power output per unit and the total power output for the farm planed (Pinilla S., 2003).

Table 16 presents all the items included in the investment cost. The cost is defined per MW (Krohn, Morthorst, \& Awerbuch, 2009). 
Table 16: Investment results.

\begin{tabular}{|l|cr|l|}
\hline \multicolumn{1}{|l|}{ Investment } & \multicolumn{3}{l|}{} \\
\hline Initial Cost per Unit & $\$$ & $1,440,000.00$ & (US\$)per MW \\
\hline Turbine (ex works) & $\$$ & $32,659,200.00$ & (US\$) \\
\hline Grid connection & $\$$ & $3,844,800.00$ & (US\$) \\
\hline Foundation & $\$$ & $2,808,000.00$ & (US\$) \\
\hline Land rent & $\$$ & $1,684,800.00$ & (US\$) \\
\hline Electric installation & $\$$ & $648,000.00$ & (US\$) \\
\hline Consultancy & $\$$ & $518,400.00$ & (US\$) \\
\hline Financial costs & $\$$ & $518,400.00$ & (US\$) \\
\hline Road construction & $\$$ & $388,800.00$ & (US\$) \\
\hline Control systems & $\$$ & $129,600.00$ & (US\$) \\
\hline Total Initial Cost & $\$ 43,200,000.00$ & (US\$) \\
\hline
\end{tabular}

Figure 40 shows the distribution of the investment between the different cost categories.

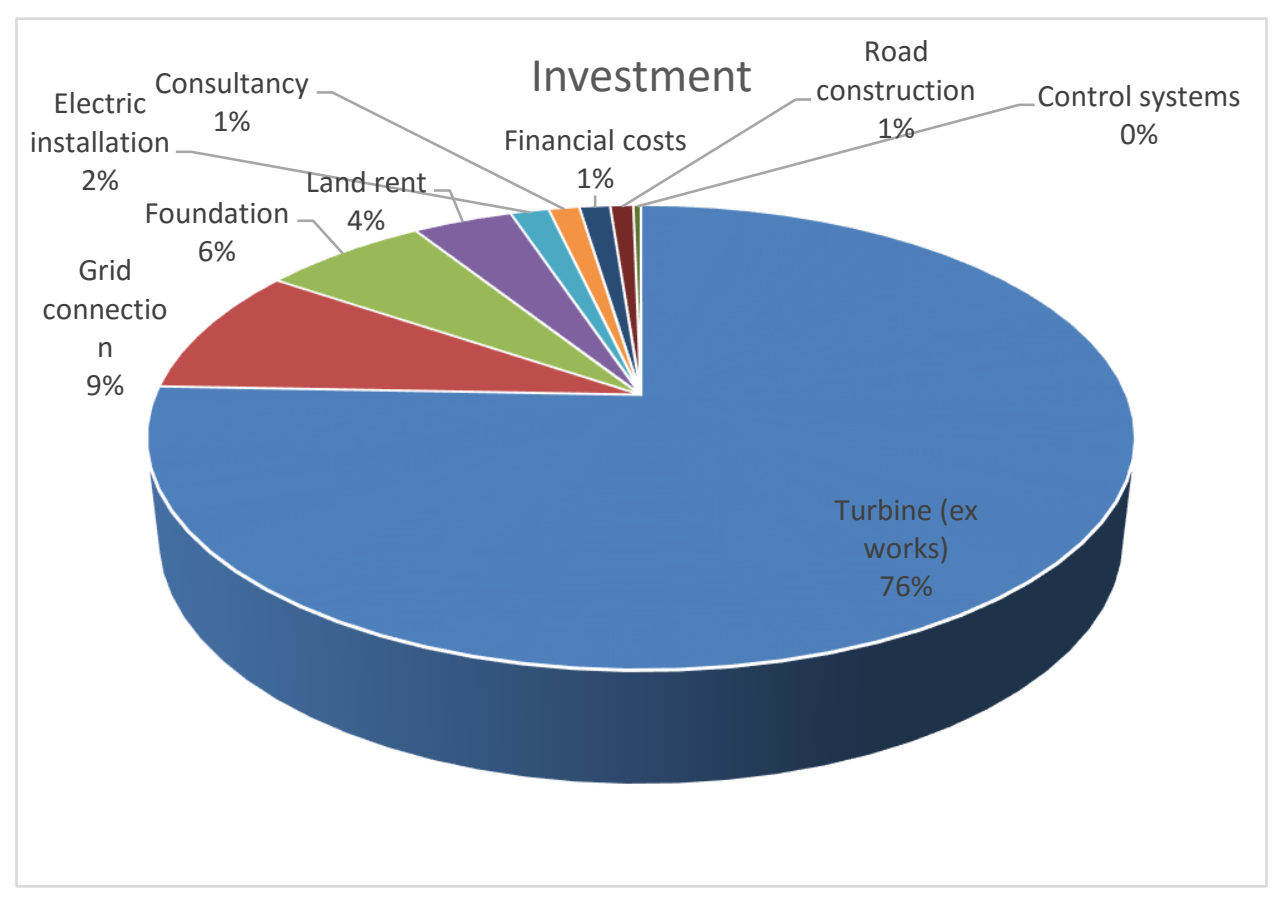

Figure 40: Investment cost categories in percentage.

Table 17 shows monthly costs for $30 \mathrm{MW}$ of electric power corresponding to the new wind farm project, these quantities can be used for each site studied. The replacement cost is a cost associated with replacing the entire plant at the end of its life. 
Table 17: Monthly costs results.

\begin{tabular}{|l|rr|r|}
\cline { 1 - 2 } Monthly Expenses & \multicolumn{3}{|c|}{} \\
\hline Maintenance & $\$$ & $1,296,000.00$ & (US\$)-year \\
\hline Operation & $\$$ & $864,000.00$ & (US\$)-year \\
\hline Replacement Cost & $\$$ & $1,728,000.00$ & (US\$)-year \\
\hline
\end{tabular}

Figure 41 summarizes all the different cost categories included in the operational cost (Krohn, Morthorst, \& Awerbuch, 2009).

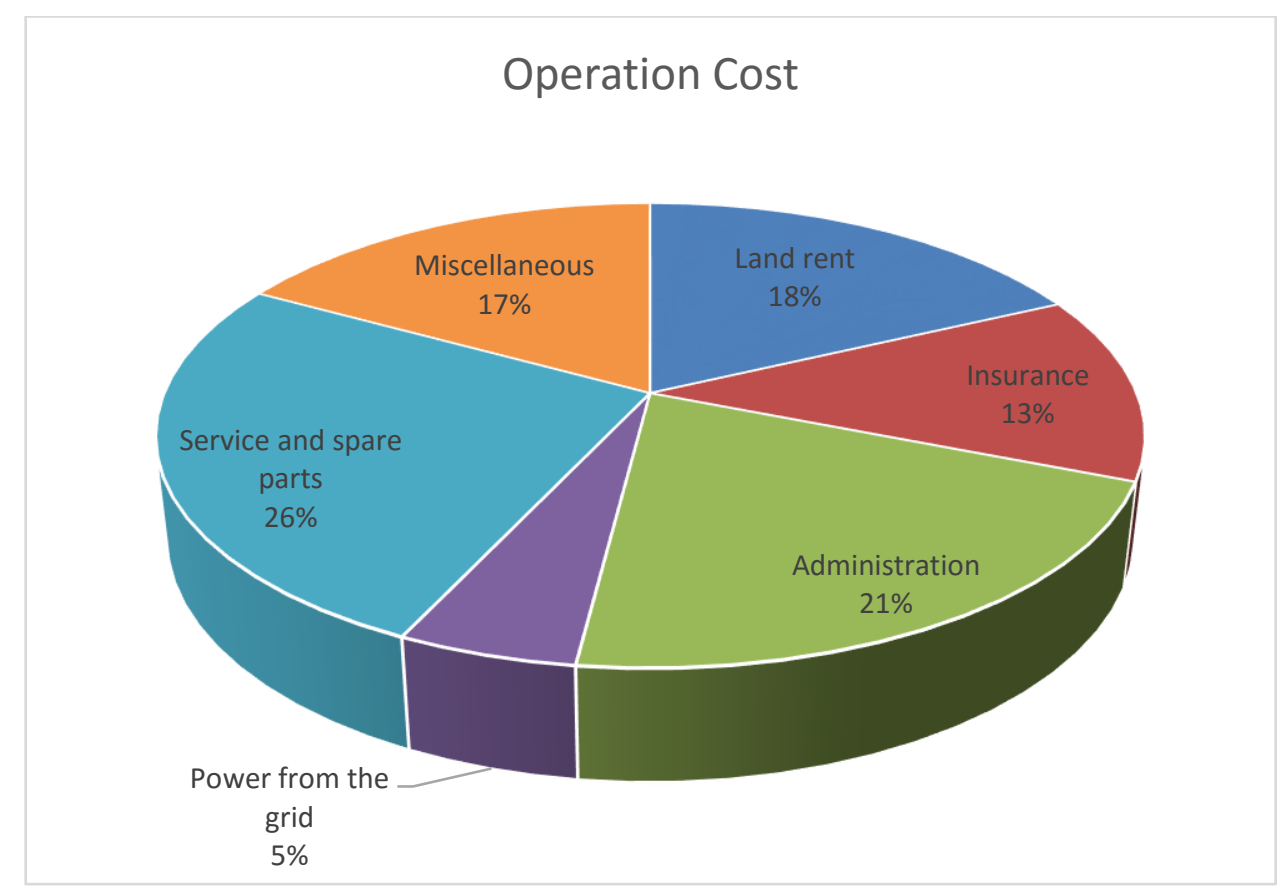

Figure 41: Operation cost categories in percentage.

We assume the spot price for electricity at today's world prices, which is about 10 cents \$/kwh (Statista, 2017).

Next, we perform the analysis for three individual sites included in the maximum weight clique, in the decreasing order of their average wind speeds. 
The first site studied corresponds to vertex \#82, named Huacullani. As we can see in Table 18 , the energy produced yearly for the wind farm varies according to the average wind speed in the site. This table shows the energy production for one generator.

Table 18: Energy production for Site 1.

\begin{tabular}{|l|l|l|}
\hline Energy & \multicolumn{2}{|c|}{} \\
\cline { 1 - 2 } Wind Speed & 6.919166667 & $\mathbf{m} / \mathbf{s}$ \\
\hline & 15.47776068 & $\mathbf{M p h}$ \\
\hline Annual Energy Production & 8.543165992 & $\mathbf{G W h}$ \\
\hline
\end{tabular}

Table 19 shows the price of the electricity used and the yearly income for selling the total amount of energy represented in the table above.

Table 19: Income evaluation for Site 1.

\begin{tabular}{|l|cc|l|}
\hline Income & \multicolumn{3}{|l|}{} \\
\hline Electric Price & $\$$ & 0.10 & $\mathbf{\$} / \mathbf{k w h}$ \\
\hline Total Income & $\$$ & $12,814,748.99$ & (US\$)-year \\
\hline
\end{tabular}

The results obtained from the economical evaluation can be seen in Table 20 .

Table 20: Results of economic evaluation for Site 1.

\begin{tabular}{|c|c|c|}
\hline Final Results & & \\
\hline Location & 82 & HUACULLANI \\
\hline NPV & $\$ \quad 15,862,147.31$ & (US\$) \\
\hline IRR & $15 \%$ & $\%$ \\
\hline PBP & 12.20237734 & Years \\
\hline
\end{tabular}

As we can, the IRR is greater that the discount rate, moreover the project is paid off in 12 years, with 15 additional years of operating for profit. The expected profit at the end of its lifetime is $\$ 15,862,147.31$.

Table 21 summarize the results of similar economic evaluation for each of the top three sites from the maximum weight clique. 
Table 21: Results of economic evaluation for Sites 1-3.

\begin{tabular}{|l|l|l|l|}
\hline Site & $\mathbf{1}$ & $\mathbf{2}$ & $\mathbf{3}$ \\
\hline Vertex \# & 82 & 40 & 175 \\
\hline Location & Huacullani & Redencion & Robore \\
\hline Wind speed & $6.919 \mathrm{~m} / \mathrm{s}$ & $4.897 \mathrm{~m} / \mathrm{s}$ & $4.354 \mathrm{~m} / \mathrm{s}$ \\
& $15.478 \mathrm{Mph}$ & $10.955 \mathrm{Mph}$ & $9 / 740 \mathrm{Mph}$ \\
\hline Annual energy production & $8.543 \mathrm{GWh} /$ gen. & $5.839 \mathrm{GWh} /$ gen. & $5.129 \mathrm{GWh} / \mathrm{gen}$. \\
\hline Total income & $\$ 12,814,748.99$ & $\begin{array}{l}\$ 8,758,762.02 \\
\text { per year }\end{array}$ & $\begin{array}{l}\$ 7,694,937.70 \\
\text { per year }\end{array}$ \\
\hline NPV & per year & $\$(8,479,245.09)$ & $\$(14,863,625.90)$ \\
\hline IRR & $\$ 15,862,147.31$ & $7 \%$ & $5 \%$ \\
\hline PBP & $15 \%$ & - & - \\
\hline
\end{tabular}

Figure 42, Figure 43, and Figure 44 show the cumulative discounted cash flow in addition to the payback period of the entire project for each of the three considered sites. Here $x$ axis corresponds to each year of the project and $y$-axis corresponds to the cash flow. The detailed yearly calendar for each project can be found in Appendix II.

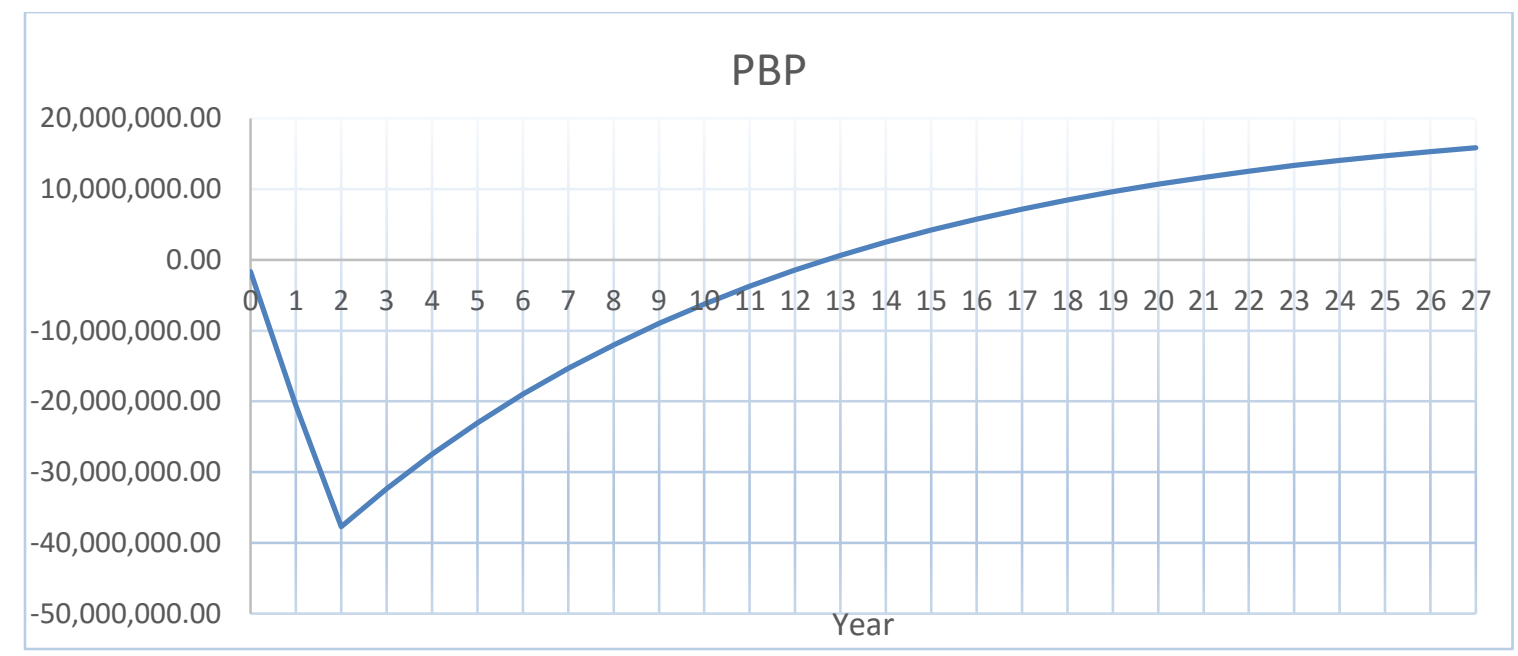

Figure 42: Cumulative discounted cash flow for Site 1. 


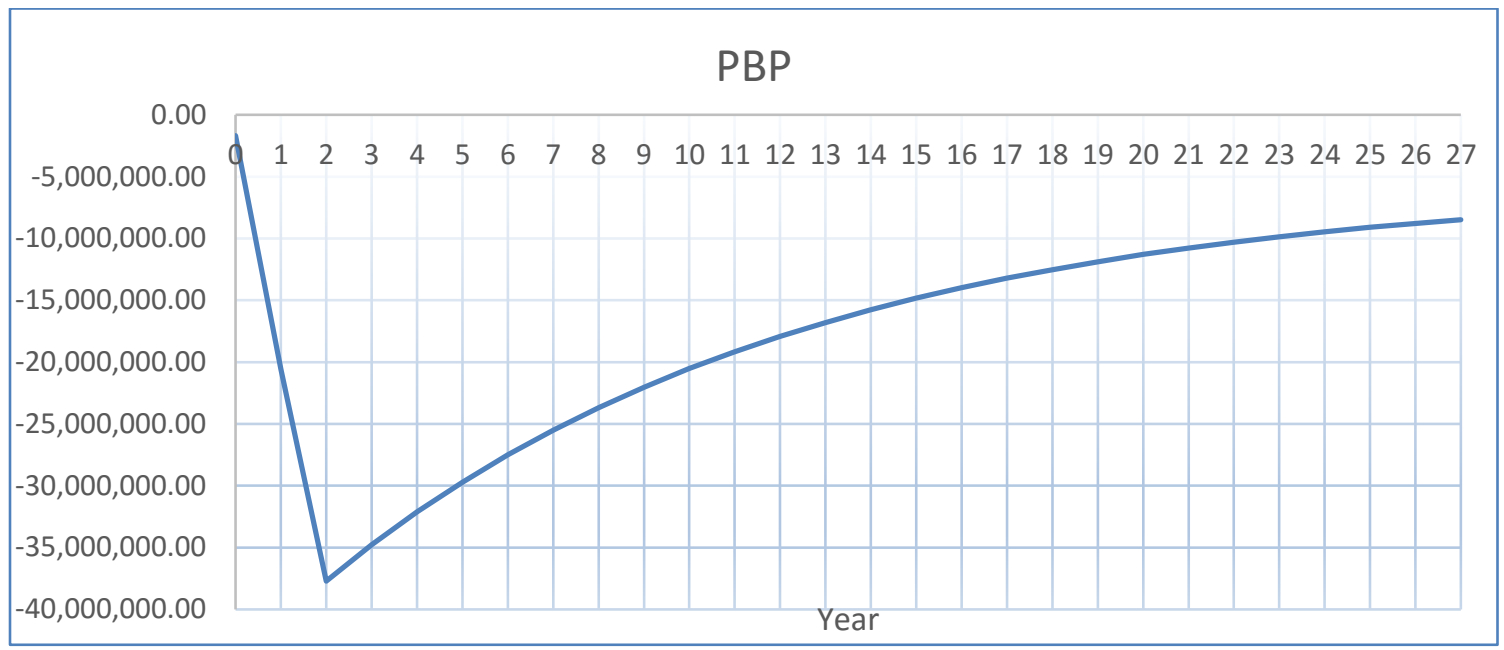

Figure 43: Cumulative discounted cash flow for Site 2.

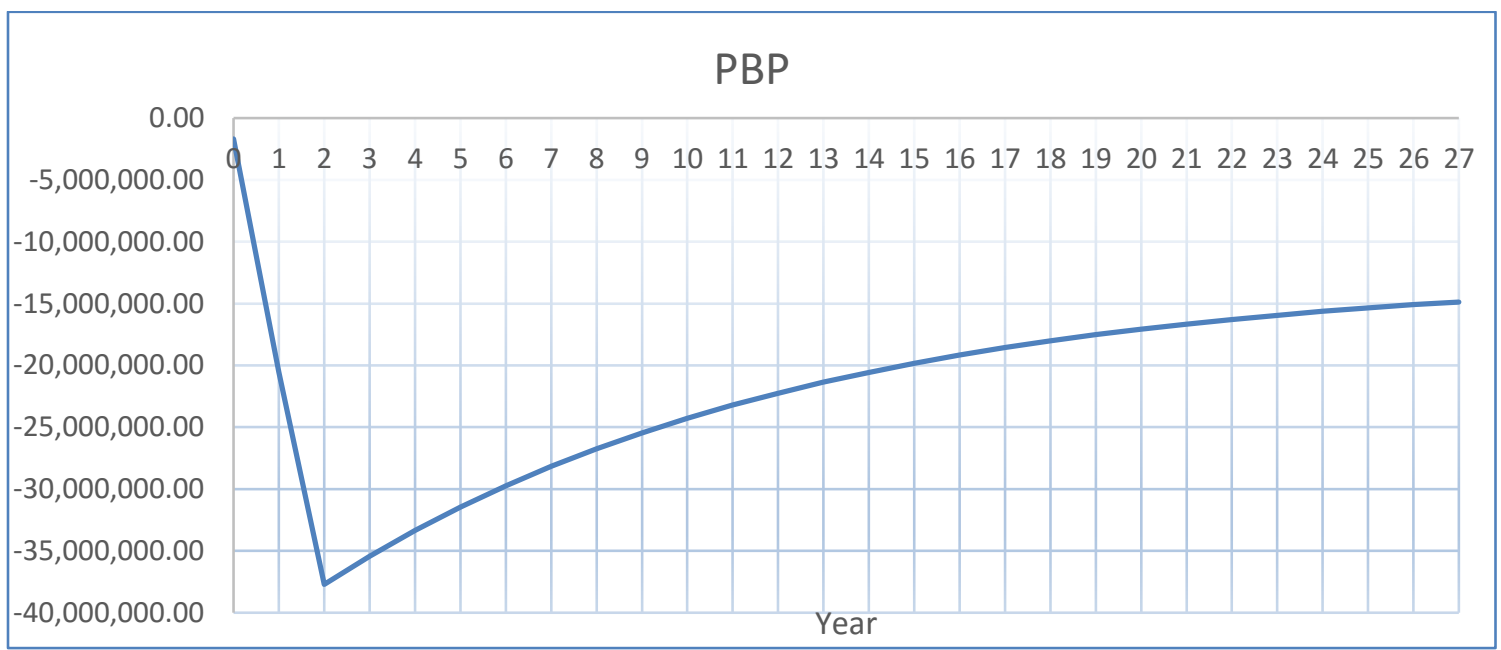

Figure 44: Cumulative discounted cash flow for Site 3.

As we can see, the project is not profitable for sites 2 and 3; the IRR is smaller than the discount rate, and the net present value is negative, meaning that the initial investment will not be recovered. 


\subsection{Alternative 2}

For the second alternative, we selected the best type and model of turbine for our location and geographic conditions, Vestas model: V136-3.45 MWTM. Table 22 and Figure 45 show the comparison performed (Vestas, 2017).

Table 22: Vestas, model type selection 3.45 MW, adapted from (Vestas, 2017).

\begin{tabular}{|c|c|c|}
\hline Model & Tower & Operating Data \\
\hline V105-3.45 MW & $\begin{array}{l}\text { Hub height: } \\
72.5 \text { m (IEC IA). }\end{array}$ & $\begin{array}{l}\text { Rated power } 3,450 \mathrm{~kW} \text {. } \\
\text { Cut-in wind speed } 3 \mathrm{~m} / \mathrm{s} \text {. } \\
\text { Cut-out wind speed } 25 \mathrm{~m} / \mathrm{s} \text {. } \\
\text { Re cut-in wind speed } 23 \mathrm{~m} / \mathrm{s} \text {. } \\
\text { Wind class IEC IA. }\end{array}$ \\
\hline V112-3.45 MW & $\begin{array}{l}\text { Hub heights: } \\
\text { - } 69 \text { m (IEC IA. } \\
\text { - } 94 \text { m (IEC IA). }\end{array}$ & $\begin{array}{l}\text { Rated power } 3,450 \mathrm{~kW} \text {. } \\
\text { Cut-in wind speed } 3 \mathrm{~m} / \mathrm{s} \text {. } \\
\text { Cut-out wind speed. } 25 \mathrm{~m} / \mathrm{s} \text {. } \\
\text { Re cut-in wind speed } 23 \mathrm{~m} / \mathrm{s} \text {. } \\
\text { Wind class IEC IIB. }\end{array}$ \\
\hline V117-3.45 MW & $\begin{array}{l}\text { Hub heights: } \\
\text { - } 80 \mathrm{~m} \text { (IEC IB). } \\
\text { - } 91.5 \mathrm{~m} \text { (IEC IB). } \\
-116.5 \mathrm{~m} \text { (IEC IB/IEC IIA/DIBtS) }\end{array}$ & $\begin{array}{l}\text { Rated power } 3,450 \mathrm{~kW} \text {. } \\
\text { Cut-in wind speed } 3 \mathrm{~m} / \mathrm{s} \text {. } \\
\text { Cut-out wind speed } 25 \mathrm{~m} / \mathrm{s} \mathrm{b} \text {. } \\
\text { Re cut-in wind speed } 23 \mathrm{~m} / \mathrm{s} \text {. } \\
\text { Wind class IEC IB/IEC IIA. }\end{array}$ \\
\hline V126-3.45 MW & $\begin{array}{l}\text { Hub heights: } \\
\text { - } 87 \mathrm{~m} \text { (IEC IIB). } \\
\text { - } 117 \mathrm{~m} \text { (IEC IIB). } \\
\text { - } 137 \mathrm{~m} \text { (IEC IIIA). }\end{array}$ & $\begin{array}{l}\text { Rated power } 3,450 \mathrm{~kW} \text {. } \\
\text { Cut-in wind speed } 3 \mathrm{~m} / \mathrm{s} \text {. } \\
\text { Cut-out wind speed. } 22.5 \mathrm{~m} / \mathrm{s} \text {. } \\
\text { Re cut-in wind speed } 20 \mathrm{~m} / \mathrm{s} \text {. } \\
\text { Wind class IEC IIB. }\end{array}$ \\
\hline V126-3.45 MW & $\begin{array}{l}\text { Hub heights: } \\
\text { - } 87 \mathrm{~m} \text { (IEC IIA). } \\
\text { - } 117 \mathrm{~m} \text { (IEC IIA/DIBtS). } \\
\text { - } 137 \mathrm{~m} \text { (IEC IIIA/DIBtS). } \\
\text { - } 147 \mathrm{~m} \text { (IEC IIIA). } \\
\text { - } 149 \mathrm{~m} \text { (DIBtS). } \\
\text { - } 166 \mathrm{~m} \text { (DIBtS). }\end{array}$ & $\begin{array}{l}\text { Rated power } 3,450 \mathrm{~kW} \text {. } \\
\text { Cut-in wind speed } 3 \mathrm{~m} / \mathrm{s} \text {. } \\
\text { Cut-out wind speed. } 22.5 \mathrm{~m} / \mathrm{s} \text {. } \\
\text { Re cut-in wind speed } 20 \mathrm{~m} / \mathrm{s} \text {. } \\
\text { Wind class IEC IIA. }\end{array}$ \\
\hline V136-3.45 MW & $\begin{array}{l}\text { Hub heights: } \\
\text { - } 82 \mathrm{~m} \text { (IEC IIB/IEC IIIA). } \\
\text { - } 105 \mathrm{~m} \text { (IEC IIIA). } \\
\text { - } 112 \mathrm{~m} \text { (IEC IIB/IEC IIIA). } \\
\text { - } 132 \mathrm{~m} \text { (IEC IIB/IEC IIIA/ DIBt2). } \\
\text { - } 142 \mathrm{~m} \text { (IEC IIIA). } \\
\text { - } 149 \mathrm{~m} \text { (DIBtS). } \\
\text { - } 166 \mathrm{~m} \text { (DIBtS). }\end{array}$ & $\begin{array}{l}\text { Rated power } 3,450 \mathrm{~kW} \text {. } \\
\text { Cut-in wind speed } 3 \mathrm{~m} / \mathrm{s} \text {. } \\
\text { Cut-out wind speed. } 22.5 \mathrm{~m} / \mathrm{s} \text {. } \\
\text { Re cut-in wind speed } 20 \mathrm{~m} / \mathrm{s} \text {. } \\
\text { Wind class IEC IIB/IEC IIIA. }\end{array}$ \\
\hline
\end{tabular}




\begin{tabular}{|c|c|c|c|}
\hline TURBINE TYPE & IECIII $(6.0-7.5 \mathrm{~m} / \mathrm{s})$ & IEC II $(7.5-8.5 \mathrm{~m} / \mathrm{s})$ & $\operatorname{IECI}(8.5-10.0 \mathrm{~m} / \mathrm{s})$ \\
\hline \multicolumn{4}{|l|}{3 MWTURBINES } \\
\hline \multicolumn{4}{|l|}{ V105-3.45 MW"' IEC IA } \\
\hline \multicolumn{4}{|l|}{ V112-3.45 MW"' IEC IA } \\
\hline \multicolumn{4}{|l|}{ V117-3.45 MW' IEC IB/IEC IIA } \\
\hline \multicolumn{4}{|l|}{ V126-3.45 MW' IEC IIA } \\
\hline \multicolumn{4}{|l|}{ V126-3.45 MW" IEC IIB } \\
\hline V136-3.45 MW'" IEC \|B/ IEC IIIA & & & \\
\hline
\end{tabular}

- Standard IEC conditions

Figure 45: Vestas, wind classes 3.0 MW, reprinted from (Vestas, 2017).

In Figure 46, and Figure 47 we can see the energy production for each type of turbine studied. Here the $\mathrm{x}$-axis represents the average wind speed at the 10-meter height and $\mathrm{y}$ axis shows a yearly output in GWh (Bañuelos-Ruedas, Rios-Marcuello, \& Camacho, 2011).

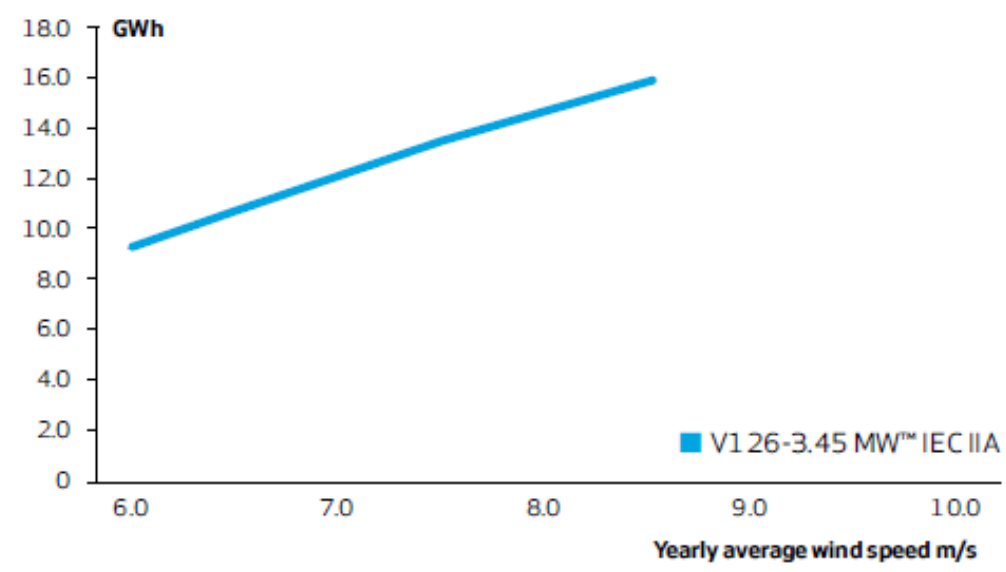

Figure 46: Annual energy production, V126, reprinted from (Vestas, 2017). 


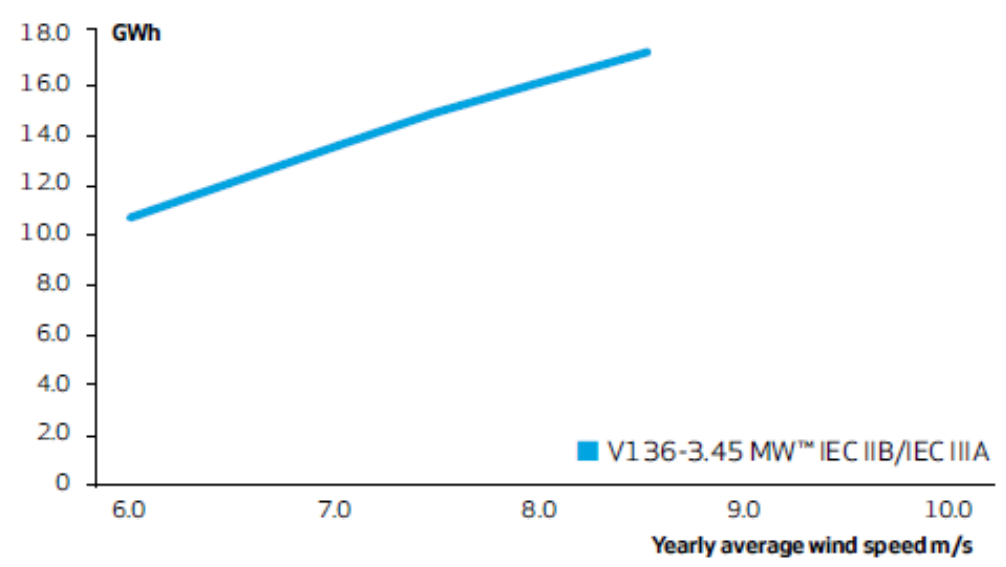

Figure 47: Annual energy production, V136, reprinted from (Vestas, 2017).

More information on characteristics and comparisons of each model of turbines can be found in Appendix II.

For the turbine selected, we approximated an equation that relates the inputs and outputs (Viera da Rosa, 2012).

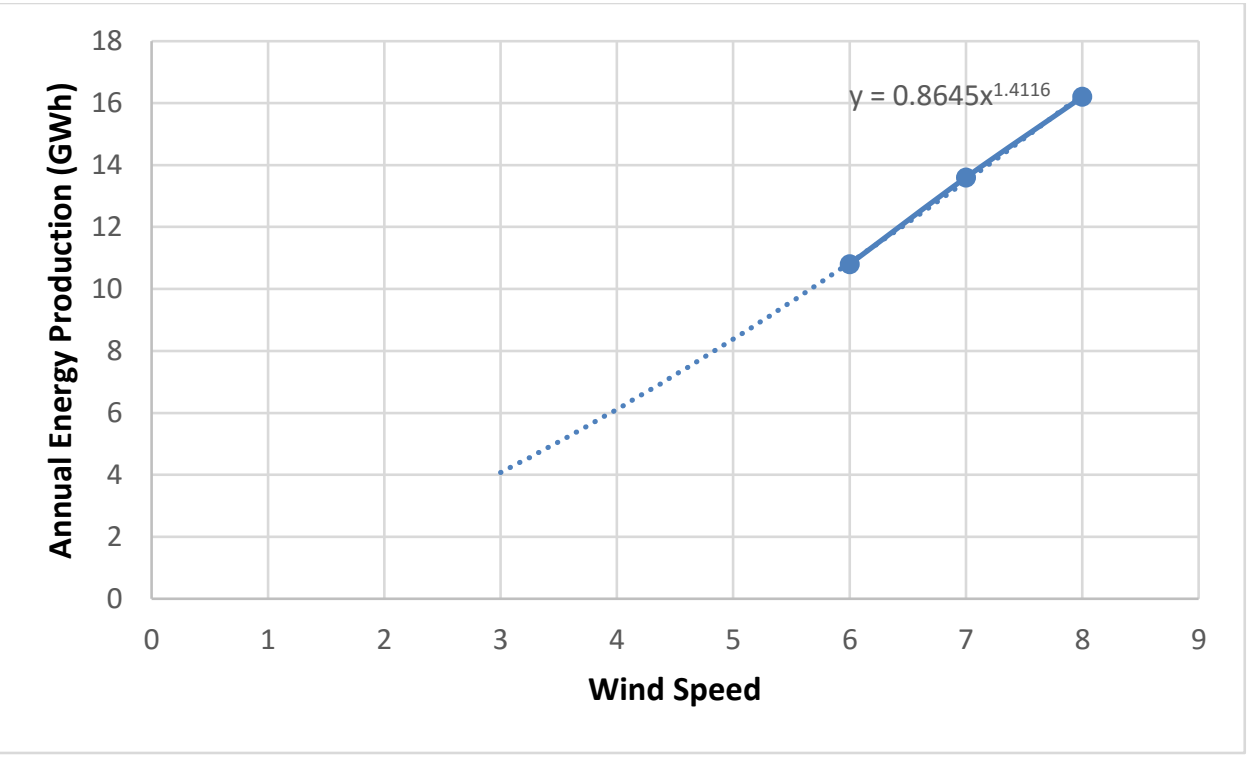

Figure 48: Energy production equation based on V136 data. 
The equation obtained is given by:

$$
y=0.8645 * x^{1.4116}
$$

where $\mathrm{y}$ is the output (in GWh per year) and $x$ is the average wind speed over the year at $10 \mathrm{~m}$ height.

Using all the data presented, we calculated NPV, IRR and PBP of the wind farm in order to determine the feasibility of the project.

Table 23 shows some important information used for each wind farm studied, similar to what was presented in Table 15 for Alternative 1.

Table 23: Characteristics of the project.

\begin{tabular}{|l|r|l|}
\hline Wind Process & \multicolumn{2}{|l|}{} \\
\hline Operation Time & 8760 & Hours/Year \\
\hline Generator Capacity & 3.45 & MW \\
\hline Rated Power & 3400 & kW \\
\hline Rotor Diameter & 136 & Meter \\
\hline & 446.19424 & Feet \\
\hline Plant Factor & $60 \%$ & \% \\
\hline Performance Coefficient & $59 \%$ & $\%$ \\
\hline Number of Generators & 9 & Units \\
\hline Total Power Output & 31.05 & MW \\
\hline Life Time & 25 & Years \\
\hline Discount Rate & $10 \%$ & $\%$ \\
\hline
\end{tabular}

As before, $10 \%$ discount rate is used.

Table 24 presents all the items included in the investment cost. The cost is defined per MW (Krohn, Morthorst, \& Awerbuch, 2009). 
Table 24: Investment results.

\begin{tabular}{|c|c|c|c|}
\hline Investment & \\
\hline Initial Cost per Unit & $\$$ & $1,440,000.00$ & (US\$) per MW \\
\hline Turbine (ex works) & $\$$ & $33,802,272.00$ & (US\$) \\
\hline Grid connection & $\$$ & $3,979,368.00$ & (US\$) \\
\hline Foundation & $\$$ & $2,906,280.00$ & (US\$) \\
\hline Land rent & $\$$ & $1,743,768.00$ & (US\$) \\
\hline Electric installation & $\$$ & $670,680.00$ & $(\mathbf{U S \$})$ \\
\hline Consultancy & $\$$ & $536,544.00$ & (US\$) \\
\hline Financial costs & $\$$ & $536,544.00$ & (US\$) \\
\hline Road construction & $\$$ & $402,408.00$ & $(\mathbf{U S \$})$ \\
\hline Control systems & $\$$ & $134,136.00$ & (US\$) \\
\hline Total Initial Cost & $\$$ & $44,712,000.00$ & (US\$) \\
\hline
\end{tabular}

Table 25 shows the monthly costs for $31.05 \mathrm{MW}$ of electric power corresponding to the new wind farm project.

Table 25: Monthly costs results.

\begin{tabular}{|l|rr|r|}
\hline Monthly Expenses & \multicolumn{4}{|c|}{} \\
\hline Maintenance & $\$$ & $1,341,360.00$ & (US\$)-year \\
\hline Operation & $\$$ & $894,240.00$ & (US\$)-year \\
\hline Replacement Cost & $\$$ & $1,788,480.00$ & (US\$)-year \\
\hline
\end{tabular}

Table 26 summarizes the results of economic evaluation for each of the top three sites from the maximum weight clique. 
Table 26: Results of economic evaluation for Sites 1-3.

\begin{tabular}{|c|c|c|c|}
\hline Site & 1 & 2 & 3 \\
\hline Vertex \# & 82 & 40 & 175 \\
\hline Location & Huacullani & Redencion & Robore \\
\hline Wind speed & $\begin{array}{l}6.919 \mathrm{~m} / \mathrm{s} \\
15.478 \mathrm{Mph}\end{array}$ & $\begin{array}{l}4.897 \mathrm{~m} / \mathrm{s} \\
10.955 \mathrm{Mph}\end{array}$ & $\begin{array}{l}4.354 \mathrm{~m} / \mathrm{s} \\
9.740 \mathrm{Mph}\end{array}$ \\
\hline Annual energy production & 13.261 GWh/gen. & $8.142 \mathrm{GWh} /$ gen. & $6.896 \mathrm{GWh} / \mathrm{gen}$. \\
\hline Total income & $\begin{array}{l}\$ 11,935,137.86 \\
\text { per year }\end{array}$ & $\begin{array}{l}\$ 7,327,830.80 \\
\text { per year }\end{array}$ & $\begin{array}{l}\$ 6,207,059.01 \\
\text { per year }\end{array}$ \\
\hline NPV & $\$ 8,446,767.04$ & $\$(19,203,289.48)$ & $\$(25,929,431.94)$ \\
\hline IRR & $13 \%$ & $3 \%$ & $0 \%$ \\
\hline PBP & 12.079 years & - & - \\
\hline
\end{tabular}

Figure 49, Figure 50, and Figure 51 show the cumulative discounted cash flow in addition to the payback period of the entire project for each of the three considered sites. The detailed yearly calendar for each project can be found in Appendix II.

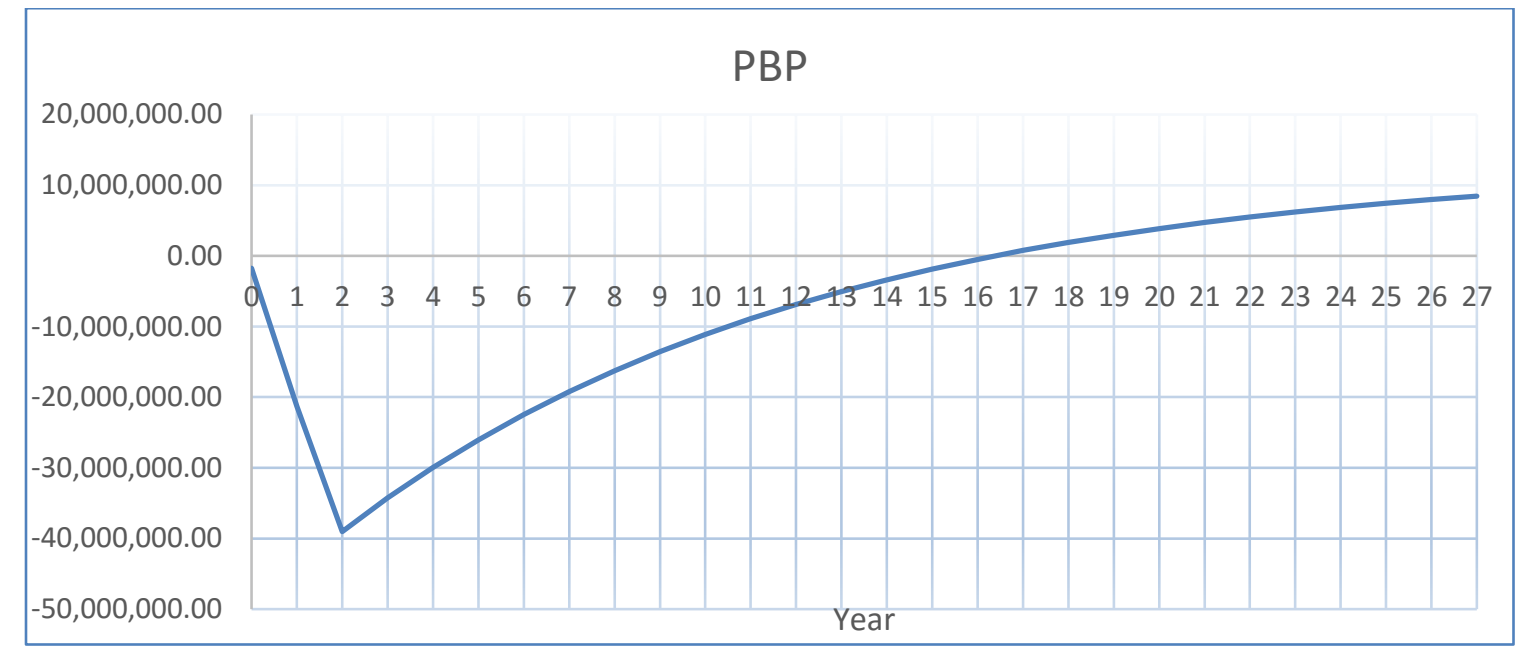

Figure 49: Cumulative discounted cash flow for Site 1. 


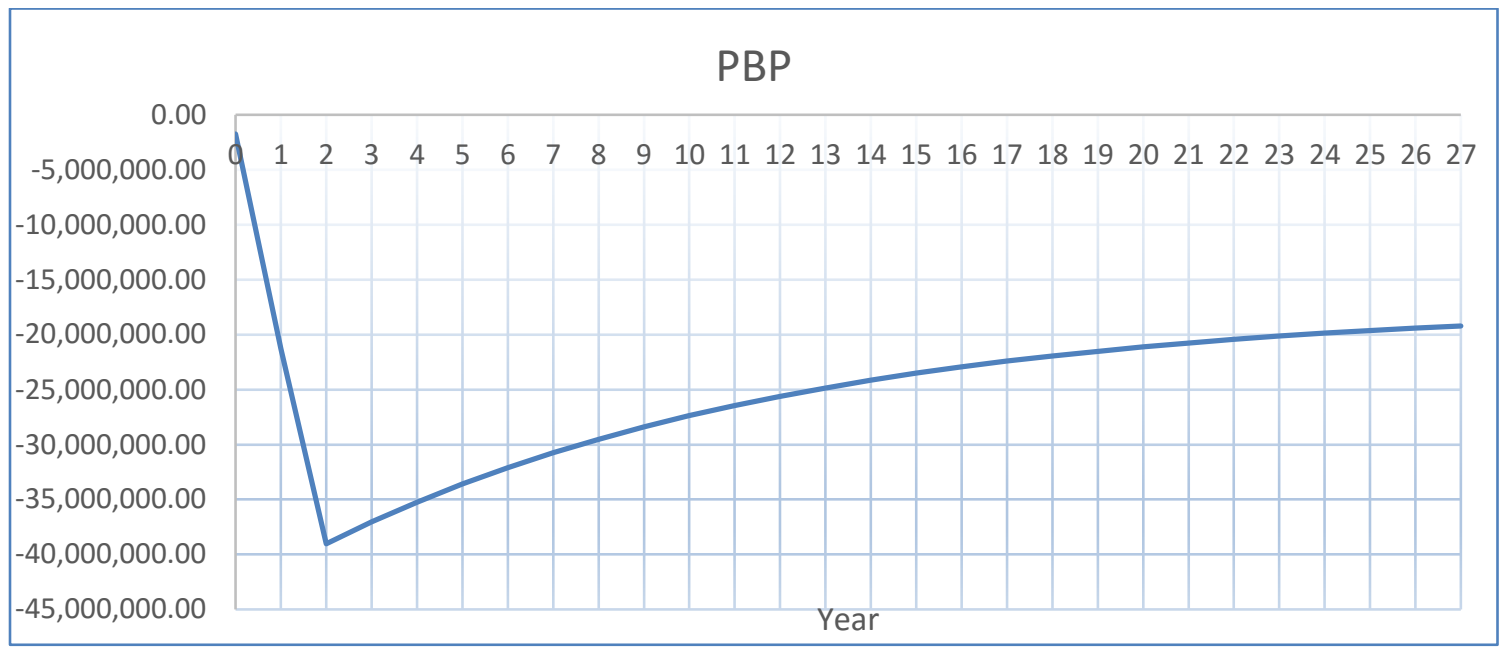

Figure 50: Cumulative discounted cash flow for Site 2.

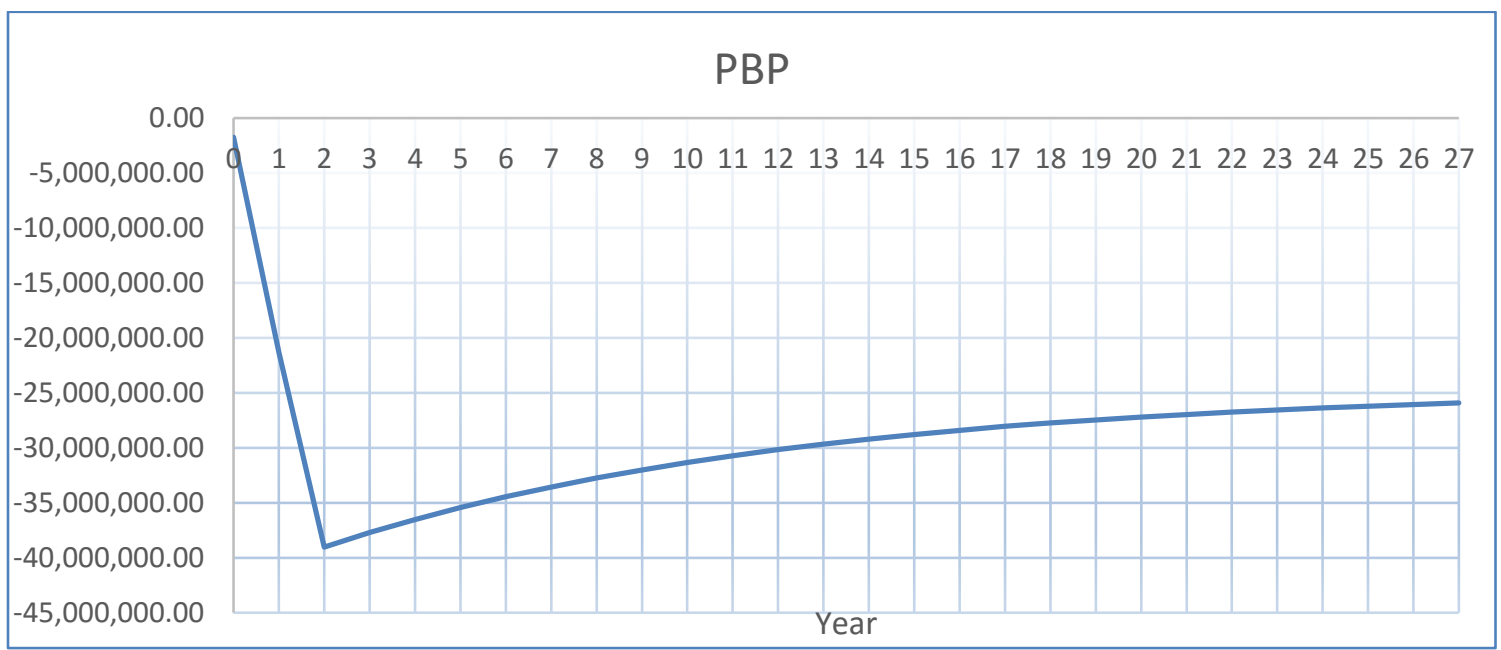

7.5.Results

Figure 51: Cumulative discounted cash flow for Site 3.

Summary of the financial analysis is presented in Table 27.

Table 27: Financial results.

\begin{tabular}{|c|c|c|c|c|}
\hline Location & Indicator & 2MW - 30 MW & $\mathbf{3 . 4 5 M W ~ - 3 1 . 0 5} \mathbf{M W}$ & \multirow{2}{*}{ Wind speed (m/s) } \\
\hline \multirow{2}{*}{ Site 1} & NPV & $\$ 15,862,147.31$ & $\$ 8,446,767.04$ & \multirow{2}{*}{6.919166667} \\
\cline { 2 - 5 } & IRR & $15 \%$ & $13 \%$ & \multirow{2}{*}{4.8975} \\
\hline \multirow{2}{*}{ Site 2} & NPV & $\$(8,479,245.09)$ & $\$(19,203,289.48)$ & \multirow{2}{*}{4.354166667} \\
\cline { 2 - 5 } & IRR & $7 \%$ & $3 \%$ & \\
\hline \multirow{2}{*}{ Site 3 } & NPV & $\$(14,863,625.90)$ & $(25,929,431.94)$ & \\
\cline { 2 - 5 } & IRR & $5 \%$ & $0 \%$ & \\
\hline
\end{tabular}


We observe that the project is profitable only for high wind speeds in the 25-year time frame. In case of lower wind speeds we can see that the project itself has losses for both considered technologies. Financially, the best technology to use is $2 \mathrm{MW}$ turbines, which yield higher profitability in all the sites studied. A major disadvantage of this technology is that we have to ensure a space for the area of the wind turbines, which is 15 generators against 9 generators for the $3 \mathrm{MW}$ technology, which represents a ratio of 5:3.

It is important to mention that for all the cases we considered a replacement cost, which ensures the reinstallation of new wind turbines at the end of the lifetime of each one, without including it in the cash flow again as new investment. This is very important if we want to extend the utility life of the project.

Since in Bolivia the energy sector belongs to the government and there is no chance for private companies to invest in the country, implementing this project could be considered as a social investment, with the government subsidizing all the investment necessary to secure sufficient electrical energy. 


\section{CHAPTER VIII}

\section{CONCLUSIONS AND RECOMMENDATIONS}

\subsection{Conclusions}

In this thesis, we approached the problem of finding optimal locations for wind farms using powerful tools from graph theory, network analysis and optimization. We constructed graphs describing wind speed data measured across Bolivian territory, with the vertices describing the 201 locations used for measurements, and the edges representing correlations of wind speed fluctuations for each pair of locations. In the first case study, the edges in the graph were built based on negative correlations, with two vertices connected by an edge if the correlation of wind speed fluctuations for the corresponding pair of locations is negative. This was done in order to diversify the potential wind energy supplies as much as possible. In the constructed graph, we search for cohesive clusters modeled using the graph-theoretic concepts of clique and $k$-plex. More specifically, we solve unweighted and weighted versions of the maximum clique and maximum $k$-plex problems, with $k=2$ and 3 . We concluded that even though the unweighted versions are helpful in identifying larger set of locations with negatively correlated wind speed fluctuations, the average wind speed in the selected locations is below the overall average. On the other hand, the weighted versions help identifying locations that are not only diverse but are also expected to yield a much higher energy output that an average location in the system. This gives an idea on where the government should install the new wind power plants while supporting the environment for changing the energy matrix, which nowadays depends mostly on fossil fuels, to renewables energies. 
The second topic of our investigation was identifying a small subset of locations that would be a good representative sample of the whole system. We used the classical minimum dominating set problem for this purpose. In this case, the edges in the wind graph were built based on positive correlations, since we want the vertices from the dominating set to represent locations with similar wind profiles rather than diverse ones. We saw that using the minimum dominating set model, we can get a reasonably good approximation of the overall system's behavior with just a few locations.

We have also performed an economical evaluation in order to assess the profitability of a potential wind farm project in different locations suggested by the maximum weight clique solution. We have considered two different alternatives for the types of wind turbines and concluded that the technology that uses $2 \mathrm{MW}$ generators was more economically attractive than the one that uses $3 \mathrm{MW}$. On the other hand, the advantage of the latter option is in that it requires less space than the former one.

\subsection{Recommendations and Future Work}

The approach for selecting wind farm locations proposed in this thesis could be used for other locations. Moreover, it could be extended to other energy sources characterized by high variability, such as solar energy. In this case, we should consider taking into account solar and heat intensity, as well as radiation data for several years measured in different locations.

Concerning the economical study we performed, the companies and stakeholders should be encouraged to develop some type of energy credit for carbon emissions, and the governments may be interested in subsidizing the clean energy production while charging higher taxes on generators that produce $\mathrm{CO} 2$, which contaminates the environment. 
As future work, we can consider calculating the NPV with the developed methodology for every single location and use it as the vertex weight in the wind energy graph. This will ensure that the locations selected by the maximum weight clique, 2-plex, and 3-plex solutions will be profitable.

Finally, it should be pointed out that this thesis focuses only on wind energy, while in reality one deals with energy systems consisting of multiple energy sources and has to balance supplies and demands in this highly heterogeneous and diverse pool of interested parties, while taking into account numerous operational constraints. To design an effective and effective energy system that would be applicable in real life, one needs to take into account a multitude of considerations that were outside of the scope of this thesis, but present an interesting direction for future research. 


\section{REFERENCES}

Bañuelos-Ruedas, F., Rios-Marcuello, S., \& Camacho, C. Á. (2011). Methodologies Used in the Extrapolation of Wind Speed Data at Different Heights and Its Impact in the Wind Energy Resource Assessment in a Region. Wind farmtechnical regulations potential estimation and siting assessment, 97-114.

Beainy, A., Maatouk, C., Moubayed, N., \& Kaddah, F. (2016). Comparison of Different Types of Generator for Wind Energy Conversion System Topologies. Beirut, Lebanon : International Conference on Renewable Energies for Developing Countries (REDEC).

Biggs, N. (1993). Algebraic Graph Theory. Cambridge: Cambridge University Press.

Boginski, V., Butenko, S., \& Pardalos, P. (2003). Modeling and Optimization in Massive Graphs. In: Novel Approaches to Hard Discrete Optimization. American Mathematical Society, 17-39.

Bomze, I. M., Budinich, M., Pardalos, P. M., \& Pelillo, M. (1999). The Maximum Clique Problem. Handbook of Combinatorial Optimization, 1-74.

Bondy, J., \& Murty, U. (2008). Graduate Texts in Mathematics, Graph Theory. Springer.

Borgatti, S. (2000, January). Graph Theory. Retrieved from Social Network Analysis Instructional : http://www.analytictech.com/networks/

Burton, T., Sharpe, D., Jenkins, N., \& Bossanyi, E. (2011). Wind Energy Hand Book. West Sussex: John Wiley \& Sons. 
Butenko, S. (2003). Maximun independent Set and Related Problems, with Applications. Florida: University of Florida.

Caldwell, C. K. (1995). Graph Theory. Retrieved from http://primes.utm.edu/graph/

Cardenas, R., Pena, R., Wheeler, P., Clare, J., \& Asher, G. (2009). Control of the reactive power supplied by a WECS based on an induction generator fed by a matrix converter. IEEE Trans. Ind. Electron, 429-438.

Chakrawarti, P. ,. (2015). Complete Analysis of Doubly Fed Induction Generator Wind Turbine-Maximum Power Tracking Characteristics. International Journal of Electrical and Electronics Research, 12-20.

Cheremushkin, S. (2008). Long-Term Financial Statements Forecasting: Reinvesting Retained Earnings. The Valuation Journal, 46-87.

Cleveland , C. (2004). History of Wind Energy Volumes 1 - 6. Elsevier.

Coleman, T. F., \& Moré, J. J. (1983). Estimation of sparse Jacobian matrices and graph coloring Problems. SIAM Journal on Numerical Analysis 20, 187-209.

Daskin, M., Snyder, L., \& Berger, R. (2003). Facility Location in Supply Chain Design. Department of Industrial Engineering and Management Sciences, Working Paper No. 03-010 .

Diestel, R. (2005). Graph Theory, Graduate Texts in Mathematics. Springer-Verlag. Discovery Education. (2016, December 16). Why Wind Energy is Important. Retrieved from http://scienceofeverydaylife.com/widgets/windenergy/windenergy/data/downloads/wind-teachers-guide.pdf 
Dubois, M. (2004). Optimized permanent magnet generator topologies for direct drive wind turbine. Netherlands: Delft University of Technology.

Dutta, S. (2012). Data mining and graph theory focused solutions to smart grid challenges. Urbana, Illinois: University of Illinois at Urbana-Champaign.

European Wind Energy Association. (2012). Wind Energy - The Facts. London: earthscan.

Fares, R. (2015). Renewable Energy Intermittency Explained: Challenges, Solutions, and Opportunities. Plugged In.

Fayyad, U., Shapiro, G. P., \& Smyth, P. (1996). From data mining to knowledge discovery in databases. AI Magazine, 37-53.

Fernandez, A. (2011). Metodo para localizacion optima de centrales de enegias renovables. Santiago: Universidad de Chile.

Garey, M. R., \& Johnson, D. S. (1979). Computers and Intractability: A Guide to the Theory of NP-Completeness. W. H. Freeman.

GeoBolivia. (2008, January 21). Mapa de energía y velocidad media anual del viento en Bolivia. Retrieved from http://geo.gob.bo/geonetwork/srv/spa/catalog.search\#/metadata/1ab373d2-85eb4171-95e9-c8d954cab457

Gerges, G., Ali, E., Moubayed, N., \& Outbib, R. (2007). L'énergie éolienne au Liban : Bilan annuel, rendement et rentabilité. International Conference on Electromecanical and power systems, 361-366. 
Grady, S., Hussaini, M., \& Abdullah, M. (2005). Placement of wind turbines using genetic algorithms. Renewable Energy, 259-270.

Gross, J. L., \& Yellen, J. (2004). Handbook of graph theory. CRC Press.

Hanneman, R. A., \& Riddle, M. (2005). Introduction to social network methods.

Riverside: University of California. Retrieved from Cliques and sub-groups: http://faculty.ucr.edu/ hanneman/nettext/C11_Cliques.html\#kplex

Hansen, L. H., Helle, L., Blaabjerg, F., Ritchie, E., Munk-Nielsen, S., Bindner, H., . . . Bak-Jensen, B. (2001). Conceptual survey of generators and power electronics for wind turbines. Conceptual survey of generators and power electronics for wind turbines,. Roskilde, Denmark, Tech.

Harary, F. (1962). The determinant of the adjacency matrix of a graph. SIAM Review, 202-210.

Harju, T. (2011). Lecture Notes on Graph Theory. Turku, Finland: University of Turku.

Hasen, L., Blaabjerg, F., Christensen, H., \& Lindhard, U. (2001). Generators and Power electronic Technologies for Wind Turbines. The 27th Annual Conference of the IEEE Industrial Electronics Society. Denver, Colorado. : IECON'O1.

Hayes, B. (2000). Graph Theory in Practice. American Scientist, 9-13 (Part I), 104-109 (Part II).

HSH Nordbank. (2016). Industry study wind energy. HSH Nordbank.

Investopedia. (2017, May 26). Internal Rate Of Return. Retrieved from http://www.investopedia.com/terms/i/irr.asp 
Investopedia. (2017, May 26). Payback period. Retrieved from

http://www.investopedia.com/terms/p/paybackperiod.asp

Investopedia. (2017, May 26). What is 'Net Present Value - $N P V$ '. Retrieved from http://www.investopedia.com/terms/n/npv.asp

IRENA Secretariat. (2012). Wind Power. International Renewable Energy Agency.

Jan, I. (2013). Payback Period. Retrieved from Managerial Accounting:

http://accountingexplained.com/managerial/capital-budgeting/payback-period

Karp, R. M. (1972). Proc. of a Symposium on the Complexity of Computer

Computations. Reducibility Among Combinatorial Problems, 85-103.

Katicaj. (2016, October 12). Molino, Paises Bajos, Kinderdjik. Retrieved from Pixabay: https://pixabay.com/es/molino-pa\%C3\%ADses-bajos-kinderdjik-1734905/

Krohn, S., Morthorst, P.-E., \& Awerbuch, S. (2009). The Economics of Wind Energy. Denmark: Risoe National Laboratory.

Kuhn, F., \& Wattenhofer, R. (2003). Constant-Time Distributed Dominating Set Approximation. Department of Computer Science ETH Zurich.

Lee, A., \& Streinu, I. (2008). Pebble game algorithms and sparse graphs. Discrete Mathematics, 1425-1437.

Legner, P. (2017, January 5). Graph Theory. Retrieved from World of Mathematics: http://world.mathigon.org/Graph_Theory

Li, H., \& Chen, Z. (2008). Overview of different wind generator systems and their comparisons. IET Renew. Power Gener, 123-138. 
Lucas, A. (2006). Wind, Water, Work: Ancient and Medieval Milling Technology. Netherlands: Brill Publishers.

Lykhovyd, E., \& Butenko, S. (2017, January). Russian Doll Search for Computing Maximum Vertex Weight. Department of Industrial and Systems Engineering, pp. 1-10.

Lynn, W. J. (1962). Medieval technology and social change. Oxford, 161-162.

McGranaghan, M. (2010). Making connections: Asset management and the smart grid. IEEE Power and Energy Magazine, 16-22.

Milligan, M., \& Artig, R. (1999). Choosing Wind Power Plant Locations and Sizes Based on Electric Reliability Measures Using Multiple-Year Wind Speed Measurements. Colorado: National Renewable Energy Laboratory.

Moten, J., \& Thron, C. (2013). Improvements on Secant Method for Estimating Internal Rate of Return. International Journal of Applied Mathematics and Statistics, 1242.

Musgrove, P. (2010). Wind Power. Cambridge: Cambridge University Press.

Musial, W., Butterfield, S., \& McNiff, B. (2007). Improving wind turbine gearbox reliability. European Wind Energy Conf.

National Wind Watch, Inc. (2015, December 24). Industrial Wind Power. Retrieved from https://www.wind-watch.org/faq-output.php

Obdam, T., Braam, H., van de Pieterman, R., \& Rademakers, L. (2011). O\&M Cost Estimation \& Feedback of Operational Data. Wind farm - technical regulations, potential estimation and siting assessment, 31-64. 
Pai, M. A. (2006). Computer Techniques in Power System Analysis. New Delhi, India: McGraw-Hill.

Patil, N., \& Bhosle, Y. (2013). A Review on Wind Turbine Generator Topologies. International Conference on Power, Energy and Control, 625-629.

Pexels. (2017, March 28). Energia, Turbinas, Viento. Retrieved from Pixabay: https://pixabay.com/es/energ\%C3\%ADa-turbinas-viento-2181904/

Piacquadio, M., \& De la Barra, A. (2014). Multifractal analysis of wind velocity data. Energy for Sustainable Development, 48-56.

Pinilla S., A. (2003). Manual de aplicación de la energía eólica. Colombia: Instituto de Ciencias Nucleares y Energías Alternativas- INEA. Retrieved from https://previa.uclm.es/profesorado/ajbarbero/FAA/EEOLICA_Febrero2012_G9.p df

Polinde, H., can der Pijl, F. F., de Vilder, G.-J., \& Tavner, P. (2005). Comparison of direct-drive and geared generator concepts for wind turbines. IEEE Int. Conf. Elect. Mach. Drives, 543-550.

Putnam, G. (1948). Power from the Wind',. New York: Van Nostrand Rheinhold.

Randic, M., Novic, M., \& Plavsic, D. (2016). Solved and Unsolved Problems of Structural Chemistry. CRC Press.

Ruohonen, K. (2013). Graph Theory. Translation by Janne Tamminen, Kung-Chung Lee and Robert Piché. 
Ruzzo, L. (2001, October 25). Non-Hierarchical Clustering. Retrieved from Brief Discussion of Graph Theory: https://courses.cs.washington.edu/courses/cse527/01au/oct25/oct25.html

S\&C Electric Company. (2017, January 16). Solutions for Wind Energy . Retrieved from http://www.sandc.com/en/solutions/wind-energy/

Saleh, A. O., \& Laughton, M. A. (1985). Cluster analysis of power-system networks for array. IEE Proceedings.

Sathiyanarayanan, J. S., \& Senthil Kumar, A. (2014). Doubly Fed Induction Generator Wind Turbines with Fuzzy Controller. ScientificWorldJournal, 252-645.

Sathyajith, M. (2006). Wind Energy: Fundamentals, Resource Analysis and Economics. Berlin: Springer Berlin Heidelberg.

Seidman, S., \& Foster, B. (1978). A graph theoretic generalization of the clique concept. J or Math Soc, 139-154. Retrieved from http://www.analytictech.com/ucinet/help/1pdb_fw.htm

Sethuraman, S., \& Butenko, S. (2015). The maximun ratio clique problem. Comput Manag Sci, 197-218.

Shahan, Z. (2012, July 27). Wind Turbine Net Capacity Factor . Retrieved from cleantechnica: https://cleantechnica.com/2012/07/27/wind-turbine-net-capacityfactor-50-the-new-normal/

Skiena, S. (1997). The Algorithm Design Manual. New York: Springer-Verlag.

Solero, L. (2002). Power Electronic converters devoted to stand-alone wind energy generating systems. EPE Journal, 43-48. 
Southwest Power Pool, Inc. (2016, January 5). Wind Integration Study. Retrieved from https://www.spp.org/documents/34200/2016\%20wind\%20integration\%20study\% 20(wis)\%20final.pdf

Statista. (2017). Global electricity prices by select countries. Retrieved from Electricity: https://www.statista.com/statistics/263492/electricity-prices-in-selectedcountries/

Sylvester, J. J. (1878). On an application of the new atomic theory to the graphical representation of the invariants and covariants of binary quantics. American Journal of Mathematics, Pure and Applied, 64-90.

Tavner, P., Xiang, J., \& Spinato, F. (2007). Reliability analysis for wind turbines. Wind Energy, 1-18.

Tocco, H. (2013, December 12). A few guidelines for selecting sites. Retrieved from http://www.windpowerengineering.com/construction/projects/guidelinesselecting-sites/

Touma, J. (1977). Dependence of the wind profile power law on stability for various locations. J. Air Pollution Control Association, 27, 863-866.

Transportadora de Electricidad S.A. (n.d.). Mapa Eolico Republica de Bolivia. Cochabamba: TDE.

Trudeau, R. J. (2012). Introduction to Graph Theory. New York: Dover Pub. Twenergy. (2014, April 30). ¿Como se elige la mejor zona para instalar molinos de viento? Retrieved from https://twenergy.com/a/como-se-elige-la-mejor-zonapara-instalar-molinos-de-viento-1469 
U.S. Departament of Energy. (2016, December 13). Advamtages and Challenges of Wind Energy. Retrieved from Energy Efficiency \& Renewable Energy: https://energy.gov/eere/wind/advantages-and-challenges-wind-energy

U.S. Department of Energy. (2013, August 15). Wind Energy Technology Basics. Retrieved from Renewable Energy: http://energy.gov/eere/energybasics/articles/wind-energy-technology-basics Vaisala. (2017, January 10). Wind and Solar Resource Maps. Retrieved from Power and Energy: http://www.vaisala.com/en/energy/support/Resources/Pages/Free-WindAnd-Solar-Resource-Maps.aspx

van Kuik, G., Peinke, J., Nijssen, R., Lekou, D., Mann, J., Sørensen, J., . . Skytte, K. (2016). Long-term research challenges in wind energy - a research agenda by the European Academy of Wind Energy. Wind Energ. Sci, 1-39.

Vestas. (2017, May 25). 2 MW Platform. Retrieved from vestas.com: http://nozebra.ipapercms.dk/Vestas/Communication/Productbrochure/2MWbroch ure/2MWProductBrochure/

Vestas. (2017, May 24). 3 MW Platform. Retrieved from vestas.com: http://nozebra.ipapercms.dk/Vestas/Communication/Productbrochure/3MWbroch ure/3MWProductBrochure/

Vestas. (2017, May 24). MW platform. Retrieved from https://www.vestas.com/en/products/turbines

Viera da Rosa, A. (2012). Fundamentals of Renewable Energy Processes. Oxford: Academin Press. 
Wind Energy Center. (2010, April 24). Wind Energy Center Alumni and the Early Wind Industry. Retrieved from University of Massachusetts Amherst: http://www.umass.edu/windenergy/about/history/alumni

Wind Energy Foundation. (2016, December 7). History of Wind Energy. Retrieved from http://windenergyfoundation.org/about-wind-energy/history/

Wind Energy the Facts. (2017, January 17). The Importance of the Wind Resource. Retrieved from https://www.wind-energy-the-facts.org/the-importance-of-thewind-resource.html

Wind Power Program. (2017, May 8). Wind turbine power ouput variation with steady wind speed. Retrieved from http://www.wind-powerprogram.com/turbine_characteristics.htm

World Nuclear Association. (2016, December 28). Renewable Energy and Electricity. Retrieved from http://www.world-nuclear.org/information-library/energy-andthe-environment/renewable-energy-and-electricity.aspx

Zhu, J. (2009). Power Systems Applications of Graph Theory. Nova Science Pub. Inc. 


\section{APPENDIX I}


The following table shows the database for the 201 locations studied, representing their coordinates (latitude and longitude), as well as monthly and average yearly wind speed for each location.

Table 28: The list of considered locations, with geographical coordinates and wind speed information.

\begin{tabular}{|c|c|c|c|c|c|c|c|c|c|c|c|c|c|c|c|c|}
\hline \multirow{2}{*}{ \# } & \multirow{2}{*}{ Name } & Lat & Long & Jan & Feb & Ma & Ap & Ma & Jun & Jul & Au & Sep & Oct & No & Dec & Av \\
\hline & & South & West & $\mathrm{m} / \mathrm{s}$ & $\mathrm{m} / \mathrm{s}$ & $\mathbf{m} / \mathbf{s}$ & $\mathbf{m} / \mathbf{s}$ & $\mathbf{m} / \mathbf{s}$ & $\mathbf{m} / \mathbf{s}$ & $\mathbf{m} / \mathbf{s}$ & $\mathbf{m} / \mathbf{s}$ & $\mathbf{m} / \mathbf{s}$ & $\mathrm{m} / \mathrm{s}$ & $\mathrm{m} / \mathrm{s}$ & $\mathrm{m} / \mathrm{s}$ & $\mathrm{m} / \mathrm{s}$ \\
\hline 1 & REYES & $14^{\circ} 19^{\prime}$ & $67^{\circ} 23^{\prime}$ & 2.7 & 2.9 & 2.35 & 2.0 & 2.45 & 2.37 & 2.73 & 2.3 & 3.1 & 3.2 & 2.7 & 3.0 & 2.6 \\
\hline 2 & RIBERALTA & $11^{\circ} 03^{\prime}$ & $66^{\circ} 03^{\prime}$ & 1.8 & 1.8 & 1.8 & 1.6 & 1.7 & 1.54 & 1.72 & 2 & 1.9 & 1.8 & 2.1 & 1.8 & 1.8 \\
\hline 3 & RURRENABAQUE & $14^{\circ} 28^{\prime}$ & $67^{\circ} 29^{\prime}$ & 1.4 & 1.2 & 1.39 & 1.1 & 1.03 & 1.13 & 1.37 & 1.6 & 1.8 & 1.8 & 1.7 & 1.6 & 1.4 \\
\hline 4 & SANB ORJA & $14^{\circ} 52^{\prime}$ & $66^{\circ} 52$ & 2.0 & 2.1 & 2 & 1.5 & 2.06 & 2.01 & 2 & 2.5 & 2.5 & 2.8 & 2.7 & 2.5 & 2.2 \\
\hline 5 & S.1. DEM OXOS & $14^{\circ} 56^{\prime}$ & $65^{\circ} 36$ & 1.8 & 2.1 & 1.8 & 1.5 & 1.8 & 1.75 & 1.87 & 1.8 & 2.2 & 2.2 & 2.2 & 1.9 & 1.9 \\
\hline 6 & SANJOAQUIN & $13^{\circ} 40^{\prime}$ & $64^{\circ} 49^{\prime}$ & 2.5 & 2.4 & 2.26 & 2.1 & 2.29 & 2.17 & 2.46 & 2.3 & 2.7 & 2.6 & 2.7 & 2.5 & 2.4 \\
\hline 7 & SANR AMON & $13^{\circ} 18^{\prime}$ & $64^{\circ} 43$ & 2.8 & 2.6 & 2.52 & 2.0 & 2.16 & 1.85 & 2.23 & 2.2 & 2.7 & 2.8 & 2.7 & 2.6 & 2.4 \\
\hline 8 & SANATNA A & $13^{\circ} 46^{\prime}$ & $65^{\circ} 26^{\prime}$ & 4.6 & 4.2 & 3.95 & 2.8 & 3.78 & 3.89 & 4.12 & 4.4 & 5.0 & 4.5 & 4.5 & 4.7 & 4.2 \\
\hline 9 & TRINIDMASADN A & $14^{\circ} 19^{\prime}$ & $64^{\circ} 54^{\prime}$ & 2.5 & 2.9 & 2.83 & 2.5 & 2.63 & 2.64 & 2.7 & 2.9 & 3.2 & 3.4 & 3.2 & 2.7 & 2.8 \\
\hline 10 & AIQUILE & $18^{\circ} 12^{\prime}$ & $65^{\circ} 10^{\prime}$ & 0.5 & 0.6 & 0.65 & 0.6 & 0.76 & 0.84 & 0.84 & 0.7 & 0.6 & 0.6 & 0.6 & 0.6 & 0.7 \\
\hline 11 & ANZALDO & $17^{\circ} 47^{\prime}$ & $65^{\circ} 55^{\prime}$ & 1.0 & 1.0 & 0.56 & 0.8 & 1.13 & 0.94 & 0.56 & 0.7 & 0.7 & 0.7 & 0.7 & 0.6 & 0.8 \\
\hline 12 & CAPINOTA & $17^{\circ} 42^{\prime}$ & $66^{\circ} 15^{\prime}$ & 0.5 & 0.6 & 0.64 & 0.7 & 0.62 & 0.78 & 0.76 & 0.7 & 0.7 & 0.6 & 0.7 & 0.7 & 0.6 \\
\hline 13 & CBB-AA ASANA & $17^{\circ} 24^{\prime}$ & $66^{\circ} 10^{\prime}$ & 1.2 & 1.5 & 1.03 & 0.8 & 0.74 & 0.71 & 1.03 & 1.6 & 2.3 & 2.2 & 2.2 & 1.8 & 1.4 \\
\hline 14 & CHIPIRIRI & $16^{\circ} 52^{\prime}$ & $65^{\circ} 28^{\prime}$ & 1.2 & 1.5 & 1.04 & 0.8 & 0.75 & 0.72 & 1.04 & 1.6 & 2.3 & 2.3 & 2.3 & 1.9 & 1.4 \\
\hline 15 & INDEPENDENCIA & $17^{\circ} 07^{\prime \prime}$ & $66^{\circ} 52$ & 0.5 & 0.5 & 0.56 & 0.5 & 0.56 & 0.56 & 0.56 & 0.5 & 0.6 & 0.7 & 0.5 & 0.5 & 0.5 \\
\hline 16 & MIZQMUAEY RA & $17^{\circ} 55^{\prime}$ & $65^{\circ} 21^{\prime}$ & 2.1 & 2.4 & 2.75 & 2.7 & 2.45 & 2.45 & 2.63 & 3.1 & 3.2 & 3.2 & 2.8 & 2.6 & 2.7 \\
\hline 17 & MOOROCHATA & $17^{\circ} 13^{\prime}$ & $66^{\circ} 49^{\prime}$ & 0.5 & 0.5 & 0.56 & 0.5 & 0.56 & 0.56 & 0.56 & 0.5 & 0.5 & 0.6 & 0.5 & 0.5 & 0.5 \\
\hline 18 & POJO & $17^{\circ} 45^{\prime}$ & $64^{\circ} 49^{\prime}$ & 1.8 & 2.3 & 1.77 & 2.1 & 2.58 & 2.89 & 3.86 & 3.4 & 3.7 & 3.4 & 2.4 & 2.6 & 2.7 \\
\hline 19 & SACABA & $17^{\circ} 26^{\prime}$ & $66^{\circ} 01^{\prime}$ & 1.5 & 1.2 & 1.27 & 1.8 & 1.69 & 1.56 & 1.27 & 2.3 & 2.4 & 2.8 & 2.3 & 1.5 & 1.8 \\
\hline 20 & SANB ENITO & $17^{\circ} 31^{\prime}$ & $65^{\circ} 54^{\prime}$ & 1.2 & 1.5 & 1.69 & 1.8 & 1.62 & 1.69 & 2.74 & 2.0 & 3.2 & 2.5 & 2.4 & 1.8 & 2.0 \\
\hline 21 & TAMBORADA & $17^{\circ} 26^{\prime}$ & $66^{\circ} 08^{\prime}$ & 0.5 & 0.5 & 0.56 & 0.5 & 0.56 & 0.56 & 1.13 & 0.5 & 0.5 & 0.5 & 0.5 & 0.5 & 0.6 \\
\hline 22 & TARTAA & $17^{\circ} 36^{\prime}$ & $66^{\circ} 01^{\prime}$ & 0.4 & 0.4 & 0.49 & 0.7 & 1 & 1.23 & 1.26 & 1.3 & 1.4 & 1.5 & 1.9 & 0.7 & 1.0 \\
\hline 23 & TIRAQ'AU"E & $17^{\circ} 25^{\prime}$ & $65^{\circ} 43^{\prime}$ & 0.5 & 0.5 & 0.56 & 0.5 & 0.56 & 0.56 & 1.13 & 0.5 & 0.8 & 0.5 & 0.5 & 0.5 & 0.6 \\
\hline 24 & TOTORA & $17^{\circ} 41^{\prime}$ & $65^{\circ} 09^{\prime}$ & 1.1 & 1.1 & 1.13 & 0.5 & 0.56 & 0.56 & 1.13 & 1.4 & 1.6 & 1.8 & 0.5 & 1.1 & 1.0 \\
\hline 25 & VILLTAU NARI & $16^{\circ} 56$ & $65^{\circ} 24^{\prime}$ & 1.6 & 1.6 & 1.69 & 1.6 & 1.69 & 2.26 & 1.69 & 1.6 & 2.2 & 3.9 & 3.9 & 0.5 & 2.0 \\
\hline 26 & VINTO & $17^{\circ} 25^{\prime}$ & $66^{\circ} 19$ & 0.5 & 0.5 & 0.56 & 2.1 & 0.56 & 0.56 & 0.56 & 0.7 & 0.7 & 0.5 & 0.5 & 0.5 & 0.7 \\
\hline 27 & J.MOLINO- & $17^{\circ} 39^{\prime}$ & $65^{\circ} 27^{\prime}$ & 4.1 & 3.7 & 0.6 & 2.9 & 2.2 & 4.2 & 7.1 & 6.7 & 7.7 & 6.2 & 6.2 & 3.9 & 4.6 \\
\hline 28 & AZURDUY & $20^{\circ} 06^{\prime}$ & $64^{\circ} 24$ & 2.8 & 2.8 & 2.98 & 3.0 & 2.68 & 2.71 & 3.02 & 2.9 & 3.6 & 3.6 & 3.9 & 3.2 & 3.1 \\
\hline
\end{tabular}




\begin{tabular}{|c|c|c|c|c|c|c|c|c|c|c|c|c|c|c|c|c|}
\hline \multirow{2}{*}{ \# } & \multirow{2}{*}{ Name } & Lat & Long & Jan & Feb & Ma & Ap & Ma & Jun & Jul & $\mathbf{A u}$ & Sep & Oct & No & Dec & Av \\
\hline & & South & West & $\mathbf{m} / \mathbf{s}$ & $\mathbf{m} / \mathbf{s}$ & $\mathbf{m} / \mathbf{s}$ & $\mathbf{m} / \mathbf{s}$ & $\mathbf{m} / \mathbf{s}$ & $\mathbf{m} / \mathbf{s}$ & $\mathbf{m} / \mathbf{s}$ & $\mathbf{m} / \mathbf{s}$ & $\mathbf{m} / \mathbf{s}$ & $\mathbf{m} / \mathbf{s}$ & $\mathbf{m} / \mathbf{s}$ & $\mathbf{m} / \mathbf{s}$ & $\mathbf{m} / \mathbf{s}$ \\
\hline 29 & CACHIM & $19^{\circ} 08^{\prime}$ & $65^{\circ} 16$ & 0.6 & 0.6 & 0.69 & 0.6 & 0.66 & 0.79 & 0.96 & 0.9 & 0.7 & 0.8 & 0.7 & 0.6 & 0.7 \\
\hline 30 & CULPINA & $20^{\circ} 49^{\prime}$ & $64^{\circ} 56^{\prime}$ & 1.7 & 1.5 & 1.66 & 3.9 & 2.08 & 2.05 & 2.19 & 2.2 & 1.8 & 1.8 & 1.8 & 1.2 & 2.0 \\
\hline 31 & CHILCARA & $21^{\circ} 01^{\prime}$ & $64^{\circ} 56^{\prime}$ & 3.7 & 3.1 & 3.4 & 3.3 & 1.64 & 0.86 & 1.28 & 1.5 & 2.3 & 3.1 & 4.4 & 3.9 & 2.7 \\
\hline 32 & CHUQUI CHUQUI & $18^{\circ} 49^{\prime}$ & $65^{\circ} 03$ & 1.0 & 0.9 & 0.94 & 0.8 & 0.94 & 0.99 & 0.99 & 1.3 & 1.5 & 1.6 & 1.4 & 1.2 & 1.1 \\
\hline 33 & EL SALVADOR & $20^{\circ} 37^{\prime}$ & $63^{\circ} 10$ & 4.2 & 4.3 & 4.57 & 4.3 & 3.9 & 4.35 & 4.94 & 6.4 & 5.4 & 6.5 & 5.1 & 4.8 & 4.9 \\
\hline 34 & EL VILLAR & $19^{\circ} 37^{\prime}$ & $64^{\circ} 18$ & 0.3 & 0.3 & 0.31 & 0.3 & 0.31 & 0.41 & 0.41 & 0.4 & 0.4 & 0.1 & 0.3 & 0.3 & 0.3 \\
\hline 35 & INCAHUASI & $20^{\circ} 46^{\prime}$ & $64^{\circ} 52$ & 1.8 & 1.9 & 1.94 & 2.0 & 2.32 & 2.28 & 2.59 & 2.3 & 2.7 & 2.8 & 1.9 & 2.0 & 2.2 \\
\hline 36 & LA TORRE & $20^{\circ} 36^{\prime}$ & $65^{\circ} 08$ & 1.1 & 1.1 & 1 & 0.8 & 0.82 & 0.87 & 0.91 & 1.0 & 1.3 & 1.6 & 1.6 & 1.3 & 1.1 \\
\hline 37 & MONTEAGUDO & $19^{\circ} 46^{\prime}$ & $63^{\circ} 57$ & 0.7 & 0.8 & 0.78 & 0.8 & 0.61 & 0.87 & 0.95 & 1.0 & 1.2 & 0.9 & 1.0 & 0.8 & 0.9 \\
\hline 38 & MUYAPAMPA & $19^{\circ} 52^{\prime}$ & $63^{\circ} 46^{\prime}$ & 0.9 & 0.9 & 1 & 1.1 & 1.09 & 1.01 & 1.11 & 1.2 & 1.2 & 1.2 & 1.0 & 0.8 & 1.0 \\
\hline 39 & PADILLA & $19^{\circ} 18^{\prime}$ & $64^{\circ} 18$ & 0.7 & 0.7 & 0.7 & 0.7 & 0.76 & 0.86 & 0.86 & 1.0 & 1.0 & 1.0 & 1.0 & 0.9 & 0.8 \\
\hline 40 & REDENCION & $18^{\circ} 49^{\prime}$ & $64^{\circ} 36^{\prime}$ & 4.5 & 4.6 & 4.74 & 4.8 & 4.92 & 4.92 & 4.85 & 4.9 & 5.0 & 5.2 & 5 & 5.0 & 4.9 \\
\hline 41 & SAN LUCAS & $20^{\circ} 05^{\prime}$ & $65^{\circ} 08$ & 1.8 & 1.9 & 2.01 & 2.2 & 2.17 & 2.66 & 3.25 & 2.6 & 2.8 & 2.7 & 2.2 & 2.2 & 2.4 \\
\hline 42 & SAR ROQUE & $20^{\circ} 46^{\prime}$ & $65^{\circ} 13$ & 0.7 & 0.8 & 0.84 & 0.8 & 0.99 & 0.84 & 0.89 & 0.8 & 0.8 & 0.7 & 0.8 & 0.8 & 0.8 \\
\hline 43 & SUCRE AASANA & $19^{\circ} 00^{\prime}$ & $65^{\circ} 17$ & 1.9 & 1.8 & 2 & 2.2 & 1.99 & 1.76 & 2.35 & 2.5 & 2.8 & 2.7 & 2.6 & 2.5 & 2.2 \\
\hline 44 & SUCRE SENAMHI & $19^{\circ} 03^{\prime}$ & $65^{\circ} 17$ & 1.4 & 1.5 & 1.56 & 1.9 & 1.77 & 1.56 & 1.58 & 1.9 & 2.0 & 1.9 & 2.0 & 1.8 & 1.7 \\
\hline 45 & TALULA & $19^{\circ} 05^{\prime}$ & $65^{\circ} 24^{\prime}$ & 0.6 & 0.7 & 0.73 & 0.9 & 1.03 & 1.13 & 1.13 & 1.2 & 1.3 & 1.4 & 1.2 & 1.1 & 1.0 \\
\hline 46 & TARABUCO & $19^{\circ} 10^{\prime}$ & $64^{\circ} 54$ & 1.1 & 1.0 & 0.87 & 1.2 & 1.72 & 1.4 & 1.62 & 1.4 & 1.3 & 1.2 & 1.2 & 1.3 & 1.3 \\
\hline 47 & TARBITA & $19^{\circ} 51^{\prime}$ & $64^{\circ} 24^{\prime}$ & 1.6 & 1.8 & 1.78 & 1.9 & 2.31 & 2.59 & 2.49 & 2.4 & 2.4 & 2.6 & 2.3 & 2.1 & 2.2 \\
\hline 48 & VILLA SERRANO & $19^{\circ} 07^{\prime}$ & $64^{\circ} 19^{\prime}$ & 0.9 & 0.9 & 0.98 & 1.0 & 1.1 & 1.22 & 1.16 & 1.3 & 1.2 & 1.1 & 1.0 & 0.9 & 1.0 \\
\hline 49 & VINA QUEMADA & $19^{\circ} 24^{\prime}$ & $64^{\circ} 51^{\prime}$ & 1.5 & 1.2 & 1.48 & 1.6 & 1.44 & 1.57 & 1.98 & 2.5 & 2.4 & 2.3 & 2.1 & 1.7 & 1.8 \\
\hline 50 & YOTALA & $19^{\circ} 09^{\prime}$ & $65^{\circ} 15^{\prime}$ & 1.3 & 1.3 & 1.34 & 1.4 & 1.22 & 1.18 & 1.1 & 1.6 & 1.8 & 2.0 & 1.8 & 1.6 & 1.5 \\
\hline 51 & ZUDANEZ & $19^{\circ} 07^{\prime}$ & $64^{\circ} 42^{\prime}$ & 2.9 & 2.8 & 2.71 & 2.8 & 2.85 & 2.85 & 2.8 & 2.8 & 2.1 & 2.8 & 2.8 & 2.8 & 2.7 \\
\hline 52 & ACHIRI & $17^{\circ} 13^{\prime}$ & $69^{\circ} 00^{\prime}$ & 1.6 & 1.4 & 1.35 & 1.2 & 1.48 & 1.36 & 1.86 & 1.8 & 3.3 & 2.4 & 2.5 & 2.1 & 1.8 \\
\hline 53 & ACHUMANI & $16^{\circ} 31^{\prime}$ & $68^{\circ} 04^{\prime}$ & 2.5 & 2.5 & 2.54 & 2.6 & 2.99 & 2.99 & 2.65 & 2.7 & 2.7 & 2.7 & 2.8 & 2.7 & 2.7 \\
\hline 54 & ALCOCHE & $15^{\circ} 44^{\prime}$ & $67^{\circ} 40^{\prime}$ & 4.5 & 4.5 & 2.82 & 2.2 & 2.26 & 2.54 & 3.67 & 3.3 & 3.6 & 3.3 & 3.9 & 3.6 & 3.3 \\
\hline 55 & APOALOA SANA & $14^{\circ} 44^{\prime}$ & $68^{\circ} 32^{\prime}$ & 1.5 & 1.8 & 1.72 & 1.8 & 2.29 & 2.52 & 2.19 & 2.5 & 2.5 & 2.2 & 2.1 & 1.8 & 2.1 \\
\hline 56 & APOSLEON AMHI & $14^{\circ} 43^{\prime}$ & $68^{\circ} 31^{\prime}$ & 2.0 & 2.1 & 1.82 & 2.0 & 2.26 & 2.2 & 2.51 & 2.6 & 2.6 & 2.4 & 2.0 & 2.3 & 2.2 \\
\hline 57 & ASUNTA & $16^{\circ} 02^{\prime}$ & $67^{\circ} 14^{\prime}$ & 1.6 & 1.4 & 0.56 & 1.4 & 1.13 & 0.23 & 0.6 & 0.7 & 0.6 & 0.7 & 0.5 & 0.5 & 0.8 \\
\hline 58 & AYAOY O & $17^{\circ} 06^{\prime}$ & $68^{\circ} 00^{\prime}$ & 4.7 & 4.7 & 4.27 & 4.1 & 4 & 3.95 & 4.86 & 5.1 & 6.2 & 5.3 & 4.9 & 4.9 & 4.7 \\
\hline 59 & CALACOTO & $17^{\circ} 17^{\prime}$ & $68^{\circ} 38^{\prime}$ & 3.6 & 2.9 & 3.03 & 2.5 & 2.77 & 2.93 & 2.57 & 3.3 & 4.2 & 3.6 & 3.4 & 3.6 & 3.2 \\
\hline 60 & CAMATA & $15^{\circ} 10^{\prime}$ & $68^{\circ} 46^{\prime}$ & 0.9 & 0.1 & 1.02 & 1.2 & 1.41 & 1.41 & 1.29 & 1.2 & 1.3 & 1.3 & 1.4 & 1.1 & 1.1 \\
\hline 61 & CAQUIAVIRI & $17^{\circ} 01^{\prime}$ & $68^{\circ} 36^{\prime}$ & 5.2 & 4.6 & 4.86 & 4.5 & 6.26 & 6.89 & 6.66 & 7.3 & 6.7 & 6.1 & 5.8 & 5.5 & 5.8 \\
\hline 62 & CARANAVI & $15^{\circ} 49^{\prime}$ & $67^{\circ} 34^{\prime}$ & 2.1 & 2.6 & 2.92 & 2.9 & 2.71 & 3.02 & 3.2 & 3.1 & 2.9 & 3.0 & 3.2 & 2.9 & 2.8 \\
\hline 63 & CARABUCO & $15^{\circ} 45^{\prime}$ & $69^{\circ} 10^{\prime}$ & 4.3 & 4.4 & 3.95 & 4 & 3.05 & 2.99 & 3.73 & 4.4 & 5.3 & 5.3 & 4.7 & 4.5 & 4.2 \\
\hline 64 & CENTRLAP LA Z & $16^{\circ} 30^{\prime}$ & $68^{\circ} 07^{\prime}$ & 2.4 & 2.6 & 2.54 & 2.5 & 2.68 & 2.5 & 2.14 & 2.8 & 2.7 & 2.1 & 3.0 & 2.8 & 2.5 \\
\hline
\end{tabular}




\begin{tabular}{|c|c|c|c|c|c|c|c|c|c|c|c|c|c|c|c|c|}
\hline \multirow{2}{*}{ \# } & \multirow{2}{*}{ Name } & Lat & Long & Jan & Feb & Ma & Ap & Ma & Jun & Jul & Au & Sep & Oct & No & Dec & Av \\
\hline & & South & West & $\mathbf{m} / \mathbf{s}$ & $\mathbf{m} / \mathbf{s}$ & $\mathbf{m} / \mathbf{s}$ & $\mathbf{m} / \mathbf{s}$ & $\mathbf{m} / \mathbf{s}$ & $\mathbf{m} / \mathbf{s}$ & $\mathbf{m} / \mathbf{s}$ & $\mathbf{m} / \mathbf{s}$ & $\mathbf{m} / \mathbf{s}$ & $\mathbf{m} / \mathbf{s}$ & $\mathbf{m} / \mathbf{s}$ & $\mathbf{m} / \mathbf{s}$ & $\mathbf{m} / \mathbf{s}$ \\
\hline 65 & COLLANA & $16^{\circ} 54^{\prime}$ & $68^{\circ} 17^{\prime}$ & 1.3 & 1.2 & 1.2 & 1.3 & 1.75 & 1.58 & 1.97 & 1.9 & 2.1 & 1.8 & 1.9 & 1.8 & 1.6 \\
\hline 66 & COPACABANA & $16^{\circ} 09^{\prime}$ & $69^{\circ} 05^{\prime}$ & 1.2 & 1.4 & 1.18 & 1.2 & 1.2 & 1.41 & 1.29 & 1.4 & 1.5 & 1.6 & 1.5 & 1.4 & 1.3 \\
\hline 67 & COPACATI & $16^{\circ} 12^{\prime}$ & $69^{\circ} 05^{\prime}$ & 1.3 & 1.3 & 1.45 & 1.1 & 1.13 & 1.56 & 1.41 & 1.8 & 1.4 & 1.5 & 1.5 & 1.5 & 1.4 \\
\hline 68 & COPAN CARA & $16^{\circ} 13^{\prime}$ & $68^{\circ} 39^{\prime}$ & 3.3 & 3.6 & 3.62 & 3.5 & 2.86 & 3.34 & 3.67 & 4.2 & 4.2 & 3.6 & 3.9 & 3.3 & 3.6 \\
\hline 69 & CORIPATA & $16^{\circ} 18^{\prime}$ & $67^{\circ} 36^{\prime}$ & 1.2 & 1.4 & 1.29 & 1.4 & 1.55 & 1.47 & 1.47 & 1.5 & 1.4 & 1.3 & 1.7 & 1.4 & 1.4 \\
\hline 70 & CATACORA & $17^{\circ} 12^{\prime}$ & $69^{\circ} 27^{\prime}$ & 4.2 & 3.6 & 4.06 & 4.3 & 5.08 & 6.15 & 6.21 & 5.9 & 5.7 & 5.6 & 4.8 & 4.9 & 5.0 \\
\hline 71 & COROICO & $16^{\circ} 14^{\prime}$ & $67^{\circ} 42^{\prime}$ & 1.0 & 0.7 & 0.79 & 0.6 & 0.79 & 1.24 & 1.24 & 0.8 & 1.1 & 0.9 & 1.1 & 0.9 & 0.9 \\
\hline 72 & CHACALTAYA & $16^{\circ} 21^{\prime}$ & $68^{\circ} 08^{\prime}$ & 1.5 & 1.3 & 1.41 & 1.2 & 1.67 & 1.83 & 1.4 & 1.6 & 1.2 & 1.3 & 1.2 & 0.9 & 1.4 \\
\hline 73 & CHARAÑA & $17^{\circ} 35^{\prime}$ & $69^{\circ} 27^{\prime}$ & 2.5 & 2.4 & 2.68 & 2.6 & 3.04 & 2.62 & 2.75 & 2.3 & 3.3 & 3.3 & 3.1 & 2.4 & 2.7 \\
\hline 74 & CHOROCONA & $16^{\circ} 56^{\prime}$ & $67^{\circ} 10^{\prime}$ & 5.9 & 5.5 & 6.32 & 6.2 & 6.55 & 6.32 & 6.38 & 6.2 & 6.1 & 6.3 & 6.1 & 6.1 & 6.1 \\
\hline 75 & CHIRAPACA & $16^{\circ} 17^{\prime}$ & $68^{\circ} 35^{\prime}$ & 1.2 & 1.2 & 1.49 & 1.6 & 1.5 & 1.41 & 1.79 & 2.0 & 2.0 & 1.9 & 1.8 & 1.7 & 1.6 \\
\hline 76 & CHULUMANI & $16^{\circ} 20^{\prime}$ & $67^{\circ} 30^{\prime}$ & 0.5 & 0.5 & 1.13 & 0.5 & 1.41 & 0.94 & 0.94 & 0.8 & 1.0 & 0.9 & 0.7 & 0.9 & 0.8 \\
\hline 77 & CHUMA & $15^{\circ} 42^{\prime}$ & $68^{\circ} 54^{\prime}$ & 1.7 & 1.6 & 1.13 & 1.5 & 1.56 & 1.81 & 1.47 & 3.2 & 2.1 & 3.1 & 2.4 & 2.0 & 1.9 \\
\hline 78 & DESAGUADERO & $16^{\circ} 34^{\prime}$ & $69^{\circ} 03^{\prime}$ & 1.6 & 1.3 & 1.23 & 1.2 & 1.13 & 1.6 & 1.79 & 1.9 & 1.5 & 1.4 & 1.5 & 1.8 & 1.5 \\
\hline 79 & EL ALTO & $16^{\circ} 31^{\prime}$ & $68^{\circ} 13^{\prime}$ & 3.6 & 3.4 & 3.37 & 3.5 & 3.37 & 3.72 & 4.37 & 3.9 & 4.1 & 3.9 & 3.7 & 3.8 & 3.7 \\
\hline 80 & EL BELEN & $16^{\circ} 04^{\prime}$ & $68^{\circ} 40^{\prime}$ & 2.8 & 2.7 & 2.48 & 2.3 & 2.01 & 1.92 & 2.2 & 2.6 & 3.0 & 3.1 & 2.9 & 2.7 & 2.5 \\
\hline 81 & HICHUCOTA & $16^{\circ} 10^{\prime}$ & $68^{\circ} 22^{\prime}$ & 2.6 & 2.8 & 2.7 & 2.4 & 1.36 & 2.58 & 2.4 & 3.6 & 4.1 & 4.2 & 3.9 & 2.9 & 3.0 \\
\hline 82 & HUACULLANI & $16^{\circ} 28^{\prime}$ & $68^{\circ} 44^{\prime}$ & 6.7 & 7.3 & 6.78 & 6.7 & 6.21 & 6.78 & 6.78 & 9.0 & 6.7 & 6.2 & 6.7 & 6.7 & 6.9 \\
\hline 83 & HUARACO & $17^{\circ} 21^{\prime}$ & $67^{\circ} 39^{\prime}$ & 5.5 & 5.2 & 5.02 & 5.1 & 4.4 & 4.97 & 5.42 & 6.1 & 7.1 & 6.4 & 5.9 & 6.4 & 5.6 \\
\hline 84 & HUARINA & $16^{\circ} 12^{\prime}$ & $68^{\circ} 38^{\prime}$ & 4.5 & 4.1 & 3.83 & 3.8 & 3.55 & 3.03 & 3.66 & 4.2 & 5.4 & 5.4 & 5.0 & 4.4 & 4.2 \\
\hline 85 & HUATAIATA & $16^{\circ} 13^{\prime}$ & $68^{\circ} 42^{\prime}$ & 1.1 & 1.0 & 1.03 & 1.0 & 1.13 & 1.23 & 0.9 & 1.4 & 1.3 & 1.6 & 1.1 & 1.1 & 1.1 \\
\hline 86 & HUMAPALCA & $16^{\circ} 43^{\prime}$ & $67^{\circ} 25^{\prime}$ & 1.5 & 1.5 & 1.69 & 2.6 & 2.54 & 1.83 & 2.54 & 1.9 & 1.8 & 2.2 & 2.1 & 1.6 & 2.0 \\
\hline 87 & HUAYROCONDO & $16^{\circ} 21^{\prime}$ & $68^{\circ} 39^{\prime}$ & 2.8 & 2.6 & 2.57 & 2.3 & 2.2 & 2.32 & 2.94 & 3.3 & 3.5 & 3.3 & 3.0 & 2.8 & 2.8 \\
\hline 88 & IRPA CHICO & $16^{\circ} 44^{\prime}$ & $68^{\circ} 22^{\prime}$ & 4.9 & 4.6 & 4.74 & 4.6 & 4.52 & 4.52 & 4.74 & 5.4 & 5.4 & 5.3 & 5.3 & 4.5 & 4.9 \\
\hline 89 & IRUPANA & $16^{\circ} 28^{\prime}$ & $67^{\circ} 25^{\prime}$ & 2.2 & 2.1 & 2.31 & 2.6 & 2.36 & 2.31 & 2.41 & 2.3 & 2.3 & 2.4 & 2.7 & 2.6 & 2.4 \\
\hline 90 & ISLA DEL SOL & $16^{\circ} 10^{\prime}$ & $69^{\circ} 09^{\prime}$ & 1.5 & 1.5 & 1.56 & 1.4 & 1.41 & 1.38 & 1.61 & 1.5 & 1.6 & 1.3 & 1.4 & 1.5 & 1.5 \\
\hline 91 & IXIAMAS & $13^{\circ} 46^{\prime}$ & $68^{\circ} 08^{\prime}$ & 3.2 & 2.2 & 1.97 & 2.4 & 1.97 & 2.63 & 2.48 & 2.2 & 2.8 & 2.6 & 2.2 & 2.4 & 2.4 \\
\hline 92 & LURIBAY & $17^{\circ} 09^{\prime}$ & $67^{\circ} 40^{\prime}$ & 3.3 & 3.5 & 3.51 & 3.5 & 3.67 & 3.73 & 3.61 & 3.6 & 3.9 & 3.6 & 4 & 4 & 3.6 \\
\hline 93 & MINACHI & $16^{\circ} 10^{\prime}$ & $67^{\circ} 43^{\prime}$ & 1.2 & 1.3 & 1.13 & 1.3 & 1.58 & 1.36 & 1.24 & 1.3 & 1.1 & 1.2 & 1.0 & 1.1 & 1.2 \\
\hline 94 & PALCA & $16^{\circ} 34^{\prime}$ & $67^{\circ} 59^{\prime}$ & 1.0 & 1.2 & 1.03 & 1.0 & 1.13 & 1.13 & 2.07 & 2.3 & 2.4 & 2.1 & 1.9 & 1.8 & 1.6 \\
\hline 95 & PATACAMAYA & $17^{\circ} 15^{\prime}$ & $67^{\circ} 57^{\prime}$ & 3.5 & 2.9 & 3.39 & 3.4 & 2.82 & 3.1 & 3.61 & 3.6 & 3.5 & 3.9 & 3.5 & 3.7 & 3.4 \\
\hline 96 & PELECHUCO & $14^{\circ} 49^{\prime}$ & $69^{\circ} 05^{\prime}$ & 1.6 & 1.6 & 1.69 & 1.5 & 1.59 & 1.69 & 1.59 & 1.5 & 1.6 & 1.7 & 1.5 & 1.5 & 1.6 \\
\hline 97 & PUERTO AGOSTA & $15^{\circ} 31^{\prime}$ & $69^{\circ} 15^{\prime}$ & 2.0 & 2.0 & 2.01 & 1.9 & 1.81 & 1.5 & 1.82 & 2.4 & 2.7 & 2.2 & 2.2 & 1.9 & 2.0 \\
\hline 98 & S. ANA DE & $15^{\circ} 53^{\prime}$ & $67^{\circ} 33^{\prime}$ & 0.7 & 1.1 & 1.13 & 0.7 & 0.89 & 0.72 & 0.88 & 0.9 & 0.8 & 1.0 & 0.8 & 0.8 & 0.9 \\
\hline 99 & S. JUAN & $16^{\circ} 35^{\prime}$ & $68^{\circ} 58^{\prime}$ & 3.8 & 3.8 & 3.83 & 3.3 & 3.51 & 3.53 & 3.76 & 4.5 & 5.2 & 5.2 & 5.0 & 4.9 & 4.2 \\
\hline 100 & SANTIAGO DE & $16^{\circ} 03^{\prime}$ & $68^{\circ} 49^{\prime}$ & 3.3 & 2.8 & 2.48 & 2.6 & 1.69 & 2.01 & 2.54 & 2.9 & 2.6 & 3.2 & 3.1 & 3.3 & 2.7 \\
\hline
\end{tabular}




\begin{tabular}{|c|c|c|c|c|c|c|c|c|c|c|c|c|c|c|c|c|}
\hline \multirow{2}{*}{ \# } & \multirow{2}{*}{ Name } & Lat & Long & Jan & Feb & Ma & Ap & Ma & Jun & Jul & Au & Sep & Oct & No & Dec & Av \\
\hline & & South & West & $\mathrm{m} / \mathrm{s}$ & $\mathbf{m} / \mathbf{s}$ & $\mathbf{m} / \mathbf{s}$ & $\mathbf{m} / \mathbf{s}$ & $\mathbf{m} / \mathbf{s}$ & $\mathbf{m} / \mathbf{s}$ & $\mathbf{m} / \mathbf{s}$ & $\mathbf{m} / \mathbf{s}$ & $\mathbf{m} / \mathbf{s}$ & $\mathbf{m} / \mathbf{s}$ & $\mathbf{m} / \mathbf{s}$ & $\mathbf{m} / \mathbf{s}$ & $\mathbf{m} / \mathbf{s}$ \\
\hline 101 & SANTIAGO DE & $17^{\circ} 04^{\prime}$ & $69^{\circ} 12^{\prime}$ & 3.6 & 3.3 & 3.1 & 3.1 & 3.5 & 3.95 & 4.07 & 4.3 & 5.4 & 4.5 & 4.6 & 4.3 & 4.0 \\
\hline 102 & SEPULTURAS & $17^{\circ} 48^{\prime}$ & $69^{\circ} 10^{\prime}$ & 3.6 & 3.5 & 3.43 & 3.7 & 4.18 & 4.34 & 4.06 & 3.9 & 3.4 & 3.4 & 3.7 & 3.9 & 3.7 \\
\hline 103 & SO RATA & $15^{\circ} 45^{\prime}$ & $68^{\circ} 41^{\prime}$ & 1.5 & 1.6 & 1.6 & 1.6 & 1.97 & 1.58 & 1.6 & 1.6 & 2.0 & 2.1 & 2.0 & 1.8 & 1.7 \\
\hline 104 & TIHUANACU & $16^{\circ} 33^{\prime}$ & $68^{\circ} 41^{\prime}$ & 3.0 & 2.9 & 2.82 & 2.6 & 2.31 & 2.07 & 2.42 & 2.8 & 3.2 & 3.2 & 3.0 & 3.2 & 2.8 \\
\hline 105 & ULLA ULLA & $15^{\circ} 01^{\prime}$ & $69^{\circ} 15^{\prime}$ & 4.7 & 4.8 & 4.58 & 3.8 & 3.88 & 3.76 & 4.02 & 4.5 & 4.9 & 5.0 & 4.7 & 4.5 & 4.4 \\
\hline 106 & VIACHA & $16^{\circ} 39^{\prime}$ & $68^{\circ} 18^{\prime}$ & 4.1 & 4 & 3.95 & 3.7 & 3.89 & 4.52 & 3.95 & 4.2 & 4.4 & 4.4 & 4.3 & 4.4 & 4.1 \\
\hline 107 & VIVERO POLEA & $16^{\circ} 40^{\prime}$ & $67^{\circ} 17^{\prime}$ & 2.2 & 2.2 & 2.45 & 2.3 & 2.88 & 3.07 & 3.39 & 3.2 & 3.0 & 2.9 & 2.8 & 2.4 & 2.7 \\
\hline 108 & VIVERO SAPECHO & $16^{\circ} 17^{\prime}$ & $67^{\circ} 19^{\prime}$ & 1.6 & 1.4 & 1.69 & 1.8 & 1.58 & 1.24 & 1.36 & 1.8 & 1.5 & 1.5 & 1.5 & 1.5 & 1.5 \\
\hline 109 & VILLA PUNI & $15^{\circ} 40^{\prime}$ & $69^{\circ} 12^{\prime}$ & 6.3 & 6.5 & 7.03 & 5.9 & 4.4 & 3.79 & 4.43 & 5.8 & 7.0 & 7.2 & 6.8 & 6.4 & 5.9 \\
\hline 110 & CALAMARCA & $16^{\circ} 54^{\prime}$ & $68^{\circ} 07^{\prime}$ & 7.6 & 7.2 & 7.77 & 7.4 & 7.84 & 9.45 & 9.88 & 9.6 & 8.7 & 7.1 & 7.8 & 6.9 & 8.1 \\
\hline 111 & TAQUIRI & $16^{\circ} 17^{\prime} 3$ & 6 & 2.2 & 2.3 & 1.9 & 1.8 & 1.6 & 1.4 & 1.6 & 1.8 & 1.8 & 2.2 & 2.2 & 2.2 & 1.9 \\
\hline 112 & SANTIAGO DE & $17^{\circ} 1^{\prime}$ & $68^{\circ} 12^{\prime}$ & 2.6 & 2.9 & 2.1 & 2.2 & 2.7 & 3.2 & 3.5 & 3.1 & 3.2 & 2.9 & 3 & 3 & 2.8 \\
\hline 113 & GONZALES & $15^{\circ} 11^{\prime} 5$ & 6 & 0.6 & 0.7 & 0.8 & 1.1 & 1.2 & 1.7 & 1.8 & 1.5 & 1.4 & 1.2 & 1.4 & 1.1 & 1.2 \\
\hline 114 & CARACOLLO & $17^{\circ} 38^{\prime}$ & $67^{\circ} 12$ & 2.1 & 2.0 & 2.15 & 2.1 & 2.48 & 2.6 & 2.48 & 2.8 & 3.0 & 2.2 & 2.4 & 2.2 & 2.4 \\
\hline 115 & CONDORIRI & $17^{\circ} 32^{\prime}$ & $67^{\circ} 14$ & 2.1 & 1.8 & 1.69 & 1.8 & 1.92 & 1.97 & 2.4 & 1.6 & 2.1 & 2.0 & 1.5 & 0.9 & 1.8 \\
\hline 116 & EUCALIPTUS & $17^{\circ} 34^{\prime}$ & $67^{\circ} 3^{\prime}$ & 0.5 & 0.5 & 0.56 & 0.5 & 0.56 & 0.92 & 0.92 & 0.9 & 0.9 & 0.5 & 0.5 & 0.5 & 0.6 \\
\hline 117 & HUACHACALLA & $18^{\circ} 46^{\prime}$ & $68^{\circ} 16$ & 0.5 & 0.5 & 0.29 & 0.6 & 0.65 & 0.84 & 1.47 & 1.3 & 1.1 & 1.4 & 1.6 & 1.1 & 0.9 \\
\hline 118 & ORINOCA & $18^{\circ} 58^{\prime}$ & $67^{\circ} 15^{\prime}$ & 3.9 & 3.3 & 3.39 & 3.7 & 3.73 & 4.09 & 4.52 & 3.3 & 4.0 & 3.8 & 4.1 & 3.6 & 3.8 \\
\hline 119 & ORURO AASANA & $17^{\circ} 58^{\prime}$ & $67^{\circ} 07$ & 2.6 & 2.1 & 1.96 & 1.7 & 1.6 & 1.37 & 1.66 & 1.7 & 2.5 & 2.6 & 2.3 & 2.7 & 2.1 \\
\hline 120 & SALINAS DE G. & $19^{\circ} 38^{\prime}$ & $67^{\circ} 40^{\prime}$ & 1.6 & 1.6 & 1.69 & 2.5 & 2.54 & 1.5 & 1.69 & 2.4 & 2.0 & 1.6 & 1.5 & 2.6 & 1.9 \\
\hline 121 & TACAGUA- & $18^{\circ} 53^{\prime}$ & $66^{\circ} 46$ & 5.8 & 5.7 & 5.39 & 5.0 & 5.65 & 5.46 & 5.26 & 5.9 & 5.7 & 5.9 & 6.1 & 5.8 & 5.6 \\
\hline 122 & SEVARUYO & $19^{\circ} 21^{\prime} 0$ & $66^{\circ} 51^{\prime}$ & 2.7 & 2.6 & 2.5 & 2.6 & 2.5 & 2.6 & 3.1 & 3 & 2.9 & 3.1 & 3.6 & 3.3 & 2.8 \\
\hline 123 & SAUNAS DE G. & $19^{\circ} 38^{\prime} 5$ & $67^{\circ} 40^{\prime}$ & 4.3 & 4.5 & 3.3 & 2.9 & 3.2 & 4.5 & 4.9 & 4.1 & 3.7 & 3.5 & 3.8 & 3.6 & 3.8 \\
\hline 124 & CHACHACOMANI & $18^{\circ} 21^{\prime} 3$ & $68^{\circ} 56^{\prime}$ & 2.5 & 3.5 & 2.9 & 3.4 & 4.2 & 5 & 6.5 & 6 & 4.6 & 3.7 & 4.7 & 3.5 & 4.2 \\
\hline 125 & CARIPE & $18^{\circ} 00^{\prime} 4$ & $68^{\circ} 50^{\prime}$ & 3.2 & 3.8 & 3.6 & 3.3 & 4.3 & 5.5 & 5.5 & 5.2 & 5.5 & 5 & 5.6 & 4.8 & 4.6 \\
\hline 126 & COMUJO - CIPASA & $19^{\circ} 12^{\prime} 5$ & $66^{\circ} 23^{\prime}$ & 4.3 & 4.5 & 4.2 & 3.9 & 3.8 & 4.1 & 4.6 & 4.5 & 4.7 & 4.9 & 5.4 & 5.1 & 4.5 \\
\hline 127 & CALCHA & $20^{\circ} 44^{\prime}$ & $65^{\circ} 28^{\prime}$ & 1.9 & 1.7 & 1.82 & 1.9 & 1.77 & 1.63 & 1.9 & 2.6 & 3.0 & 3.0 & 2.8 & 2.7 & 2.2 \\
\hline 128 & COLCHA K & $20^{\circ} 44^{\prime}$ & $67^{\circ} 40^{\prime}$ & 1.9 & 1.5 & 1.68 & 1.8 & 2.25 & 2.36 & 2.28 & 2.0 & 2.3 & 2.5 & 2.4 & 2.1 & 2.1 \\
\hline 129 & COLQUECHACA & $18^{\circ} 41^{\prime}$ & $66^{\circ} 10$ & 2.1 & 1.8 & 2.26 & 2.6 & 2.4 & 2.82 & 2.99 & 3.6 & 4.2 & 3.4 & 3.8 & 2.2 & 2.8 \\
\hline 130 & COTAGAITA & $20^{\circ} 48^{\prime}$ & $65^{\circ} 39^{\prime}$ & 2.0 & 2.0 & 1.89 & 2.0 & 2.09 & 2.57 & 2.89 & 2.4 & 2.4 & 2.7 & 2.4 & 2.5 & 2.3 \\
\hline 131 & $\mathrm{CHICO} \mathrm{CHICO}$ & $19^{\circ} 40^{\prime}$ & $65^{\circ} 32^{\prime}$ & 1.2 & 1.1 & 1.14 & 1.2 & 1.52 & 1.81 & 2.17 & 1.8 & 1.8 & 1.6 & 1.7 & 1.4 & 1.5 \\
\hline 132 & CHALVIRI & $19^{\circ} 39^{\prime}$ & $65^{\circ} 43^{\prime}$ & 2.1 & 2.1 & 2.26 & 2.1 & 2.54 & 2.66 & 2.5 & 2.4 & 2.5 & 2.2 & 2.5 & 2.5 & 2.4 \\
\hline 133 & CHAQUI & $19^{\circ} 35^{\prime}$ & $65^{\circ} 34^{\prime}$ & 1.4 & 1.1 & 1.47 & 1.5 & 1.97 & 2.26 & 2.08 & 2.1 & 2.1 & 1.9 & 1.6 & 1.9 & 1.8 \\
\hline 134 & ESCARA & $20^{\circ} 39^{\prime}$ & $65^{\circ} 40^{\prime}$ & 3.6 & 3.6 & 3.63 & 4.3 & 4.43 & 4.52 & 3.71 & 3.6 & 4.1 & 3.7 & 3.8 & 4.1 & 3.9 \\
\hline 135 & JULACA & $20^{\circ} 57^{\prime}$ & $67^{\circ} 57^{\prime}$ & 6.5 & 6.2 & 6.27 & 6.3 & 6.52 & 6.21 & 6.71 & 8.0 & 7.0 & 6.4 & 6.9 & 6.9 & 6.6 \\
\hline 136 & LllCA & $19^{\circ} 51^{\prime}$ & $68^{\circ} 15^{\prime}$ & 2.3 & 2.9 & 2.78 & 2.5 & 2.75 & 3.43 & 3.27 & 3.1 & 3.0 & 3.5 & 3.6 & 3.3 & 3.0 \\
\hline
\end{tabular}




\begin{tabular}{|c|c|c|c|c|c|c|c|c|c|c|c|c|c|c|c|c|}
\hline \multirow{2}{*}{ \# } & \multirow{2}{*}{ Name } & Lat & Long & Jan & Feb & Ma & Ap & Ma & Jun & Jul & Au & Sep & Oct & No & Dec & Av \\
\hline & & South & West & $\mathbf{m} / \mathbf{s}$ & $\mathbf{m} / \mathbf{s}$ & $\mathbf{m} / \mathbf{s}$ & $\mathbf{m} / \mathbf{s}$ & $\mathbf{m} / \mathbf{s}$ & $\mathbf{m} / \mathbf{s}$ & $\mathbf{m} / \mathbf{s}$ & $\mathbf{m} / \mathbf{s}$ & $\mathbf{m} / \mathbf{s}$ & $\mathbf{m} / \mathbf{s}$ & $\mathbf{m} / \mathbf{s}$ & $\mathbf{m} / \mathbf{s}$ & $\mathbf{m} / \mathbf{s}$ \\
\hline 137 & MILLARES & $19^{\circ} 25^{\prime}$ & $65^{\circ} 10^{\prime}$ & 2.6 & 2.6 & 2.62 & 2.7 & 2.87 & 2.42 & 2.6 & 2.8 & 2.7 & 2.8 & 2.9 & 2.8 & 2.7 \\
\hline 138 & MACHA & $18^{\circ} 49^{\prime}$ & $66^{\circ} 02^{\prime}$ & 3.3 & 3.3 & 3.43 & 3.4 & 3.76 & 3.86 & 4.05 & 4.3 & 3.7 & 4.1 & 4.0 & 3.8 & 3.7 \\
\hline 139 & MIRAFLORES & $19^{\circ} 28^{\prime}$ & $65^{\circ} 47^{\prime}$ & 2.4 & 2.4 & 3.02 & 1.9 & 2.26 & 2.26 & 2.26 & 2.5 & 2.5 & 2.5 & 2.2 & 2.8 & 2.4 \\
\hline 140 & MOSOJ LLAJTA & $20^{\circ} 49^{\prime}$ & $65^{\circ} 35^{\prime}$ & 2.1 & 2.2 & 1.92 & 2.3 & 2.87 & 3.1 & 3.39 & 3.1 & 3.3 & 2.9 & 3.0 & 2.7 & 2.7 \\
\hline 141 & OCURI & $18^{\circ} 50^{\prime}$ & $65^{\circ} 47^{\prime}$ & 2.7 & 2.4 & 2.82 & 3.3 & 3.76 & 4.7 & 4.44 & 3.3 & 2.6 & 2.8 & 2.7 & 2.2 & 3.1 \\
\hline 142 & OPLOCA & $21^{\circ} 20^{\prime}$ & $65^{\circ} 50^{\prime}$ & 1.5 & 1.4 & 1.48 & 1.8 & 2.32 & 2.45 & 2.26 & 2.4 & 2.8 & 2.0 & 1.9 & 1.6 & 2.0 \\
\hline 143 & OTAVI & $20^{\circ} 03^{\prime}$ & $65^{\circ} 20^{\prime}$ & 3.6 & 3.6 & 3.69 & 3.8 & 3.28 & 3.91 & 3.51 & 4.2 & 4.4 & 4.1 & 4.6 & 4.1 & 3.9 \\
\hline 144 & PALCA DE & $20^{\circ} 42^{\prime}$ & $65^{\circ} 26^{\prime}$ & 4.1 & 3.4 & 3.44 & 2.7 & 2.82 & 3.05 & 3.44 & 3.7 & 3.9 & 3.6 & 4 & 4.3 & 3.5 \\
\hline 145 & POTOSI AASANA & $19^{\circ} 35^{\prime}$ & $66^{\circ} 45^{\prime}$ & 3.0 & 2.6 & 3.15 & 2.8 & 3.66 & 4.17 & 3.54 & 3.8 & 3.4 & 3.9 & 3.7 & 3.0 & 3.4 \\
\hline 146 & PUNA & $19^{\circ} 47^{\prime}$ & $65^{\circ} 30^{\prime}$ & 1.6 & 1.8 & 1.69 & 2.2 & 2.48 & 2.45 & 2.03 & 2.1 & 2.4 & 2.5 & 2.4 & 2.6 & 2.2 \\
\hline 147 & RAVELO & $18^{\circ} 48^{\prime}$ & $65^{\circ} 30^{\prime}$ & 2.0 & 1.8 & 2.07 & 2.1 & 1.92 & 2.27 & 2.13 & 2.5 & 2.2 & 2.2 & 2.9 & 2.5 & 2.2 \\
\hline 148 & SAN J DE PAMPA & $21^{\circ} 40^{\prime}$ & $65^{\circ} 48^{\prime}$ & 1.6 & 1.1 & 1.83 & 2.5 & 1.56 & 2.37 & 2.26 & 3.9 & 3.9 & 4.2 & 1.8 & 1.6 & 2.4 \\
\hline 149 & SAMASA & $19^{\circ} 29^{\prime}$ & $65^{\circ} 41^{\prime}$ & 3.6 & 3.6 & 3.89 & 4.2 & 4.57 & 5.83 & 5.61 & 5.1 & 5.1 & 4.1 & 3.6 & 3.9 & 4.4 \\
\hline 150 & SAN P. DE BUENA & $18^{\circ} 21^{\prime}$ & $65^{\circ} 58^{\prime}$ & 2.9 & 2.0 & 1.69 & 2.0 & 1.97 & 2.37 & 2.48 & 2.9 & 3.0 & 2.9 & 2.9 & 2.9 & 2.5 \\
\hline 151 & SAN AGUSTIN & $21^{\circ} 10^{\prime}$ & $67^{\circ} 40^{\prime}$ & 4.5 & 4.3 & 4.52 & 4.7 & 5.13 & 4.74 & 5.08 & 5.2 & 5.2 & 5.6 & 5.2 & 4.4 & 4.9 \\
\hline 152 & TARAPAYA & $19^{\circ} 27^{\prime}$ & $65^{\circ} 48^{\prime}$ & 2.8 & 2.3 & 2.54 & 2.4 & 2.26 & 2.37 & 2.71 & 2.4 & 2.6 & 2.5 & 2.8 & 2.7 & 2.5 \\
\hline 153 & TINQUIPAYA & $19^{\circ} 13^{\prime}$ & $65^{\circ} 49^{\prime}$ & 4.0 & 4.0 & 3.95 & 4.4 & 5.64 & 6.26 & 6.38 & 5.9 & 5.0 & 4.6 & 4.3 & 4.2 & 4.9 \\
\hline 154 & TORO TORO & $18^{\circ} 7^{\prime}$ & $65^{\circ} 46^{\prime}$ & 1.5 & 1.5 & 1.38 & 1.0 & 1.25 & 1.36 & 1.63 & 1.6 & 1.8 & 1.8 & 1.8 & 1.6 & 1.5 \\
\hline 155 & TUMUSLA & $20^{\circ} 29^{\prime}$ & $65^{\circ} 37^{\prime}$ & 1.1 & 1.2 & 1.63 & 1.5 & 1.86 & 2.26 & 2.31 & 2.8 & 2.3 & 2.0 & 2.1 & 1.8 & 1.9 \\
\hline 156 & TUPIZA & $21^{\circ} 26^{\prime}$ & $65^{\circ} 43^{\prime}$ & 2.4 & 2.3 & 2.38 & 2.2 & 1.94 & 2.88 & 2.65 & 2.9 & 3.2 & 3.0 & 2.8 & 2.9 & 2.6 \\
\hline 157 & TURUCHIPA & $19^{\circ} 49^{\prime}$ & $64^{\circ} 56^{\prime}$ & 0.9 & 0.8 & 0.92 & 1.0 & 1.01 & 1.01 & 1.01 & 1.1 & 1.0 & 1.0 & 1.0 & 0.9 & 1.0 \\
\hline 158 & UNCIA & $18^{\circ} 28^{\prime}$ & $66^{\circ} 34^{\prime}$ & 2.1 & 1.8 & 2.02 & 2.1 & 2.91 & 2.95 & 2.32 & 2.4 & 2.4 & 2.5 & 2.0 & 1.7 & 2.2 \\
\hline 159 & UYUNI & $20^{\circ} 27^{\prime}$ & $66^{\circ} 49^{\prime}$ & 3.4 & 3.8 & 3.69 & 3.6 & 4.23 & 4.82 & 4.08 & 4.1 & 5.2 & 4.9 & 4.6 & 4.4 & 4.2 \\
\hline 160 & VITICHI & $20^{\circ} 07^{\prime}$ & $65^{\circ} 29^{\prime}$ & 3.5 & 4.1 & 4.18 & 4.4 & 4.52 & 4.63 & 5.65 & 5.9 & 4.7 & 5.0 & 4.8 & 5.0 & 4.7 \\
\hline 161 & VIVERO FORESTAL & $19^{\circ} 23^{\prime}$ & $65^{\circ} 45^{\prime}$ & 2.9 & 3.1 & 2.65 & 2.7 & 3.16 & 2.76 & 3.51 & 3.5 & 3.7 & 3.6 & 3.6 & 3.2 & 3.2 \\
\hline 162 & YOCALLA & $19^{\circ} 33^{\prime}$ & $65^{\circ} 55^{\prime}$ & 2.3 & 2.3 & 2.38 & 2.7 & 3.39 & 3.33 & 3.61 & 2.9 & 3.1 & 2.9 & 3.2 & 2.7 & 2.9 \\
\hline 163 & YURA & $19^{\circ} 43^{\prime}$ & $66^{\circ} 23^{\prime}$ & 1.0 & 1.0 & 1.05 & 1.2 & 1.27 & 1.24 & 1.36 & 1.2 & 1.1 & 1.1 & 1.2 & 1.2 & 1.1 \\
\hline 164 & COBIJA & $11^{\circ} 02^{\prime}$ & $68^{\circ} 47^{\prime}$ & 1.9 & 1.8 & 1.7 & 1.4 & 1.6 & 1.41 & 1.89 & 1.5 & 1.8 & 2.1 & 2.2 & 1.8 & 1.8 \\
\hline 165 & A. DE GUARAYOS & $15^{\circ} 42^{\prime}$ & $63^{\circ} 06^{\prime}$ & 1.4 & 1.9 & 1.6 & 1.6 & 1.94 & 2.06 & 2.43 & 2.3 & 2.4 & 2.3 & 2.4 & 1.9 & 2.0 \\
\hline 166 & CAMIRI & $20^{\circ} 03^{\prime}$ & $63^{\circ} 34^{\prime}$ & 1.4 & 1.4 & 1.25 & 1.3 & 1.14 & 1.72 & 2.19 & 2.4 & 3.0 & 2.6 & 2.1 & 1.7 & 1.8 \\
\hline 167 & COLINIA SAN JUAN & $16^{\circ} 59^{\prime}$ & $64^{\circ} 02^{\prime}$ & 0.8 & 0.8 & 0.76 & 1.0 & 1.03 & 1.03 & 1.13 & 0.9 & 0.9 & 0.9 & 1.1 & 0.9 & 0.9 \\
\hline 168 & COMARAPA & $17^{\circ} 53^{\prime}$ & $64^{\circ} 32^{\prime}$ & 4.0 & 3.7 & 3.44 & 5.0 & 5.22 & 6.64 & 6.64 & 7.5 & 7.1 & 6.1 & 5.3 & 4.2 & 5.4 \\
\hline 169 & CONCEPCION & $16^{\circ} 07^{\prime}$ & $62^{\circ} 02^{\prime}$ & 2 & 2.3 & 1.66 & 1.7 & 2.06 & 2.52 & 2.75 & 3.0 & 2.9 & 2.6 & 2.6 & 2.2 & 2.3 \\
\hline 170 & EL VALLECITO & $17^{\circ} 46^{\prime}$ & $63^{\circ} 09^{\prime}$ & 4.6 & 4.7 & 4.23 & 5.0 & 5.12 & 6.34 & 6.13 & 5.6 & 5.5 & 5.3 & 5.0 & 5.0 & 5.2 \\
\hline 171 & HUARIRENDA & $19^{\circ} 14^{\prime}$ & $62^{\circ} 20^{\prime}$ & 1.1 & 1.1 & 1.41 & 1.1 & 1.69 & 1.85 & 2.98 & 2.6 & 2.5 & 2.1 & 1.8 & 1.6 & 1.8 \\
\hline 172 & MAIRANA & $18^{\circ} 07^{\prime}$ & $63^{\circ} 57^{\prime}$ & 2.4 & 2.4 & 2.5 & 2.5 & 2.75 & 3.18 & 3.74 & 3.6 & 3.6 & 3.5 & 3.1 & 2.9 & 3.0 \\
\hline
\end{tabular}




\begin{tabular}{|c|c|c|c|c|c|c|c|c|c|c|c|c|c|c|c|c|}
\hline \multirow{2}{*}{ \# } & \multirow{2}{*}{ Name } & Lat & Long & Jan & Feb & Ma & Ap & Ma & Jun & Jul & Au & Sep & Oct & No & Dec & Av \\
\hline & & South & West & $\mathbf{m} / \mathbf{s}$ & $\mathbf{m} / \mathbf{s}$ & $\mathbf{m} / \mathbf{s}$ & $\mathbf{m} / \mathbf{s}$ & $\mathbf{m} / \mathbf{s}$ & $\mathbf{m} / \mathbf{s}$ & $\mathbf{m} / \mathbf{s}$ & $\mathbf{m} / \mathbf{s}$ & $\mathbf{m} / \mathbf{s}$ & $\mathbf{m} / \mathbf{s}$ & $\mathbf{m} / \mathbf{s}$ & $\mathbf{m} / \mathbf{s}$ & $\mathbf{m} / \mathbf{s}$ \\
\hline 173 & PUERO SUAREZ & $19^{\circ} 00^{\prime}$ & $57^{\circ} 44^{\prime}$ & 2.3 & 1.9 & 1.34 & 1.9 & 2.26 & 2.83 & 2.63 & 3.2 & 3.0 & 3.1 & 2.5 & 1.9 & 2.4 \\
\hline 174 & PUERTO & $17^{\circ} 00^{\prime}$ & $63^{\circ} 14^{\prime}$ & 2.8 & 2.8 & 4.93 & 3.5 & 3.25 & 4.52 & 4.37 & 3.5 & 3.9 & 3.9 & 3.7 & 3.3 & 3.7 \\
\hline 175 & ROBORE & $18^{\circ} 19^{\prime}$ & $59^{\circ} 45^{\prime}$ & 2.0 & 2.2 & 1.94 & 1.6 & 1.65 & 2.32 & 27 & 2.7 & 2.8 & 3.0 & 2.6 & 2.0 & 4.3 \\
\hline 176 & SAMAIPATA & $18^{\circ} 10^{\prime}$ & $63^{\circ} 57^{\prime}$ & 4.1 & 3.9 & 5.31 & 6.2 & 7 & 7.57 & 7.12 & 7 & 8.0 & 7.6 & 6.6 & 5.6 & 6.3 \\
\hline 177 & SAN ANTONIO & $20^{\circ} 00^{\prime}$ & $63^{\circ} 11^{\prime}$ & 5.2 & 5.1 & 4.56 & 3.7 & 3.64 & 3.95 & 5.41 & 6.3 & 7.3 & 8.0 & 7.2 & 6.0 & 5.5 \\
\hline 178 & S. 1. VElASCO & $16^{\circ} 22^{\prime}$ & $60^{\circ} 58^{\prime}$ & 1.7 & 1.9 & 1.6 & 1.6 & 2.01 & 2.06 & 2.32 & 2.5 & 2.5 & 2.7 & 2.6 & 2.0 & 2.1 \\
\hline 179 & SAN JAVIER & $16^{\circ} 20^{\prime}$ & $62^{\circ} 38^{\prime}$ & 2.4 & 2.7 & 2.38 & 2.3 & 4.94 & 3.2 & 2.97 & 3.4 & 3.4 & 3.1 & 3.1 & 2.5 & 3.0 \\
\hline 180 & SAN JOSE & $17^{\circ} 47^{\prime}$ & $60^{\circ} 47^{\prime}$ & 1.2 & 1.5 & 1.54 & 1.8 & 2.17 & 2.52 & 2.51 & 2.7 & 2.5 & 2.3 & 2.3 & 1.6 & 2.0 \\
\hline 181 & SAN JULIAN & $16^{\circ} 45^{\prime}$ & $62^{\circ} 30^{\prime}$ & 2.0 & 1.6 & 1.69 & 2.0 & 2.26 & 3.14 & 3.8 & 3.2 & 3.1 & 3.2 & 2.4 & 2.1 & 2.5 \\
\hline 182 & SAN MATIAS & $16^{\circ} 22^{\prime}$ & $58^{\circ} 23^{\prime}$ & 1.4 & 1.7 & 1.35 & 1.1 & 1.44 & 1.85 & 2.17 & 2.6 & 2.8 & 2.7 & 2.2 & 1.6 & 1.9 \\
\hline 183 & SANTA ANA & $18^{\circ} 21^{\prime}$ & $64^{\circ} 09^{\prime}$ & 3.8 & 3.8 & 3.45 & 3.1 & 6.69 & 3.14 & 3.26 & 3.3 & 3.4 & 3.6 & 3.9 & 3.5 & 3.7 \\
\hline 184 & SANTA CRUZ & $17^{\circ} 47^{\prime}$ & $63^{\circ} 10^{\prime}$ & 5.2 & 5.4 & 5.09 & 5.3 & 4.52 & 6.18 & 6.1 & 6.4 & 6.3 & 5.9 & 5.8 & 5.0 & 5.6 \\
\hline 185 & SANTA CRUZ & $17^{\circ} 45^{\prime}$ & $63^{\circ} 10^{\prime}$ & 5.2 & 5.4 & 5.08 & 5.3 & 4.51 & 6.17 & 6.12 & 6.4 & 6.3 & 5.9 & 5.8 & 5.0 & 5.6 \\
\hline 186 & SANTA CRUZ VIRU & $17^{\circ} 40^{\prime}$ & $63^{\circ} 11^{\prime}$ & 4.8 & 5.0 & 4.63 & 5.0 & 5.47 & 6.15 & 6.32 & 6.2 & 6.1 & 5.8 & 5.5 & 5.1 & 5.5 \\
\hline 187 & AEROPUERTO & $17^{\circ} 36^{\prime}$ & $61^{\circ} 08^{\prime}$ & 6.2 & 5.3 & 5.69 & 5.7 & 6.36 & 6.61 & 7.83 & 7.2 & 7.0 & 7.0 & 6.9 & 6.2 & 6.5 \\
\hline 188 & SAN JAVIER & $16^{\circ} 20^{\prime}$ & $62^{\circ} 38^{\prime}$ & 3.6 & 3.6 & 3.58 & 3.3 & 3.45 & 4.14 & 3.86 & 4.3 & 4.3 & 4.1 & 3.8 & 3.3 & 3.8 \\
\hline 189 & VIRU VIRU & $17^{\circ} 38^{\prime}$ & $63^{\circ} 08^{\prime}$ & 4.8 & 4.6 & 4.53 & 4.6 & 5.21 & 5.37 & 5.64 & 4.6 & 5.5 & 5.2 & 5.2 & 4.6 & 5.0 \\
\hline 190 & BERMEJO & $22^{\circ} 46^{\prime}$ & $64^{\circ} 18^{\prime}$ & 2.9 & 2.3 & 2.54 & 2.4 & 2.26 & 2.48 & 2.82 & 2.3 & 3.3 & 3.6 & 2.8 & 2.8 & 2.7 \\
\hline 191 & EL PUENTE & $21^{\circ} 14^{\prime}$ & $65^{\circ} 12^{\prime}$ & 0.3 & 0.3 & 0.91 & 0.7 & 0.31 & 0.31 & 0.31 & 0.3 & 0.3 & 0.3 & 0.3 & 0.3 & 0.4 \\
\hline 192 & ENTRE RIOS & $21^{\circ} 30^{\prime}$ & $64^{\circ} 10^{\prime}$ & 4.5 & 4.3 & 4.2 & 4.3 & 4.01 & 3.83 & 4.52 & 4.7 & 5.3 & 5.2 & 5.6 & 4.6 & 4.6 \\
\hline 193 & RIO CONCHAS & $21^{\circ} 52^{\prime}$ & $64^{\circ} 36^{\prime}$ & 2.2 & 1.1 & 1.69 & 1.1 & 0.56 & 0.56 & 1.69 & 2.8 & 0.5 & 2.2 & 0.5 & 1.1 & 1.3 \\
\hline 194 & SAN ANDRES & $21^{\circ} 37^{\prime}$ & $64^{\circ} 48^{\prime}$ & 0.5 & 1.6 & 0.56 & 0.5 & 0.56 & 0.56 & 0.56 & 0.5 & 0.5 & 1.6 & 0.5 & 0.5 & 0.7 \\
\hline 195 & SAN JACINTO & $21^{\circ} 36^{\prime}$ & $64^{\circ} 43^{\prime}$ & 1.3 & 1.6 & 2.4 & 2.3 & 1.34 & 1.29 & 1.89 & 1.8 & 2.6 & 2.5 & 2.3 & 1.7 & 1.9 \\
\hline 196 & TARIJA AASANA & $21^{\circ} 32^{\prime}$ & $64^{\circ} 42^{\prime}$ & 2.4 & 2.2 & 2.11 & 2.3 & 2.11 & 1.54 & 1.89 & 3.0 & 3.3 & 3.4 & 3.5 & 2.9 & 2.5 \\
\hline 197 & TARIJA SENAMHI & $21^{\circ} 35^{\prime}$ & $64^{\circ} 49^{\prime}$ & 1.6 & 1.6 & 1.63 & 1.9 & 1.69 & 1.63 & 1.63 & 2.3 & 2.8 & 3.0 & 2.6 & 2.3 & 2.0 \\
\hline 198 & TARIQUIA & $22^{\circ} 0^{\prime}$ & $64^{\circ} 28^{\prime}$ & 1.1 & 1.4 & 1.13 & 1.4 & 1.41 & 2.26 & 0.84 & 0.5 & 1.6 & 2.5 & 0.5 & 1.1 & 1.3 \\
\hline 199 & VILLAMONTES & $21^{\circ} 15^{\prime}$ & $63^{\circ} 27^{\prime}$ & 1.6 & 1.6 & 5.2 & 1.2 & 0.97 & 1.2 & 1.93 & 2.1 & 2.6 & 2.9 & 4.8 & 1.7 & 2.3 \\
\hline 200 & VILLAMONTES & $21^{\circ} 15^{\prime}$ & $63^{\circ} 30^{\prime}$ & 2.6 & 2.3 & 2.82 & 2.0 & 1.89 & 1.85 & 1.78 & 2.3 & 2.3 & 2.7 & 2.4 & 2.1 & 2.2 \\
\hline 201 & YACUIBA & $21^{\circ} 56^{\prime}$ & $63^{\circ} 38^{\prime}$ & 2.2 & 2.4 & 2.16 & 1.9 & 1.85 & 2.01 & 2.57 & 3.0 & 3.2 & 3.6 & 2.8 & 2.4 & 2.5 \\
\hline
\end{tabular}


The following graph shows all the possible pairs of correlations among the 201 locations studied.

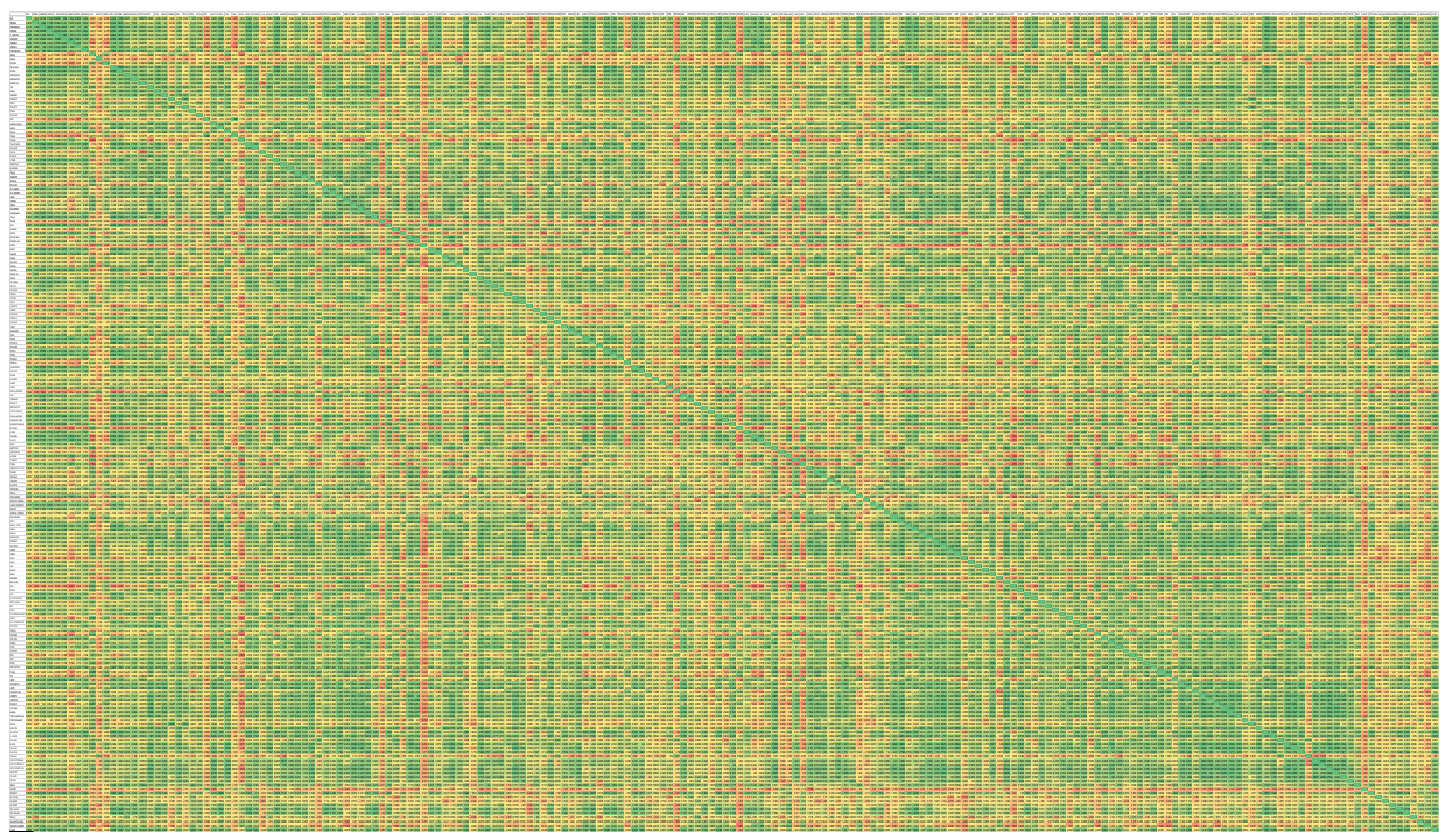

Figure 52: Correlation coefficients. 
The following graph shows all the edges for the threshold value selected, " 0 ", all negative correlations.

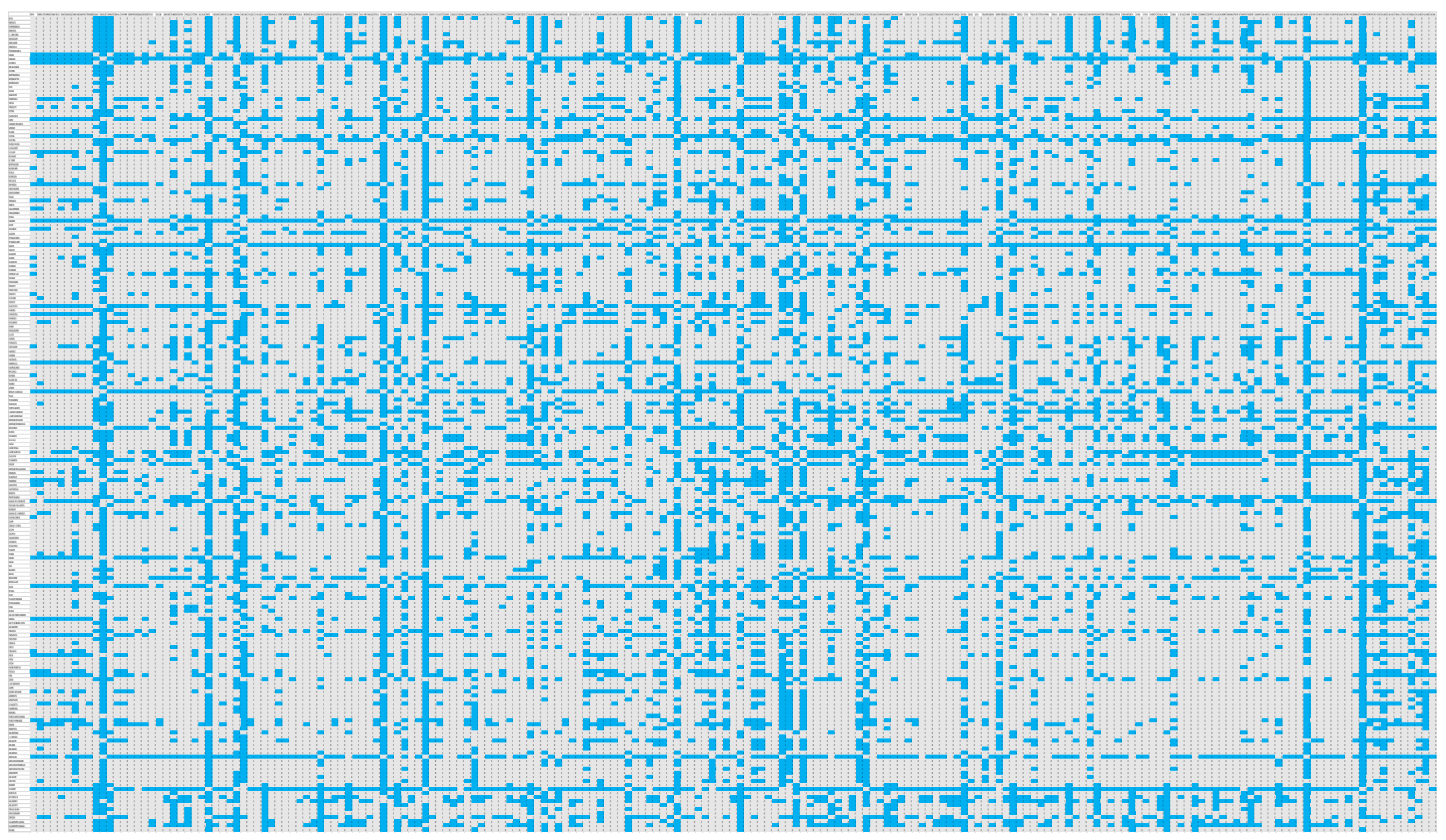

Figure 53: Adjacency matrix visualization. 
The following table includes the code created in C++ and CPLEX for processing the data and finding the minimum dominating set.

Table 29: MDS Code.

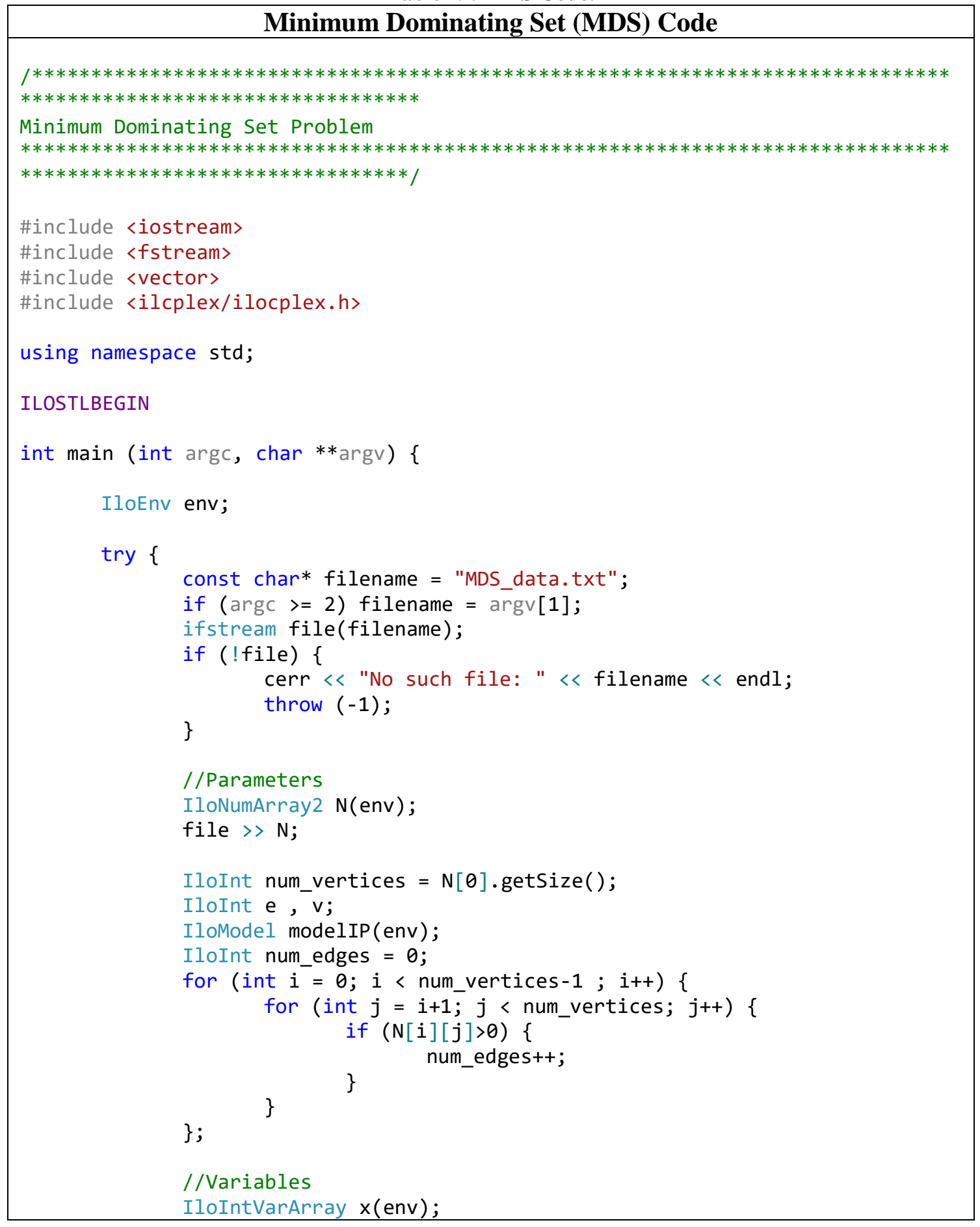




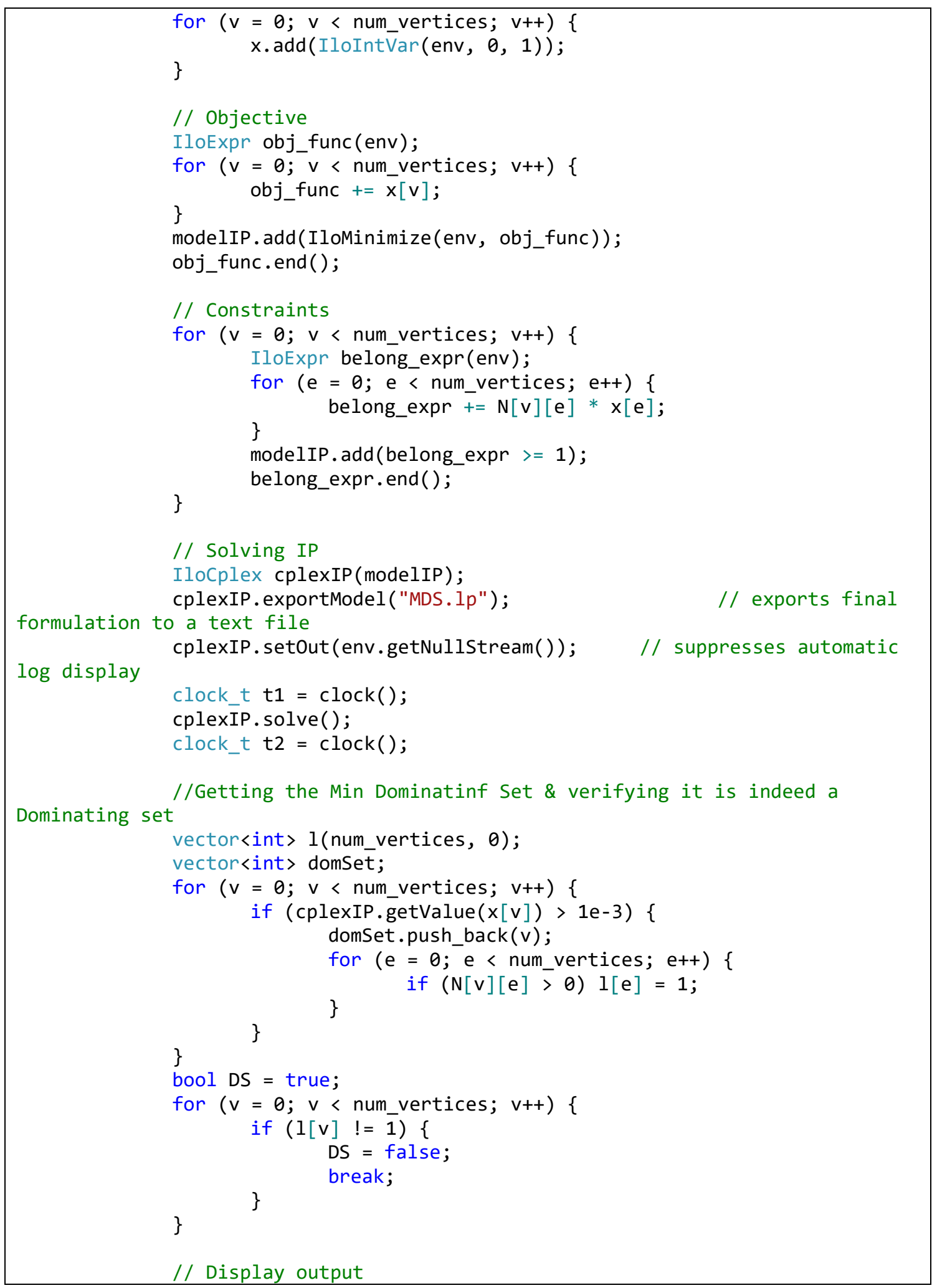




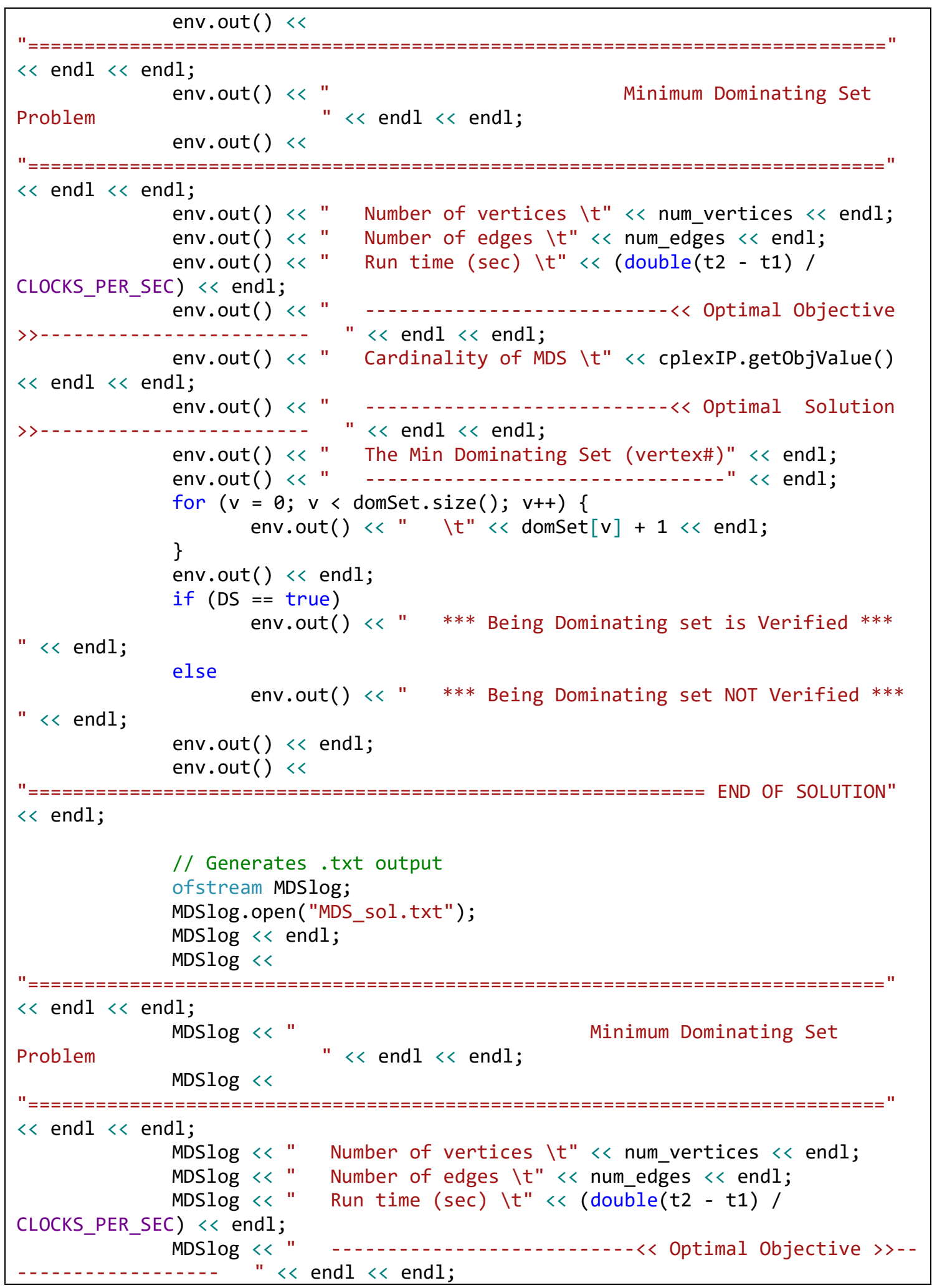




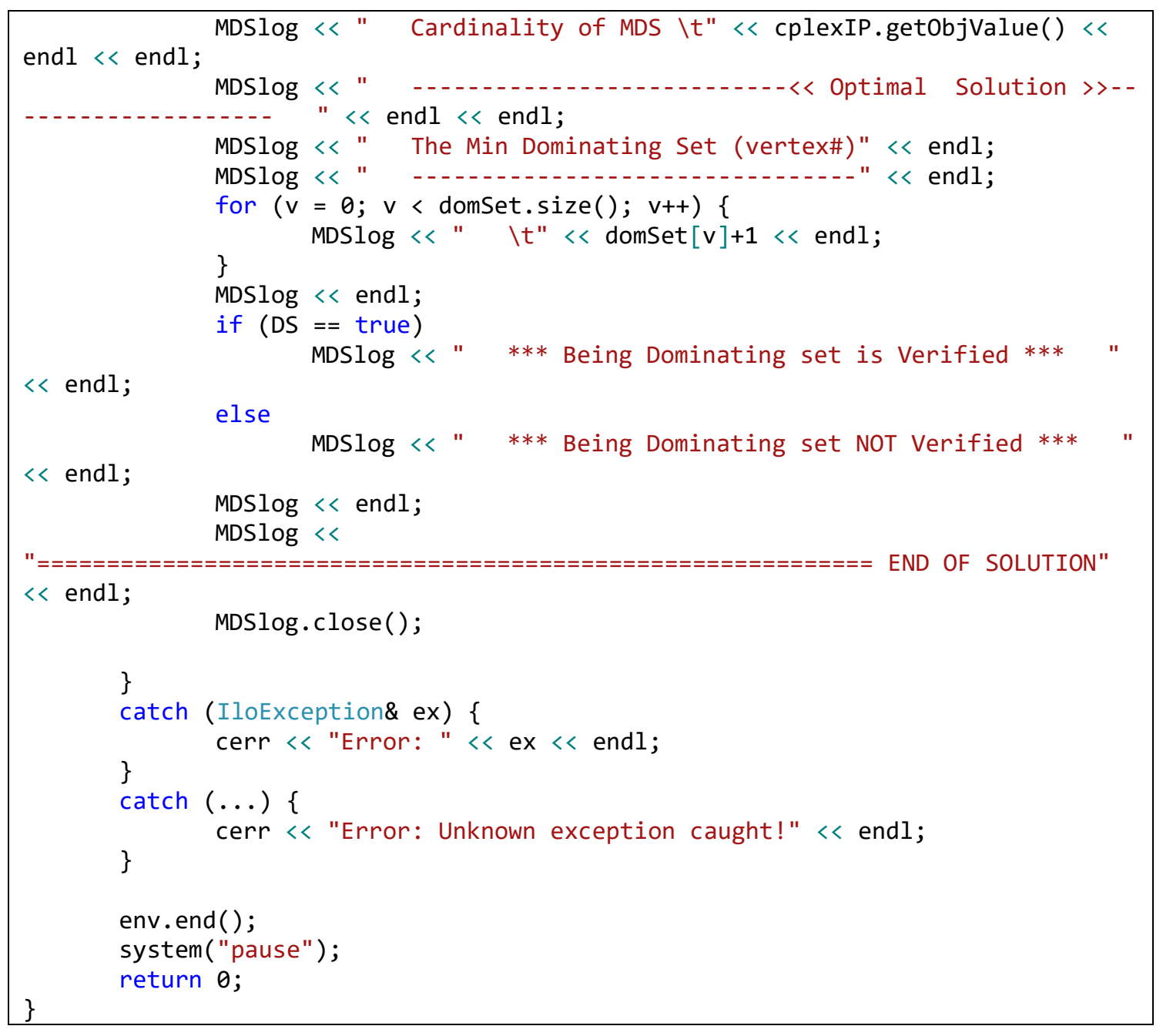


APPENDIX II 
In the following figure we can see all the details for the wind turbine studied in the project.

The turbine corresponds to V116-2.0 MW ${ }^{\mathrm{TM}}$ IEC IIB.

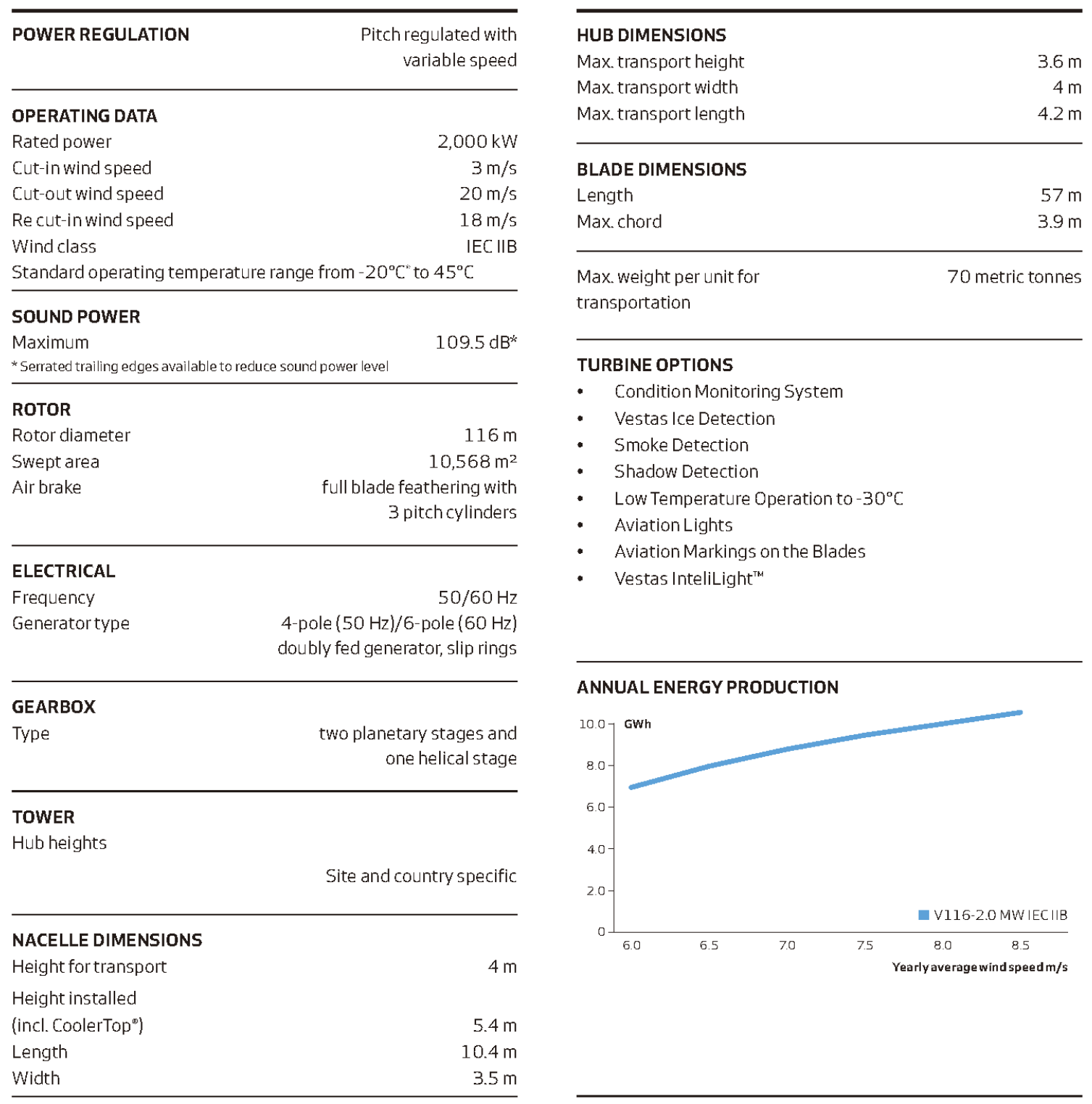

Figure 54:V116-2MW Datasheet. 
In the following figure we can see all the details for the wind turbine studied in the project.

The turbine corresponds to V136-3.45 MWTM IEC IIB/IEC IIIA.

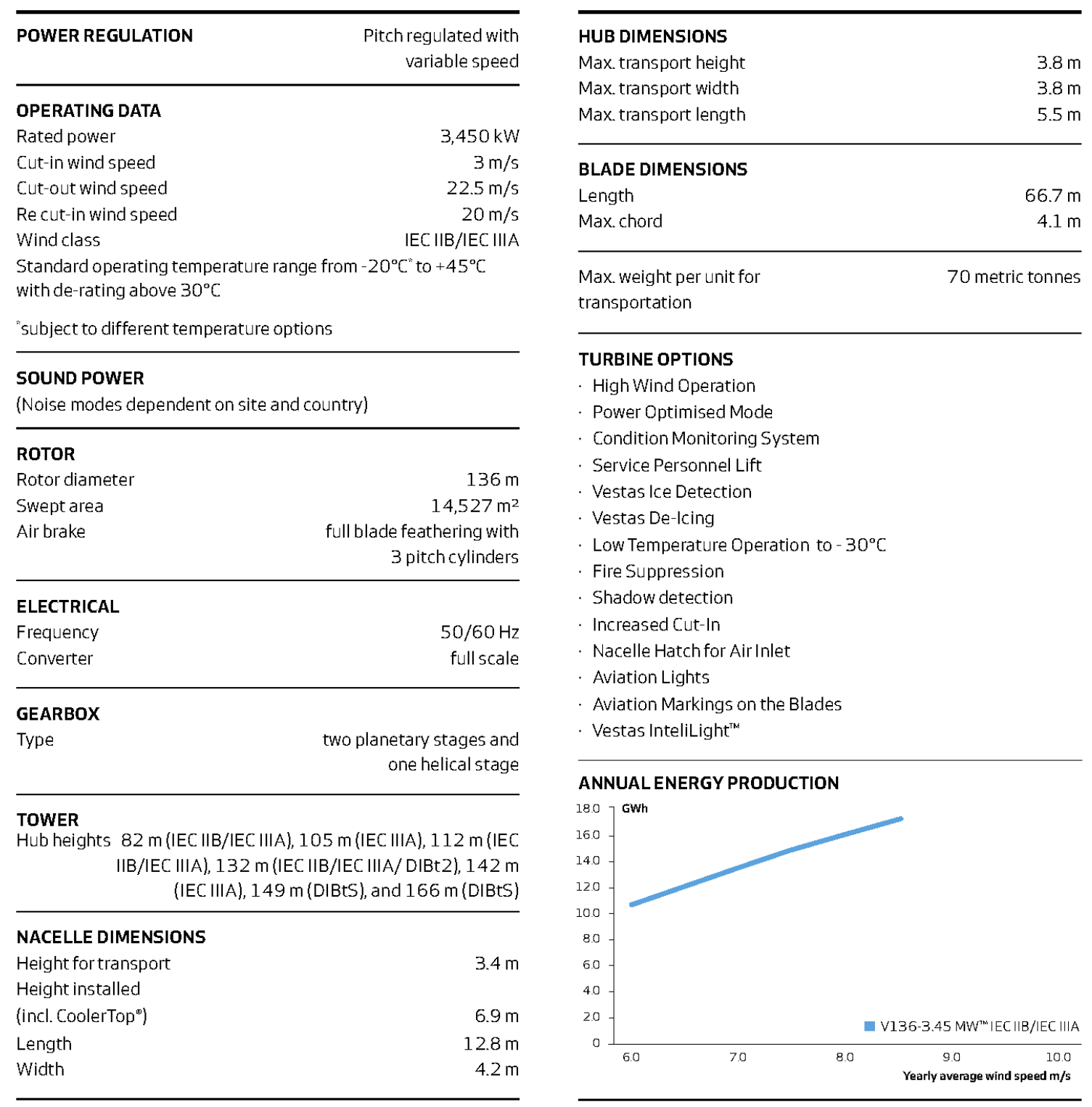

Figure 55:V136-3.45MW Datasheet. 
As an example we will only include de economically study for the first site for both types of technologies, the other types are similar but not included, since they have negative values. Following we can see the $2 \mathrm{MW}$ alternative

\begin{tabular}{|c|c|c|c|c|c|c|}
\hline Cost & 100 & 001 & 083 & O 75 & 068 & 062 \\
\hline Calendar Year & 2017 & 2018 & 2010 & 2020 & 2021 & 2020 \\
\hline Project Year & 0 & 1 & 2 & 3 & 4 & 5 \\
\hline \multicolumn{7}{|l|}{ BENEFICTS FROM THE PROJECT } \\
\hline \multicolumn{7}{|l|}{ Wind Farm - Vestas } \\
\hline Production of Electricity (KWatt-hour) & & & & $128,147,490$ & $128,147,490$ & $128,147,490$ \\
\hline Income for Electricity (US\$) & & & & $12,814,749$ & $12,814,749$ & $12,814,749$ \\
\hline Income (US\$) & & & & $12,814,749$ & $12,814,749$ & $12,814,749$ \\
\hline Calendar Year & 2017 & 2018 & 2019 & 2020 & 2021 & 2022 \\
\hline Project Year & $\mathbf{0}$ & 1 & 2 & 3 & 4 & 5 \\
\hline \multicolumn{7}{|l|}{ PROJECT COSTS } \\
\hline \multicolumn{7}{|l|}{ Wind Farm - Vestas } \\
\hline Land Use (US\$) & $1,684,800$ & & & & & \\
\hline Investment (US\$) & & $20,757,600$ & $20,757,600$ & & & \\
\hline \multicolumn{7}{|l|}{ O\&M Costs (US\$) } \\
\hline Cost Maintenance (US\$) & & & & $1,296,000$ & $1,296,000$ & $1,296,000$ \\
\hline Cost Operation (US\$) & & & & 864,000 & 864,000 & 864,000 \\
\hline Recovery Cost (US\$) & & & & $1,728,000$ & $1,728,000$ & $1,728,000$ \\
\hline Costs & $1,684,800$ & $20,757,600$ & $20,757,600$ & $3, \mathbf{8 8 8 , 0 0 0}$ & $3,888,000$ & $3,888,000$ \\
\hline Cash Flow after tax & $-1,684,800$ & $-20,757,600$ & $-20,757,600$ & $7,141,399$ & $7,141,399$ & $7,141,399$ \\
\hline Cash Flow & $-1,684,800$ & $-18,870,545$ & $-17,155,041$ & $5,365,439$ & $4,877,672$ & $4,434,247$ \\
\hline
\end{tabular}


Table 30: Flow Site 1 - 2MW (Continued).

\begin{tabular}{|c|c|c|c|c|c|c|}
\hline Cost & 0.56 & 0.51 & 0.47 & 0.42 & 0.39 & 0.35 \\
\hline Calendar Year & 2023 & 2024 & 2025 & 2026 & 2027 & 2028 \\
\hline Project Year & 6 & 7 & 8 & 9 & 10 & 11 \\
\hline \multicolumn{7}{|l|}{ BENEFICTS FROM THE PROJECT } \\
\hline \multicolumn{7}{|l|}{ Wind Farm - Vestas } \\
\hline Production of Electricity (KWatt-hour) & $128,147,490$ & $128,147,490$ & $128,147,490$ & $128,147,490$ & $128,147,490$ & $128,147,490$ \\
\hline Income for Electricity (US\$) & $12,814,749$ & $12,814,749$ & $12,814,749$ & $12,814,749$ & $12,814,749$ & $12,814,749$ \\
\hline Income (US\$) & $12,814,749$ & $12,814,749$ & $\mathbf{1 2 , 8 1 4 , 7 4 9}$ & $\mathbf{1 2 , 8 1 4 , 7 4 9}$ & $12,814,749$ & $\mathbf{1 2 , 8 1 4 , 7 4 9}$ \\
\hline Calendar Year & 2023 & 2024 & 2025 & 2026 & 2027 & 2028 \\
\hline Project Year & 6 & 7 & 8 & 9 & 10 & 11 \\
\hline \multicolumn{7}{|l|}{ PROJECT COSTS } \\
\hline \multicolumn{7}{|l|}{ Wind Farm - Vestas } \\
\hline \multicolumn{7}{|l|}{ Land Use (US\$) } \\
\hline \multicolumn{7}{|l|}{ Investment (US\$) } \\
\hline \multicolumn{7}{|l|}{ O\&M Costs (US\$) } \\
\hline Cost Maintenance (US\$) & $1,296,000$ & $1,296,000$ & $1,296,000$ & $1,296,000$ & $1,296,000$ & $1,296,000$ \\
\hline Cost Operation (US\$) & 864,000 & 864,000 & 864,000 & 864,000 & 864,000 & 864,000 \\
\hline Recovery Cost (US\$) & $1,728,000$ & $1,728,000$ & $1,728,000$ & $1,728,000$ & $1,728,000$ & $1,728,000$ \\
\hline Costs & $3, \mathbf{8 8 8 , 0 0 0}$ & $3, \mathbf{8 8 8 , 0 0 0}$ & 3,888,000 & 3,888,000 & 3,888,000 & $3,888,000$ \\
\hline Cash Flow after tax & 7,141,399 & 7,141,399 & 7,141,399 & 7,141,399 & 7,141,399 & 7,141,399 \\
\hline Cash Flow & $4,031,134$ & $3,664,667$ & $3,331,515$ & $3,028,650$ & $2,753,319$ & 2,503,017 \\
\hline
\end{tabular}


Table 30: Flow Site 1 - 2MW (Continued).

\begin{tabular}{|c|c|c|c|c|c|c|}
\hline Cost & 0.32 & 0.29 & 0.26 & 0.24 & 0.22 & 0.20 \\
\hline Calendar Year & 2029 & 2030 & 2031 & 2032 & 2033 & 2034 \\
\hline Project Year & 12 & 13 & 14 & 15 & 16 & 17 \\
\hline \multicolumn{7}{|l|}{ BENEFICTS FROM THE PROJECT } \\
\hline \multicolumn{7}{|l|}{ Wind Farm - Vestas } \\
\hline Production of Electricity (KWatt-hour) & $128,147,490$ & $128,147,490$ & $128,147,490$ & $128,147,490$ & $128,147,490$ & $128,147,490$ \\
\hline Income for Electricity (US\$) & $12,814,749$ & $12,814,749$ & $12,814,749$ & $12,814,749$ & $12,814,749$ & $12,814,749$ \\
\hline Income (US\$) & $12,814,749$ & $12,814,749$ & $\mathbf{1 2 , 8 1 4 , 7 4 9}$ & $12,814,749$ & $12,814,749$ & $\mathbf{1 2 , 8 1 4 , 7 4 9}$ \\
\hline Calendar Year & 2029 & 2030 & 2031 & 2032 & 2033 & 2034 \\
\hline Project Year & 12 & 13 & 14 & 15 & 16 & 17 \\
\hline \multicolumn{7}{|l|}{ PROJECT COSTS } \\
\hline \multicolumn{7}{|l|}{ Wind Farm - Vestas } \\
\hline \multicolumn{7}{|l|}{ Land Use (US\$) } \\
\hline \multicolumn{7}{|l|}{ Investment (US\$) } \\
\hline \multicolumn{7}{|l|}{ O\&M Costs (US\$) } \\
\hline Cost Maintenance (US\$) & $1,296,000$ & $1,296,000$ & $1,296,000$ & $1,296,000$ & $1,296,000$ & $1,296,000$ \\
\hline Cost Operation (US\$) & 864,000 & 864,000 & 864,000 & 864,000 & 864,000 & 864,000 \\
\hline Recovery Cost (US\$) & $1,728,000$ & $1,728,000$ & $1,728,000$ & $1,728,000$ & $1,728,000$ & $1,728,000$ \\
\hline Costs & 3,888,000 & $3, \mathbf{8 8 8 , 0 0 0}$ & 3,888,000 & $\mathbf{3 , 8 8 8 , 0 0 0}$ & 3,888,000 & $3,888,000$ \\
\hline Cash Flow after tax & 7,141,399 & 7,141,399 & 7,141,399 & 7,141,399 & 7,141,399 & $7,141,399$ \\
\hline Cash Flow & $2,275,470$ & $2,068,609$ & $\mathbf{1 , 8 8 0 , 5 5 4}$ & $\mathbf{1 , 7 0 9 , 5 9 4}$ & $\mathbf{1 , 5 5 4 , 1 7 7}$ & 1,412,888 \\
\hline
\end{tabular}


Table 30: Flow Site 1 - 2MW (Continued).

\begin{tabular}{|c|c|c|c|c|c|c|}
\hline Cost & 0.18 & 0.16 & 0.15 & 0.14 & 0.12 & 0.11 \\
\hline Calendar Year & 2035 & 2036 & 2037 & 2038 & 2039 & 2040 \\
\hline Project Year & 18 & 19 & 20 & 21 & 22 & 23 \\
\hline \multicolumn{7}{|l|}{ BENEFICTS FROM THE PROJECT } \\
\hline \multicolumn{7}{|l|}{ Wind Farm - Vestas } \\
\hline Production of Electricity (KWatt-hour) & $128,147,490$ & $128,147,490$ & $128,147,490$ & $128,147,490$ & $128,147,490$ & $128,147,490$ \\
\hline Income for Electricity (US\$) & $12,814,749$ & $12,814,749$ & $12,814,749$ & $12,814,749$ & $12,814,749$ & $12,814,749$ \\
\hline Income (US\$) & $12,814,749$ & $12,814,749$ & $\mathbf{1 2 , 8 1 4 , 7 4 9}$ & $12,814,749$ & $\mathbf{1 2 , 8 1 4 , 7 4 9}$ & $\mathbf{1 2 , 8 1 4 , 7 4 9}$ \\
\hline Calendar Year & 2035 & 2036 & 2037 & 2038 & 2039 & 2040 \\
\hline Project Year & 18 & 19 & 20 & 21 & 22 & 23 \\
\hline \multicolumn{7}{|l|}{ PROJECT COSTS } \\
\hline \multicolumn{7}{|l|}{ Wind Farm - Vestas } \\
\hline \multicolumn{7}{|l|}{ Land Use (US\$) } \\
\hline \multicolumn{7}{|l|}{ Investment (US\$) } \\
\hline \multicolumn{7}{|l|}{ O\&M Costs (US\$) } \\
\hline Cost Maintenance (US\$) & $1,296,000$ & $1,296,000$ & $1,296,000$ & $1,296,000$ & $1,296,000$ & $1,296,000$ \\
\hline Cost Operation (US\$) & 864,000 & 864,000 & 864,000 & 864,000 & 864,000 & 864,000 \\
\hline Recovery Cost (US\$) & $1,728,000$ & $1,728,000$ & $1,728,000$ & $1,728,000$ & $1,728,000$ & $1,728,000$ \\
\hline Costs & $3, \mathbf{8 8 8 , 0 0 0}$ & $3, \mathbf{8 8 8 , 0 0 0}$ & 3,888,000 & 3,888,000 & 3,888,000 & $3,888,000$ \\
\hline Cash Flow after tax & 7,141,399 & 7,141,399 & 7,141,399 & 7,141,399 & 7,141,399 & 7,141,399 \\
\hline Cash Flow & $1,284,443$ & $1,167,676$ & $1,061,523$ & 965,021 & 877,292 & $\mathbf{7 9 7 , 5 3 8}$ \\
\hline
\end{tabular}


Table 30: Flow Site 1-2MW (Continued).

\begin{tabular}{|c|c|c|c|c|}
\hline Cost & 0.10 & 0.09 & 0.08 & 0.08 \\
\hline Calendar Year & 2041 & 2042 & 2043 & 2044 \\
\hline Project Year & 24 & 25 & 26 & 27 \\
\hline \multicolumn{5}{|l|}{ BENEFICTS FROM THE PROJECT } \\
\hline \multicolumn{5}{|l|}{ Wind Farm - Vestas } \\
\hline Production of Electricity (KWatt-hour) & $128,147,490$ & $128,147,490$ & $128,147,490$ & $128,147,490$ \\
\hline Income for Electricity (US\$) & $12,814,749$ & $12,814,749$ & $12,814,749$ & $12,814,749$ \\
\hline Income (US\$) & $12,814,749$ & $12,814,749$ & $12,814,749$ & $12,814,749$ \\
\hline Calendar Year & 2041 & 2042 & 2043 & 2044 \\
\hline Project Year & 24 & 25 & 26 & 27 \\
\hline \multicolumn{5}{|l|}{ PROJECT COSTS } \\
\hline \multicolumn{5}{|l|}{ Wind Farm - Vestas } \\
\hline \multicolumn{5}{|l|}{ Land Use (US\$) } \\
\hline \multicolumn{5}{|l|}{ Investment (US\$) } \\
\hline \multicolumn{5}{|l|}{ O\&M Costs (US\$) } \\
\hline Cost Maintenance (US\$) & $1,296,000$ & $1,296,000$ & $1,296,000$ & $1,296,000$ \\
\hline Cost Operation (US\$) & 864,000 & 864,000 & 864,000 & 864,000 \\
\hline Recovery Cost (US\$) & $1,728,000$ & $1,728,000$ & $1,728,000$ & $1,728,000$ \\
\hline Costs & $3,888,000$ & $3,888,000$ & 3,888,000 & $3,888,000$ \\
\hline Cash Flow after tax & 7,141,399 & 7,141,399 & 7,141,399 & $7,141,399$ \\
\hline Cash Flow & 725,035 & 659,123 & $\mathbf{5 9 9 , 2 0 2}$ & 544,729 \\
\hline
\end{tabular}


Following we can see the $3 \mathrm{MW}$ alternative

Table 31: Flow Site 1 - 3MW.

\begin{tabular}{|c|c|c|c|c|c|c|}
\hline Cost & 1.00 & 0.91 & 0.83 & 0.75 & 0.68 & 0.62 \\
\hline Calendar Year & 2017 & 2018 & 2019 & 2020 & 2021 & 2022 \\
\hline Project Year & $\mathbf{0}$ & 1 & 2 & 3 & 4 & 5 \\
\hline \multicolumn{7}{|l|}{ BENEFICTS FROM THE PROJECT } \\
\hline \multicolumn{7}{|l|}{ Wind Farm - Vestas } \\
\hline Production of Electricity (KWatt-hour) & & & & $119,351,379$ & $119,351,379$ & $119,351,379$ \\
\hline Income for Electricity (US\$) & & & & $11,935,138$ & $11,935,138$ & $11,935,138$ \\
\hline Income (US\$) & & & & $\mathbf{1 1 , 9 3 5 , 1 3 8}$ & $\mathbf{1 1 , 9 3 5 , 1 3 8}$ & $\mathbf{1 1 , 9 3 5 , 1 3 8}$ \\
\hline Calendar Year & 2017 & 2018 & 2019 & 2020 & 2021 & 2022 \\
\hline Project Year & $\mathbf{0}$ & 1 & 2 & 3 & 4 & 5 \\
\hline \multicolumn{7}{|l|}{ PROJECT COSTS } \\
\hline \multicolumn{7}{|l|}{ Wind Farm - Vestas } \\
\hline Land Use (US\$) & $1,743,768$ & & & & & \\
\hline Investment (US\$) & & $21,484,116$ & $21,484,116$ & & & \\
\hline \multicolumn{7}{|l|}{ O\&M Costs (US\$) } \\
\hline Cost Maintenance (US\$) & & & & $1,341,360$ & $1,341,360$ & $1,341,360$ \\
\hline Cost Operation (US\$) & & & & 894,240 & 894,240 & 894,240 \\
\hline Recovery Cost (US\$) & & & & $1,788,480$ & $1,788,480$ & $1,788,480$ \\
\hline Costs & $1,743,768$ & $21,484,116$ & $21,484,116$ & $4,024,080$ & $4,024,080$ & $4,024,080$ \\
\hline Cash Flow after tax & $-1,743,768$ & $-21,484,116$ & $-21,484,116$ & $6,328,846$ & $6,328,846$ & $6,328,846$ \\
\hline Cash Flow & $-1,743,768$ & $-19,531,015$ & $-17,755,468$ & $4,754,956$ & $4,322,687$ & $3,929,716$ \\
\hline
\end{tabular}


Table 31: Flow Site 1 - 3MW (Continued).

\begin{tabular}{|c|c|c|c|c|c|c|}
\hline Cost & 0.56 & 0.51 & 0.47 & 0.42 & 0.39 & 0.35 \\
\hline Calendar Year & 2023 & 2024 & 2025 & 2026 & 2027 & 2028 \\
\hline Project Year & 6 & 7 & 8 & 9 & 10 & 11 \\
\hline \multicolumn{7}{|l|}{ BENEFICTS FROM THE PROJECT } \\
\hline \multicolumn{7}{|l|}{ Wind Farm - Vestas } \\
\hline Production of Electricity (KWatt-hour) & $119,351,379$ & $119,351,379$ & $119,351,379$ & $119,351,379$ & $119,351,379$ & $119,351,379$ \\
\hline Income for Electricity (US\$) & $11,935,138$ & $11,935,138$ & $11,935,138$ & $11,935,138$ & $11,935,138$ & $11,935,138$ \\
\hline Income (US\$) & $\mathbf{1 1 , 9 3 5 , 1 3 8}$ & $\mathbf{1 1 , 9 3 5 , 1 3 8}$ & $\mathbf{1 1 , 9 3 5 , 1 3 8}$ & $\mathbf{1 1 , 9 3 5 , 1 3 8}$ & $\mathbf{1 1 , 9 3 5 , 1 3 8}$ & $\mathbf{1 1 , 9 3 5 , 1 3 8}$ \\
\hline Calendar Year & 2023 & 2024 & 2025 & 2026 & 2027 & 2028 \\
\hline Project Year & 6 & 7 & 8 & 9 & 10 & 11 \\
\hline \multicolumn{7}{|l|}{ PROJECT COSTS } \\
\hline \multicolumn{7}{|l|}{ Wind Farm - Vestas } \\
\hline \multicolumn{7}{|l|}{ Land Use (US\$) } \\
\hline \multicolumn{7}{|l|}{ Investment (US\$) } \\
\hline \multicolumn{7}{|l|}{ O\&M Costs (US\$) } \\
\hline Cost Maintenance (US\$) & $1,341,360$ & $1,341,360$ & $1,341,360$ & $1,341,360$ & $1,341,360$ & $1,341,360$ \\
\hline Cost Operation (US\$) & 894,240 & 894,240 & 894,240 & 894,240 & 894,240 & 894,240 \\
\hline Recovery Cost (US\$) & $1,788,480$ & $1,788,480$ & $1,788,480$ & $1,788,480$ & $1,788,480$ & $1,788,480$ \\
\hline Costs & $4,024,080$ & $4,024,080$ & $4,024,080$ & $4,024,080$ & $4,024,080$ & $4,024,080$ \\
\hline Cash Flow after tax & $6,328,846$ & $6,328,846$ & $6,328,846$ & $6,328,846$ & $6,328,846$ & $6,328,846$ \\
\hline Cash Flow & $3,572,469$ & $3,247,699$ & $2,952,454$ & $2,684,049$ & $2,440,044$ & $2,218,222$ \\
\hline
\end{tabular}


Table 31: Flow Site 1 - 3MW (Continued).

\begin{tabular}{|c|c|c|c|c|c|c|}
\hline Cost & 0.32 & 0.29 & 0.26 & 0.24 & 0.22 & 0.20 \\
\hline Calendar Year & 2029 & 2030 & 2031 & 2032 & 2033 & 2034 \\
\hline Project Year & 12 & 13 & 14 & 15 & 16 & 17 \\
\hline \multicolumn{7}{|l|}{ BENEFICTS FROM THE PROJECT } \\
\hline \multicolumn{7}{|l|}{ Wind Farm - Vestas } \\
\hline Production of Electricity (KWatt-hour) & $119,351,379$ & $119,351,379$ & $119,351,379$ & $119,351,379$ & $119,351,379$ & $119,351,379$ \\
\hline Income for Electricity (US\$) & $11,935,138$ & $11,935,138$ & $11,935,138$ & $11,935,138$ & $11,935,138$ & $11,935,138$ \\
\hline Income (US\$) & $11,935,138$ & $\mathbf{1 1 , 9 3 5 , 1 3 8}$ & $\mathbf{1 1 , 9 3 5 , 1 3 8}$ & $11,935,138$ & $\mathbf{1 1 , 9 3 5 , 1 3 8}$ & $11,935,138$ \\
\hline Calendar Year & 2029 & 2030 & 2031 & 2032 & 2033 & 2034 \\
\hline Project Year & 12 & 13 & 14 & 15 & 16 & 17 \\
\hline \multicolumn{7}{|l|}{ PROJECT COSTS } \\
\hline \multicolumn{7}{|l|}{ Wind Farm - Vestas } \\
\hline \multicolumn{7}{|l|}{ Land Use (US\$) } \\
\hline \multicolumn{7}{|l|}{ Investment (US\$) } \\
\hline \multicolumn{7}{|l|}{ O\&M Costs (US\$) } \\
\hline Cost Maintenance (US\$) & $1,341,360$ & $1,341,360$ & $1,341,360$ & $1,341,360$ & $1,341,360$ & $1,341,360$ \\
\hline Cost Operation (US\$) & 894,240 & 894,240 & 894,240 & 894,240 & 894,240 & 894,240 \\
\hline Recovery Cost (US\$) & $1,788,480$ & $1,788,480$ & $1,788,480$ & $1,788,480$ & $1,788,480$ & $1,788,480$ \\
\hline Costs & $4,024,080$ & $4,024,080$ & $4,024,080$ & $4,024,080$ & $4,024,080$ & $4,024,080$ \\
\hline Cash Flow after tax & $6,328,846$ & $6,328,846$ & $6,328,846$ & $6,328,846$ & $6,328,846$ & $6,328,846$ \\
\hline Cash Flow & $2,016,565$ & $1,833,241$ & $1,666,583$ & $\mathbf{1 , 5 1 5 , 0 7 5}$ & $\mathbf{1 , 3 7 7 , 3 4 1}$ & $1,252,128$ \\
\hline
\end{tabular}


Table 31: Flow Site 1 - 3MW (Continued).

\begin{tabular}{|c|c|c|c|c|c|c|}
\hline Cost & 0.18 & 0.16 & 0.15 & 0.14 & 0.12 & 0.11 \\
\hline Calendar Year & 2035 & 2036 & 2037 & 2038 & 2039 & 2040 \\
\hline Project Year & 18 & 19 & 20 & 21 & 22 & 23 \\
\hline \multicolumn{7}{|l|}{ BENEFICTS FROM THE PROJECT } \\
\hline \multicolumn{7}{|l|}{ Wind Farm - Vestas } \\
\hline Production of Electricity (KWatt-hour) & $119,351,379$ & $119,351,379$ & $119,351,379$ & $119,351,379$ & $119,351,379$ & $119,351,379$ \\
\hline Income for Electricity (US\$) & $11,935,138$ & $11,935,138$ & $11,935,138$ & $11,935,138$ & $11,935,138$ & $11,935,138$ \\
\hline Income (US\$) & $11,935,138$ & $11,935,138$ & $\mathbf{1 1 , 9 3 5 , 1 3 8}$ & 11,935,138 & $11,935,138$ & 11,935,138 \\
\hline Calendar Year & 2035 & 2036 & 2037 & 2038 & 2039 & 2040 \\
\hline Project Year & 18 & 19 & 20 & 21 & 22 & 23 \\
\hline \multicolumn{7}{|l|}{ PROJECT COSTS } \\
\hline \multicolumn{7}{|l|}{ Wind Farm - Vestas } \\
\hline \multicolumn{7}{|l|}{ Land Use (US\$) } \\
\hline \multicolumn{7}{|l|}{ Investment (US\$) } \\
\hline \multicolumn{7}{|l|}{ O\&M Costs (US\$) } \\
\hline Cost Maintenance (US\$) & $1,341,360$ & $1,341,360$ & $1,341,360$ & $1,341,360$ & $1,341,360$ & $1,341,360$ \\
\hline Cost Operation (US\$) & 894,240 & 894,240 & 894,240 & 894,240 & 894,240 & 894,240 \\
\hline Recovery Cost (US\$) & $1,788,480$ & $1,788,480$ & $1,788,480$ & $1,788,480$ & $1,788,480$ & $1,788,480$ \\
\hline Costs & $4,024,080$ & $4,024,080$ & $4,024,080$ & $4,024,080$ & $4,024,080$ & $4,024,080$ \\
\hline Cash Flow after tax & $6,328,846$ & 6,328,846 & 6,328,846 & 6,328,846 & 6,328,846 & $6,328,846$ \\
\hline Cash Flow & $\mathbf{1 , 1 3 8 , 2 9 9}$ & $\mathbf{1 , 0 3 4 , 8 1 7}$ & 940,743 & 855,221 & 777,473 & 706,794 \\
\hline
\end{tabular}


Table 31: Flow Site 1 - 3MW (Continued).

\begin{tabular}{|c|c|c|c|c|}
\hline Cost & 0.10 & 0.09 & 0.08 & 0.08 \\
\hline Calendar Year & 2041 & 2042 & 2043 & 2044 \\
\hline Project Year & 24 & 25 & 26 & 27 \\
\hline \multicolumn{5}{|l|}{ BENEFICTS FROM THE PROJECT } \\
\hline \multicolumn{5}{|l|}{ Wind Farm - Vestas } \\
\hline Production of Electricity (KWatt-hour) & $119,351,379$ & $119,351,379$ & $119,351,379$ & $119,351,379$ \\
\hline Income for Electricity (US\$) & $11,935,138$ & $11,935,138$ & $11,935,138$ & $11,935,138$ \\
\hline Income (US\$) & $11,935,138$ & $11,935,138$ & $11,935,138$ & $11,935,138$ \\
\hline Calendar Year & 2041 & 2042 & 2043 & 2044 \\
\hline Project Year & 24 & 25 & 26 & 27 \\
\hline \multicolumn{5}{|l|}{ PROJECT COSTS } \\
\hline \multicolumn{5}{|l|}{ Wind Farm - Vestas } \\
\hline \multicolumn{5}{|l|}{ Land Use (US\$) } \\
\hline \multicolumn{5}{|l|}{ Investment (US\$) } \\
\hline \multicolumn{5}{|l|}{ O\&M Costs (US\$) } \\
\hline Cost Maintenance (US\$) & $1,341,360$ & $1,341,360$ & $1,341,360$ & $1,341,360$ \\
\hline Cost Operation (US\$) & 894,240 & 894,240 & 894,240 & 894,240 \\
\hline Recovery Cost (US\$) & $1,788,480$ & $1,788,480$ & $1,788,480$ & $1,788,480$ \\
\hline Costs & $4,024,080$ & $4,024,080$ & $4,024,080$ & $4,024,080$ \\
\hline Cash Flow after tax & $6,328,846$ & $6,328,846$ & $6,328,846$ & $6,328,846$ \\
\hline Cash Flow & 642,540 & 584,127 & $\mathbf{5 3 1 , 0 2 5}$ & 482,750 \\
\hline
\end{tabular}

